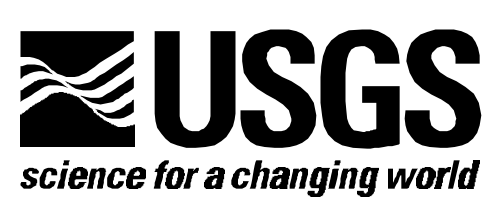

\title{
3M/U.S. Geological Survey/Bureau of Land Management Cooperative Research and Development Agreement: On-Demand Printing
}

Open File Report OF 99-176

1999

Any use of trade, product, or firm names is for descriptive purposes only and does not imply endorsement by the U.S. Government.

U.S Department of the Interior U.S. Geological Survey 


\section{Table of Contents}

1. Background

2. List of Contributors

3. Executive Summary

4. Phase 1

5. Phase 2

6. Phase 3

7. Customer Survey Report: IMTA Conference

8. Customer Survey Report: Topographic Map Buyers

9. Customer Survey Report: Focus Group

10. Technical Recommendations

11. Bureau of Land Management Final Report

12. Appendix A: Request for Partnerships

13. Appendix B: Press Release

14. Appendix C: Fact Sheet

15. Appendix D: Statement of Work

16. Appendix E: Frequently Asked Questions

17. Appendix F: 3M Product Literature p. 3

p. 4

p. 6

p. 11

p. 15

p. 18

p. 42

p. 51

p. 59

p. 69

p. 76

p. 85

p. 87

p. 89

p. 92

p.101

p.103 


\section{Background}

In July 1996, the U.S. Geological Survey (USGS) and the 3M Corporation of St. Paul, Minn., entered into a Cooperative Research and Development Agreement (CRADA) to investigate mapon-demand technology for producing USGS mapping products. The CRADA was designed to help the USGS develop on-demand alternatives to lithographic maps and to help $3 \mathrm{M}$ develop a series of commercial, instant map-printing systems.

A joint effort of 16 months was planned for the map-on-demand segment. The CRADA statement of work described a six-phase program that investigated both inkjet and electrostatic printing technologies. The map-on-demand CRADA dealt with the following topics:

- $\quad$ digital storage and archive systems, software, and media development

- $\quad$ evaluation of user requirements

- $\quad$ customer and user software interface development

- $\quad$ scanning resolution

- map accuracy, geometric correction

- $\quad$ color mapping and calibration

- data access, sources, and data bases

- $\quad$ investigation of geographic information systems (GIS) software

The USGS provided expertise in map products, color replication, and the use and application of digital data and GIS technology. The 3M Corporation provided most of the hardware and software used for investigation, both proprietary and commercial off-the-shelf products, and expertise in map printing software, color science, and imaging science.

Making the best use of inkjet and electrostatic printing systems in replicating USGS map products was the primary goal of the CRADA, with superior replication of the 1:24,000-scale topographic map as the primary focus. Thematic map products from the USGS, as well as map products from other cooperating agencies (Bureau of Land Management (BLM)), were also investigated. Customer assessment activities were used to gather responses to the prototype map-on-demand products. The USGS and 3M also participated in map trade shows and technical mapping conferences to showcase their progress and solicit responses during the course of the CRADA.

The investigation of electrostatic printing systems allowed the USGS to explore the feasibility of high-productivity map-printing systems, and the investigation of inkjet systems focused on lowvolume requirements for use in retail environments.

The following report was co-authored by members of the CRADA team, which was comprised of participants from both the USGS and BLM, as well as 3M. It reflects more than 16 months of technical evaluations and development using systems integrated by $3 \mathrm{M}$. Sections of the report also deal with customer assessment activities jointly investigated under the CRADA. The BLM completed a separate report describing their collaborative experiences, and that report is also included here. 


\section{M/USGS/BLM CRADA Contributors}

\section{M}

Administrators

Ralph Grant (Programmatic Lead)

Richard Moore (Technical Lead)

Rod Larkins

Ken Wilson

\section{Technical Researchers}

Larry Gunderson

Carlos Tobon

Robert Grun

\section{Marketing and Promotion}

Liz Keene

\section{CRADA Coordinators}

John Gerver

\section{Business Opportunities}

Kent Stewart

\section{USGS/BLM}

\section{Administrators}

John Evans (Programmatic Lead)

Dave Catts (Technical Lead)

Hedy Rossmeissl

Dan Cavanaugh

Randle Olsen

Craig Skalet

Wendy Hassibe 
Technical Researchers

Ben Kelley

Maria McCormick

Jim Wilkinson

Kirk Volkel

\section{Technical Advisors}

Debra Dinville

Ken Schauer

Chris Smith

Maury Nyquist

Bob Fraser

Susan Price

Bob Bier

Wayne Vickers

Jack Wittmann

Terry Kiser

Greg Allord

Margaret Hamilton

Lloyd Cornett

Steve Johnson

Ed Burke

John Hutchinson

\section{Marketing and Promotion}

Cynthia Cluck

Beth Duff

Tom Clines

Gene Jackson

Pat Hytes

Beth Stettner

Dan Gallagher

Steve Gillespie

\section{CRADA Coordinators}

Steve Strader

\section{Business Opportunities}

Ernie Brunson 


\section{Executive Summary}

\section{Background}

The U.S. Geological Survey (USGS) has been aggressively pursuing Cooperative Research and Development Agreements (CRADA) with the private sector. From July 1996 until May1998, 3M and the USGS were engaged in a CRADA to investigate the potential for printing maps on an ondemand basis. The CRADA was used to ensure that the cost burden for the research and technology investigation was shared equitably between private and public sources.

$3 \mathrm{M}$ was selected for participation in the CRADA because the company was perceived as an innovative organization with the necessary technical expertise and resources to ensure a thorough investigation of the technology and a positive outcome from the research. From a 3M perspective, this research supported the existing commercial business direction of an operating unit of the company. It advanced more expertise in on-demand map printing as a precursor to expanded participation in that business sector.

The CRADA was directed toward developing a cost-effective, easily maintainable, distributed system with the potential to support government and private industry needs for printing maps ondemand. Under the CRADA, the USGS supplied cartographic expertise and customer knowledge, and $3 \mathrm{M}$ was responsible for using its commercial technology to solve problems and meet the needs of the USGS customer.

From the outset, on-demand maps were viewed as an adjunct to maps produced by the normal lithographic production methods used by the USGS. Maps produced by the non-impact printers used under the CRADA were intended to be replicates of printed maps. Part of the CRADA process was to investigate the necessary tradeoffs required by the use of non-lithographic production methods and to assess the general acceptability of the on-demand maps.

\section{Introduction}

The advent of high-quality, large-format print engines has enabled graphics of many different formats to be printed by other than conventional lithographic means. Large-format printers, integrated with today's workstations (or PC's), plus system and application software, can be used to print a wide variety of graphics. This technology can also be extended to print maps on demand with sufficient quality to augment existing lithographic printing methods.

A map-on-demand system has been designed by $3 \mathrm{M}$ and is currently being used by the U.S. Department of Defense (DoD). This system is a commercial-off-the-shelf (COTS) configuration (using only items that are commercialized and readily available) that has been well proven for DoD applications. The lessons learned from designing and implementing this system formed the basis for this CRADA, which had the goal of producing a low-cost, low-maintenance, distributed map printing system.

This report will examine the technology used to implement a map-on-demand system, user feedback on the initial 3M map products supplied to the USGS, and some of the considerations that are crucial to implementing a successful system. 


\section{Discussion}

With the continued evolution of computer and large-format graphics printer technologies, lowercost and higher-performance systems have become more available. When applied to on-demand map printing, these technological advancements have allowed system designers and builders great versatility and flexibility in system configuration. Further, systems can be built with very extensive capabilities that replace many time-consuming manual operations that required great skill and much time to accomplish.

Computer systems for map editing and creation and for map image processing have become faster and much more capable. To produce map images that can be printed with on-demand printers requires a processor that can perform many computer-intensive processes. The advent of 64-bit UNIX processors operating at speeds in excess of $250 \mathrm{MHz}$ has facilitated the editing and conversion of raster products into printable images. These workstations allow a very high-speed input and output architecture in which large datasets can be processed efficiently and effectively. A typical topographic map with dimensions 24 in x 36 in, scanned at 400 dots per inch, contains nearly 400 megabytes of raster data. Larger maps or maps of higher dots-per-inch resolution require commensurately larger file sizes.

One goal of the CRADA was to develop a low-cost, map-on-demand printing system matched to the requirements of the customer. If a low-cost system configuration is desired, a low-cost workstation can be paired with an inkjet graphics printer. If higher performance is desired, the use of a high-performance UNIX-based workstation coupled with a high-volume electrostatic printer will be required.

Map printing requires large memory capacity for efficiency; the amount of RAM suggested is several hundred megabytes. High-capacity hard drives are needed to move and process very large files. Hard drives with 9 gigabytes of capacity will be required for the greatest versatility and efficiency. This hard disk capability should be augmented with additional gigabytes of supplemental capacity by using a disk array storage subsystem.

A large-format scanner is suggested for creating digital files when only a map exists. For highest precision, a drum type scanner is recommended. Operator productivity can be enhanced by using flatbed or sheet-feed scanners, provided that slight quality tradeoffs are acceptable. A scanner that operates at higher resolutions (> $600 \mathrm{dpi}$ ) is strongly recommended, though there are file size and cost issues that have to be considered in selecting the scanner type and manufacturer.

Importing and exporting digital data can be accomplished by using telecommunications, networks, or common data storage devices. Selecting the appropriate file conversion software packages allows data to be input from a variety of different file types. Digital files can be edited using any of a variety of commercially available software packages. Once created, digital files can be archived to tape or saved on CD recordable media (CD-R).

The 3M Scotchprint Graphic Maker Software with an add-on Map Enhancement Module can convert map products to printer native format. This state-of-the-art software package is from 3M's Commercial Graphics Division. Either Tagged Image File Format (TIFF) or Encapsulated PostScript (EPS) file formats can be converted to print format. Depending on what printer has been chosen, map-sized graphics ( 24 in x 36 in) can be produced at speeds of up to approximately 
350 maps per hour.

Maps are produced from either scanned paper maps or vector data. Hybrid maps (sometimes called tailored hardcopy maps) are produced by combining map data from both raster and vector sources to meet the needs of the customer. Raster data from scanned maps require specialized color conversion to achieve the best color reproduction. The 3M system uses a closed-loop color calibration system that makes the conversion from scanner data (which are RGB; red, green, and blue) to printer requirements (which are CMYK; cyan, magenta, yellow, and black). Then, additional printing techniques like gray component replacement (GCR) are applied to improve the resultant printed rendition and to ensure the best possible quality.

Of particular importance when producing maps are the techniques used in screening the image. If appropriate techniques are not used, lines and text will be poorly rendered. 3M has developed special screening approaches that enhance edge detail and produce printed maps with sharp text and line detail. To further enhance line and text detail, 3M provides user-adjustable edge enhancement techniques.

The speed with which maps can be produced is largely controlled by two factors. One is the speed of the printer. The CRADA has investigated various printing devices that provide a choice of speeds dependent on the needs and budget of the user. The other production factor controlling speed is the conversion of the file to print language. All the map enhancement features and color conversion techniques used in the $3 \mathrm{M}$ software are highly optimized for processing and for print speed.

\section{Conclusion}

Printing maps on demand is being done and is practical as an alternative to conventional production methods. Systems can be configured to meet a wide variety of user needs and applications.

Materials are available for producing maps that can be used in many different environmental circumstances. Maps that are printed using on-demand techniques can be equal to lithographed maps in serviceability and durability.

The lack of good quality digital map data to support a print-on-demand system is a severe limiting factor on producing maps, in this way, for broad use.

The advantages of printing maps on demand fall under two categories:

(1) responsiveness to the customer who wants a particular map and who wants the data contained therein to be current, and

(2) the ability to produce any map from a digital archive so that "out-of-print" or out-ofstock are no longer reasons for being unable to deliver a map to a customer. 


\section{Impacts to the USGS}

The first use of map-on-demand technology in the USGS will be primarily confined to supporting open-file thematic map products from the Geologic Division. An on-demand facility has been created at the National Mapping Division's Rocky Mountain Mapping Center to realize this initial goal. Since customer demand for thematic map products is relatively low (less than 100 copies per year), the facility was equipped with a 600-dpi inkjet plotter running off a high-end graphics workstation.

It is anticipated that additional USGS mapping titles will be supported through on-demand means in the future. These titles will be primarily maps that are out of stock or out of print and for which demand is low. In many cases, the hardcopy originals will have to be scanned to obtain the digital data for on-demand printing.

The 1:24,000-scale topographic maps will continue to be printed through lithographic processes for the foreseeable future. Although many titles are low sellers in the 1:24,000 series, the large available inventory of these products at the USGS Denver warehouse precludes the additional expense of printing on demand. However, the CRADA team suggests that a cost/benefit study be conducted to calculate whether the costs of maintaining a huge inventory of low sellers outweighs the cost of printing as needed.

The expense of on-demand products and the hardware and software needed to support them is a major issue for the USGS. Currently, lithographic maps are priced at $\$ 4.00$ per sheet for sale to the general public. On-demand products would be priced much higher, since costs for supplies and materials are added to other expenses that the USGS is mandated to recover.

After evaluation of both electrostatic and inkjet technologies during the course of the CRADA, the team determined that the printing resolution of the electrostatic systems (400 dpi) was not of sufficient quality to support USGS map products, whereas the 600-dpi inkjet plotter achieved satisfactory USGS quality standards for both the 1:24,000 series and the thematic geologic mapping products tested. It should be noted, however, that respondents to USGS/3M customer assessment surveys stated that the quality of both the electrostatic and inkjet versions was acceptable.

Focus groups conducted by the USGS and 3M showed overwhelming support for on-demand products. However, all respondents voiced concerns about the cost of the systems needed and the cost of the on-demand product. Respondents identified several benefits to on-demand printing. These benefits were primarily in the areas of customizing maps to meet user requirements and of map retail owners being able to carry less inventory in their stores.

Lithographic printing technologies continue to provide the highest quality product at a substantially lower cost, on the basis of relatively long print runs (over 300 sheets). The USGS must decide whether keeping a huge inventory of paper maps truly outweighs on-demand alternatives. In addition, in order for maps-on-demand to become a reality, readily available digital data must be created. Because current USGS digital raster graphics (DRG) were not designed for 
on-demand printing, new sources are needed for these digital data. 


\section{Phase 1}

\section{Optimization of Ink jet Printing Technologies}

The objective of this phase was to provide a prototype ink jet system suitable for use by a skilled operator at the Denver Rocky Mountain Mapping Center (RMMC) to produce maps for initial evaluation by the USGS. See Figure 1 below.

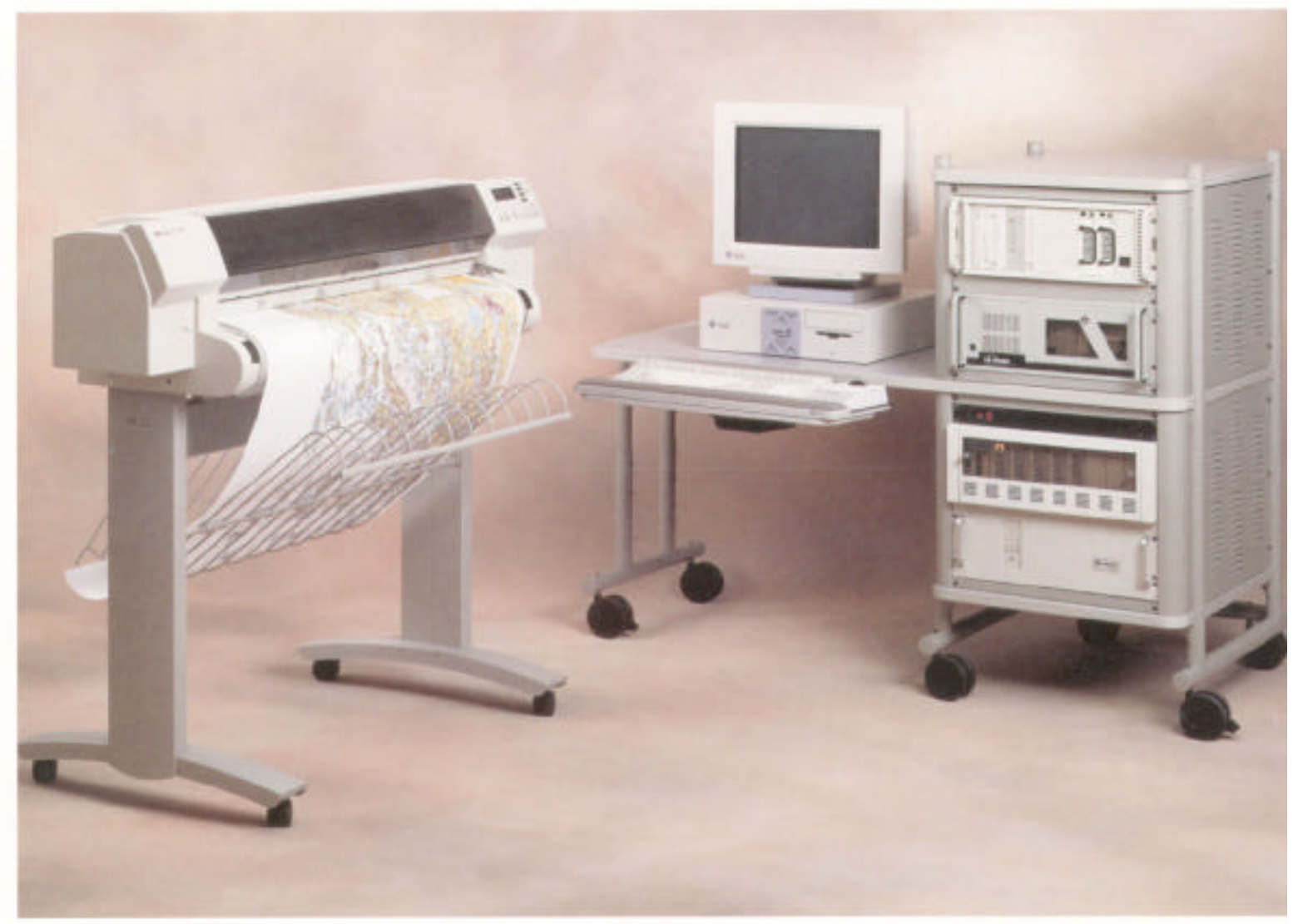

Figure 1: 3M Scotchprint Mapping System utilized in Phase 1.

3M has experience, developed over the past 5 years, working with the U.S. Army Topographic Engineering Center (TEC) Full Color Recorder and the National Imagery and Mapping Agency (NIMA) Remote Replication System, experience which provides unique insight in developing software and hardware to meet Government mapping requirements. 
$3 \mathrm{M}$ provided software and engineering expertise to the USGS to optimize the system currently installed at Denver by providing 3M-developed Scotchprint ${ }^{\mathrm{TM}}$ software, which improved the readability of the maps produced at the RMMC site. As part of this phase, $3 \mathrm{M}$ developed algorithms, with feedback from the USGS, for color matching (provides capability to replicate color), white point calculation (provides automatic detection of paper white and makes adjustments for non-white paper), special screening techniques (an example is halftoning techniques for map printing to achieve high-quality output on low-resolution printers) and edge enhancement (ensures that text and lines are readable). 3M provided initial supplies of ink jet materials (paper and inks) for the USGS to use in evaluating, testing, and training for approximately 100 - 200 maps.

$3 \mathrm{M}$ delivered a modified Openlook version of Scotchprint ${ }^{\mathrm{TM}} 3.0$ on a SUN Solaris operating system. This is a large-format graphics printing software package that allows users to take scanned or graphic art files and print them on large-format printers. This product has been on the commercial market for over 5 years and is undergoing its third major revision.

During phase 1, 3M worked with the USGS to evaluate the quality of print-on-demand maps. Data used in this evaluation were derived from USGS digital data sources and from scanning USGS maps at 3M. The USGS provided 3M with an in-house DRG of the 1:24,000-scale Boulder USGS quadrangle. It was determined that color gamut conversion from 24 bits to a 16-color palette was losing information, especially purple roads in a forest region (green), rendering DRG data useless for print-on-demand applications. Standard USGS DRG CD-ROM digital data were evaluated for print-on-demand maps, and it was determined that color gamut reduction was of very low quality and not usable for this task. The resolution ( $254 \mathrm{dpi}$ ) of DRG data did not seem to be a deterrent for maps printed on 300-dpi ink jet printers, and no evaluation was performed with 600-dpi ink jet printers. 3M scanned the Boulder quadrangle using a Tangent 400-dpi drum scanner to 24-bit RGB color. Printed results from the Tangent scanner were used for phase 1 evaluations and user surveys.

Feedback from the USGS and customers provided some areas of concern for print-on-demand maps. These areas were ringing at line edges, color shifts at edges, noisy colors, and misalignment of colors on black text and lines. 3M addressed these issues by reengineering its map enhancement and color conversion algorithms. Another concern was color flaring on electrostatic printers, which $3 \mathrm{M}$ was unable to completely resolve. The next two sections outline the work done by $3 \mathrm{M}$ on resolving the concerns for improved print on demand.

A ringing artifact was introduced by $3 \mathrm{M}$ map stochastic screening at line edges, especially on lake regions on USGS maps. To remove this artifact, $3 \mathrm{M}$ modified its map stochastic screening to dampen ringing caused by edge enhancement and sharpening contained in the screening method.

Color shifting was occurring with 3M's original edge enhancement algorithms, which caused printed output of contour lines to be much darker and take on a reddish color. Correction for this was accomplished by changing the edge enhancement algorithm used when an edge was detected. This proprietary edge enhancement takes into account the color mix of an edge feature being accentuated.

High-quality printed output from scanned map data requires specialized color conversion to achieve color matching and to correct for printer and scanning problems. The $3 \mathrm{M}$ print-on- 
demand map system has a closed loop color calibration system that uses a scanner to create red, green, blue (RGB) to cyan, magenta, yellow, black (CMYK) calibration tables. Calibration targets are printed on a target printer and scanned on the map scanner. Scanned RGB pattern data are used to create a calibration table for a scanner/printer combination. In generating the calibration RGB to CYMK conversion table, a high level of gray component replacement (GCR) is used, along with special color-gamut clipping techniques to provide color fidelity and stable printing on ink jet and electrostatic printers. Use of a heavy GCR in color highlights caused a speckle noise in many of the solid colors that the USGS uses (green, light blue, and so on). 3M color conversion generation was modified to allow user control over the amount and characteristics of the GCR replacement. This control, along with changes to the color conversion science, provided cleaner color reproduction in lighter color regions.

A problem that occurs when printing scanned map data that contain black text and lines is that RGB black values are converted to a combination of CMYK data. This conversion causes spurious CMY dots around black text and lines. Use of CMYK data can also provide a ghosting effect around black text and lines, which can degrade sharpness on printers that do not possess good head alignment between printing colors. Elimination of spurious CMY dots is achieved by mapping near-gray RGB values to only use the black (K) ink for printing. This mapping of neargray values was incorporated into 3M's color conversion tables to provide higher quality with no additional time required in generating printable map products.

These four modifications to $3 \mathrm{M}$ existing map enhancement algorithms provided considerable improvement to the visual quality and readability of print-on-demand maps. This led to the high acceptance level found in user surveys performed in phases 1 and 3 (see customer assessment sections).

Digital vector data from the USGS was also evaluated during phase 1, with the results being superior to scanned paper map results. PostScript data were captured from the USGS map production cycle and sent to 3M for processing with 3M Graphic Maker Software and map enhancement algorithms. The CRADA team determined that although printing only vector products would give the highest quality print-on-demand maps, the USGS did not have procedures in place or sufficient coverage to provide such vector products.

\section{Customer Assessment Activities during Phase 1}

The USGS and 3M were interested in assessing both the interest in map-on-demand products by customers who are map buyers (general public) and the impacts of map-on-demand technology on customers who are map dealers or in map-related businesses (private industry). The purpose of these surveys was to obtain customer information for the CRADA team and help focus technical developments to deal with identified concerns.

The first of these surveys was conducted in conjunction with the International Map Trade Association (IMTA) Conference held in Denver on September 17 - 21, 1996. Visitors to the joint 3M/USGS booth and the Rocky Mountain Mapping Center tours were asked to compare a standard 1:24,000-scale topographic map with an experimental map of the same area produced by ink jet technology on 3M's waterproof paper. After their evaluation, respondents were asked to complete a short questionnaire. 
A complete copy of the IMTA customer service report is included in a later section.

\section{Map-on-Demand Workshops at RMMC}

On September 17, 1996, approximately 150 IMTA participants attended tours and workshops at RMMC. RMMC highlighted the USGS/3M CRADA, as part of the open house, and had three, half-hour workshops to inform the IMTA members of USGS activities under the CRADA. Both USGS and 3M personnel were on hand to conduct the workshops and to answer any questions related specifically to the Business Partner association (the arrangement the USGS has with its network of map dealers). The workshop attendees were encouraged to fill out a customer assessment survey and critique the displayed map-on-demand products.

As part of the workshops, the CRADA team displayed the original lithographs with map-on-demand versions of several 1:24,000 scale topoquadrangles, such as the Boulder quadrangle, Estes Park quadrangle, and Longs Peak quadrangle. The CRADA team also displayed a map-on-demand version of the Land Cover map that the EROS Data Center (EDC) provided to 3M. A customized map-on-demand Denver Core Map was provided as a giveaway. This map showed the Currigan Exhibition Hall (Denver Convention Center) circled in the center of the map with the surrounding downtown area. All map-on-demand maps were produced by scanning the original lithograph at 400 dpi on a Tangent drum scanner, manipulating the digital data with 3M's Scotchprint software as well as Adobe Photoshop, and sending the digital file to an HP $750 \mathrm{C}$ ink jet plotter printing at $300 \mathrm{dpi}$. The paper used was 3M's waterproof paper (V6060), which reacts with the pigments in the inks, causing the image to be water stable. 


\section{Phase 2}

\section{Integration of a High-Productivity System Electrostatic Printing Technologies}

The objective of phase 2 was to integrate and install a $3 \mathrm{M}$ high-speed map printing system at the USGS RMMC. Training USGS/BLM CRADA personnel on the system operation was included in this phase. System functions included map scanning, editing, raster image processing (RIPing), archiving, and printing USGS and BLM map products from paper and digital sources. Figure 2 provides a diagram of the installed system, which formed the basis for the evaluations done during phase 3 .

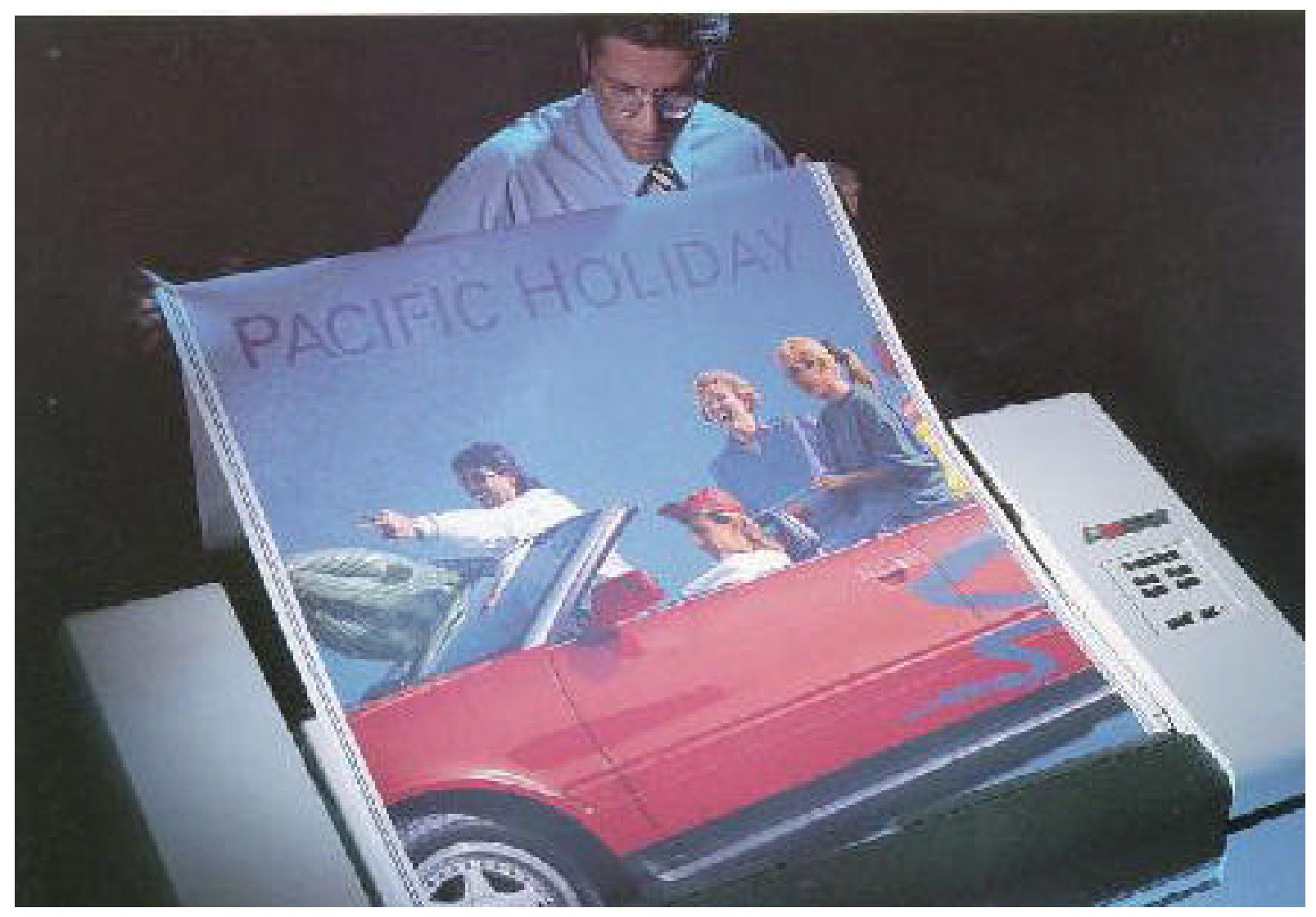

Figure 2: 3M Scotchprint Electronic Graphics System utilized in Phase 2 and Phase 3.

For scanning paper map products, a sheet-fed scanner with the following specifications was used:

- Minimum of 400-dpi optical scan resolution

- Minimum of 36-inch scan width 
- SUN Solaris scanning software

- Single Computer System Interface (SCSI)

On the basis of 3M's research and experience with NIMA Remote Replication System, the ANAtech 3640 scanner was selected for the system. During phase 3, this scanner proved to be unsuitable and was replaced with an ANAtech 4080 scanner unit, which provided the quality required.

The Editing of scanned map data was accomplished by installing the following commercial software packages:

- Adobe Photoshop 3.0

- Research Systems ENVI

- ERDAS Imagine

A SUN Ultra Sparc 2 was used to provide the performance required for large-map scanning and editing. The system configuration for the installed system was the following:

- SUN Ultra Sparc 2, $200 \mathrm{MHz}$

- $384 \mathrm{Mb}$ RAM

- 2 × 2 Gb SCSI fast, wide, hard disk drives

- Second SCSI interface ( installed in phase 3 )

- CD-ROM

- 3.5 inch floppy

- $10 / 100 \mathrm{Mbit} / \mathrm{second} \mathrm{Ethernet}$

- Solaris 2.5.1 UNIX operating system

The 3M Scotchprint Graphic Maker Software was installed to provide high-speed conversion of scanned and digital map data files to printer format. This software provides conversion for TIFF and EPS data files with $3 \mathrm{M}$ proprietary map data enhancement, color conversion, and screening algorithms. Also installed was 3M's Color Table Manager software to provide color calibration and enable high-quality color matching and replication for scanned paper maps.

Archiving scanned map data was accomplished with a recordable CD-ROM unit (CD-R ). Any files that need to be archived are written to the CD-R which provides a storage capacity of 650 megabytes. Using CD-R format provides a universal file format, allowing archived files to be read on any computer system. A Young Minds CD-R unit was integrated with the Ultra Sparc system and the Young Minds CD-R software package that were installed.

Maps were printed on a 3M M9612 electrostatic printer and an HP750C ink jet printer. For highvolume printing, the 3M M9612 provides an output of 60 USGS quadrangle maps per hour. The M9612 printer was connected with a $10 \mathrm{Mbit} / \mathrm{second}$ Ethernet connection. For proofing and lowvolume printing, an HP750C was connected to the Ultra Sparc system through a parallel port 
interface. To help with system power conditioning and avoid system crashes from power outages, an uninterruptible power supply (UPS) unit was installed.

The $3 \mathrm{M}$ company submitted all system equipment purchase orders to the equipment vendors in October 1996. Equipment shipments were all received by 3M in the middle of December 1996, and the system was integrated, the software installed, and all of it tested at $3 \mathrm{M}$ during the last 2 weeks of December 1996. The system, excluding the M9612, was shipped to the USGS and installed the second week of January 1997. During the installation, 2 days of system operation training was done with BLM and USGS personnel. In February 1997, the M9612 printer was installed in the trailer at the USGS, and training was given on operating the M9612 and on system operation, completing the phase 2 work. 


\section{Phase 3: Optimizing a High-Productivity System: Electrostatic Printing System}

\section{Overview}

Phase 3 of the CRADA outlined the installation of an optimal high-productivity map-on-demand system for testing at a site in the Denver Federal Center in Lakewood, Colo. The USGS provided feedback to $3 \mathrm{M}$ on the usability of the system and the quality of the printed maps. The USGS and $3 \mathrm{M}$ were directed to work together to evolve the characteristics of the system architecture and software needed to develop an easy-to-use production system.

A 12 ' by 40' trailer was leased by the USGS RMMC and located on the northeast loading dock of Building 810 at the Denver Federal Center in Lakewood, Colo. The floor plan configuration allowed for a 12' by 12' plotter room for the 3M ScotchPrint Model 9612 (M9612) electrostatic printer. Other 3M equipment provided under the terms of the CRADA, (such as the ANAtech Eagle 4080C scanner, Young Minds CD-Recordable system, and Sun UltraSparc 2 workstation) was housed in the trailer's 12 ' by 28' workroom. In addition, the RMMC Information Services Branch Hewlett-Packard DesignJet 750 (HP750C) color ink jet plotter was placed in the workroom of the trailer. The trailer was leased for a 6-month period beginning on January 15, 1997. An option to extend the lease for an additional 6 months was exercised at the end of July 1997, extending the trailer lease until February 1998.

\section{Investigation of system components}

\section{Scanning}

3M provided a 36-inch, 400-dpi ANAtech Eagle 3640C sheet-feed scanner for evaluation and investigation during phase 3 of the CRADA. This was not the original scanner used to develop prototype products during phases 1 and 2, but the equipment substitution was recommended by $3 \mathrm{M}$ at the meeting of October 22-23, 1996, in Saint Paul, Minn. The Eagle 3640C has three CCD cameras covering the 36-inch media width; each camera covers 12 inches of the manuscript. The specified error within the camera imaging sweep $(\mathrm{X})$ is 0.008 inch. The specified offset between red, green, and blue sampling (Y) is 0.012 inch.

Recurring problems with the image quality of the Eagle 3640C were observed over several months of phase 3, and 3M agreed to replace the 3640C with an Eagle 4080C scanner. The Eagle 4080C has seven CCD cameras covering the 40-inch media width; each camera covers 5.7 inches of the manuscript. The specified error within the camera imaging sweep $(\mathrm{X})$ is 0.004 inch. The specified offset between red, green, and blue (RGB) sampling (Y) is 0.006 inch. The image quality was noticeably much improved on this scanner, even at $400 \mathrm{dpi}$. 
Under the work plan, several areas were identified to concentrate the research investigations, including achieving optimal scanning resolutions, doing cost comparisons, and evaluating options in scanning.

The variety of USGS topographic maps and the variety of USGS products replicated during phase 3 prevented attempts to standardize color reclassification between products. The scanner interface (ANAtech ascan/C) on the Sun workstation did not allow for color reclassification of the scanned image. All scanning was performed in 24-bit color. All attempts to reduce the number of colors were performed in Adobe Photoshop, using the adaptive 8-bit color reclassification; however, the ScotchPrint Print Module was expecting 24-bit color as the image format. The USGS has had much success in using the adaptive 8-bit color technique, and suggested that ScotchPrint be modified to accept this image format.

ANAtech has suggested that using its at-scan color reclassification interface, SCANSMITH, would help in standardizing similar USGS products and symbology. This interface is available only on the Windows NT platform environment.

The condition of the original document was found to be critical in obtaining a good-quality image. Map products that had been folded were a consistent problem. Fading of the stock paper was less of a concern. Slight creases, or wrinkles, in the original document were captured in the scanned image, but resolved in ScotchPrint.

Folding of the original map creates two problems in the captured image: (1) shadowing in the scanned image; and (2) paper tears that reduce color consistency. Documents that had been folded only once, for packaging, consistently displayed the effects of the shadowing problem, even after ironing. As the folding and unfolding procedure was repeated, the documents displayed paper tears and ink inconsistency, which compounded the effects of the document folds. The use of the "User Selected Area" (which is an area of black ink on the paper stock of the document within the Print Module) reduced, but did not eliminate, the effects in the reproduced image.

The procedure for highlighting a "User Selected Area" within the Print Module consistently removed the effects and inconsistencies associated with faded paper stock, and this included and resolved paper "wrinkles" also.

Attempts to replicate and match similar USGS topographic maps were quite successful using the ScotchPrint Print Modules and 24-bit TIFF format. For example, adjacent map sheets for Baltimore, Md. were tested for reproduction. The condition of both the east and west sheets allowed for a near-perfect imaging of the original documents. Slight differences in the lithographic originals were highlighted using the Print Module, and these differences were compensated on the east sheet by varying the cyan and magenta color densities.

The scanner feeding mechanism needs to be improved in several areas. It was difficult to get the correct document angle in the scanner (see notes on Photoshop regarding image rotation), and using the feed guard on the left side of the document feeding area does not guarantee that the document will feed correctly (perpendicular). Also, the moving document tends to get caught on the take-up tray and move considerably after passing through the scanning area. ANAtech technicians suggested that this document movement would not affect the quality of the scanned 
image, but variations in the image density appeared to coincide with this movement. The take-up tray was removed to allow consistent document movement through the scanner.

The effects of scanning and reproducing screened patterns was not considered a problem. The 45-degree, 12-percent screened black of the Building Omission areas (also known as "Built Up Area") did create one noticeable problem when using the Eagle 3640C and the "Narrow Black Mask" in the Print Module. For a period under phase 3, the USGS consistently set the Black mask to "Off." As the "Narrow" mask attempts to separate areas of equivalent RGB values within 8 percent, this consistent gray area was alternately reclassified as either Black or RGB and gave a blotchy look to the tinted area. Installation of the Eagle 4080C and ScotchPrint 2.1 Beta 2 appeared to resolve this problem, and the USGS returned to use the Black Mask as "Narrow" and "Medium" categories.

Scanning and reproducing geologic titles with color printed over base map information was definitely the greatest challenge for phase 3. Four geologic titles were selected from GD's list of 85 publications that are currently out of print and identified for continued support by methods such as print-on-demand. Three other titles of local (Denver) interest were added: Geology of Boulder, Geology of Denver, and Geology of Colorado Springs. Distribution of these last three titles as electrostatic reproductions from the M9612 printer was significant during phase 3 (see "Time line" section). Although the CRADA team did not have the opportunity to obtain firsthand evaluation information for these titles, they were able to gather some general observations about the quality of these reproductions.

The 400-dpi M9612 output was generally reviewed as "muddy" compared with the 300-dpi HP750C ink jet reproduction. The ink jet version of the same image contained "crisper" line symbology and greater line-to-background contrast.

The base map information printed in conjunction with the geologic units was mostly illegible. The general impression from a cartographic perspective was that the reproduction was sufficient. From a geologist's perspective, and as the base map information was not legible, the specific impression was that the electrostatic copies were of little usefulness for scientific purposes.

In respect to the various geologic titles scanned and reproduced under phase 3 , in most cases the dimensions of the original map determined the scanning resolution that was used. A higher scanning resolution would have been preferred. A geologic map 34 inches high and 45 inches wide could use only 400-dpi scanning and archiving.

In respect to USGS 1:24,000-scale topographic maps, efforts under phase 3 revealed that the era of mapping and map symbology was critical in determining the best map resolution for scanning. Maps created in the early part of this century, primarily from copperplate engraving methods, contained a substantial amount of fine cartographic detail and required a higher scanning resolution $(600+$ dpi). USGS topographic maps from the latter part of this century contained coarser detail and relatively larger symbols, which could afford a lower resolution of scanning (600- dpi). For most topographic 1:24,000-scale and 1:62,000-scale titles, a scan resolution of 600 dpi was found to provide the greatest reproduction of map detail and the most affordable file size for Photoshop work and archiving to the CD-Recordable media. 


\section{Processing and archiving}

\section{Creation of Color Lookup Table}

Creation of a color lookup table for a specific output device and media was one of the two unique qualities of this entire printing system that was superior. The other was raster image processing time enhancement options to the image.

It was suggested that the generation of a color lookup table needs to be simplified. Does the target of the table cover a wide enough spectrum to accurately predict the wide range of colors found on topographic and geologic quadrangles? Could the color matching ability of the software be improved by using a wider spectral band in the existing closed loop system? Ideally, the software should produce close-matching colors without having to adjust color curves and parameters.

A preview of the final image using the selected creation of color lookup table might be of value in production. This feature could reduce the number of test plots required to produce a final product. It would also save time in waiting for an image to plot to see what needs to be adjusted. The display would not be closed-loop corrected, and therefore a bad looking display might produce an excellent plot, or a good display might produce a poor quality plot. This type of enhancement may or may not be of high value for color previews, but it might be helpful in edge enhancements.

\section{Adobe Photoshop 3.0}

Photoshop was used throughout this activity, primarily to crop or rotate the scanned map image. Difficulty in feeding the original document through the Eagle scanner at a perpendicular orientation (see "Scanning" section) necessitated rotating the image to within perpendicular of the clipping box. Other Photoshop functions were investigated to repair scanned irregularities of the original document and reduce the image file size by using the Adaptive 8-Bit Color Mode on the 24-bit scanned image.

Photoshop did not appear to be designed or intended for use with large $(100+\mathrm{Mb})$ files, and performance is a serious concern for production work. Additional investigation may uncover software better suited for work on large files.

It seemed that Photoshop attempted to allocate $250 \mathrm{Mb}$ of memory to start a session. When a previous Photoshop session was aborted with a UNIX kill or reboot, the application token appeared to remain active, and Photoshop would generate a "View Only" message, indicating that only $70 \mathrm{Mb}$, not $250 \mathrm{Mb}$, were being allocated. A resolution generally occurred by starting this "limited" session, closing the session, and restarting Photoshop. The subsequent session appeared to be fully active in viewing and editing capabilities.

Photoshop-based operations were certainly the bottleneck in the process flow of jobs. The CRADA team was constantly monitoring disk usage, cleaning up residual files, and archiving used images to increase the available disk space for Photoshop. 
Photoshop was primarily used to orient (rotate) or crop scanned images. During the later stages of phase 3, the team experimented with the Adaptive 8-Bit Color Mode for TIFF images, as the file size was reduced by over 60 percent.

Depending on TIFF size, resolution, and dimensions, Photoshop constantly gave error messages, usually at the end of completing an operation, and generally for TIFF image files exceeding 500 megabytes ("PhotoFalse error: PhotoShop is out of RAM"). In most cases, the operation was indeed completed successfully, though some operations weren't completed.

All attempts using PhotoShop to layer map information failed. This investigation was precipitated by several questions from the Geologic Division's Geologic Mapping Program regarding layering geologic content information over the topographic base map, and whether a layered product could be merged and printed on this system. PhotoShop does allow the separation of graphic content into layers and layer masks. In this attempt, the symbolized map information and text (black) were scanned as separate TIFF images. The text layer was scanned at 24-bit color (450 $\mathrm{Mb})$ and reduced to an 8-bit gray-scale $(150 \mathrm{Mb})$ image in PhotoShop. During the merge process, no operations were allowed ("out of memory") once the 24-bit image (450 Mb) of the symbolized color map information was loaded in Photoshop. The 24-bit map image was then reduced to 8-bit Adaptive color $(150 \mathrm{Mb})$, and the operation was re-attempted. In this case, the only attempt that was partially successful was to load the gray-scale text (as a "just text" Photoshop selection) into the Clipboard buffer, then load the color map image and retrieve the Clipboard. The layered text image was loaded over the color map image, maintaining transparency to the text layer; but all attempts to move and rotate the text layer into position returned the "out of memory" message and were unsuccessful.

\section{Young Minds CD-Recordable}

The Young Minds CD-Recordable (CD-R) was used extensively throughout this activity, and generally without error or difficultly. All cases of CD-R which failed were attributed to user error; whereby the configuration file was not loaded, the write speed was not altered, or the $\mathrm{CD}-\mathrm{R}$ premastering step did not precede the CD-R cut process. Because available disk space was restricted on the workstation, CD-R's were generally cut by creating a file link (unix: ln -s) to the image file as it resided in the /home/user/images directory, rather than by copying the file over to the CD-R recording directory. In limited cases, this file link was not created properly, and the CD-record step failed.

The one recommendation for the Young Minds interface is to reload the recording speed as part of the configuration file.

\section{ENVI}

3M demonstrated the use of ENVI for image display during the beginning of phase 3. The use of ENVI was investigated during the March-June time period when the use of Photoshop was sluggish and system disk errors were prevalent. Experience with ENVI was limited, and most operators preferred Photoshop for the clipping and rotating operations required. 


\section{Product Generation: Output from scanned documents}

\section{ScotchPrint 3.1 Beta 1, Beta 2}

The following comments are in regard to the Beta 1 and Beta 2 releases of ScotchPrint version 3.1 The original version was updated to Beta 2 in April 1997:

- The ScotchPrint software documentation was for Revision 3.0. There was no documentation for image enhancements options under the Print Module for ScotchPrint 3.1 (Beta 1, Beta 2).

- Output from scanned documents and Postscript graphic files was generated by using the ScotchPrint Print and Raster Modules. As the user interfaces of these two modules differed substantially, operators generally developed a preference for using one module over another.

- Operators suggested an integration of print and raster modules to allow easy use of color curve and white value in the same module.

- Color curve needs to be quantified so that a good value derived through testing can be used on future quadrangles with a similar color spectrum. These values can be listed in mathematical values that make up the curve.

- Color curves from previous jobs remained loaded unless reset. This created some confusion when setting enhancements on a new job, because the color curves had to be reset before changes were made.

- Operators wanted to print only part of a map from the Raster Module. This option is available under the Print Module by changing the size of the print cell dimension and selecting only the cell portion you want to print.

- One operator suggested an option to beep when a task is completed so that the user would not have to change modules to check status. This option may be available in the Print Module options.

- In creating and modifying the job control files (jcf), operators liked having the warning about overwriting the job control file.

- The zooming and panning operations for the User-Selected Area often drop the window off the screen. This may be a function of the workstation environment and the window placement settings. Selecting an overedge zoom-in window would resolve this problem, but it was often hard to see enough detail in the map content to determine the optimum area and overedge area.

- The method for selecting the User Selected Area for determining the paper white point 
appeared to change in its presentation of image colors when zooming in and zooming out to refine this area. Occasionally, the color palette used in the User Selected Area would distort the color presentation of the original TIFF. In one extreme case, the colors used appeared to be a brownish (sepia) monotone, and no other colors were present. During this particular session, the appearance of the palette and image became increasingly worse as parameters were changed, and the job was resubmitted several times. $3 \mathrm{M}$ stated that this method was changed in subsequent software releases.

- The black mask appears to toggle to ON whenever a new file is loaded. This function should be optional.

\section{ScotchPrint Raster image processing and Print queues}

- The presentation of percentage completed in the Raster image processing (RIP) and print queues was very helpful.

- Previously composed jobs could be reinserted to RIP or could print directly from the queue. The RIP queues required that the job control file and the image file be loaded as originally configured. Resubmitting jobs to the Print Queue required the print control file (pcf) and the 590-type files or just the 590-type files to recreate the job. The 590-type file is a product of 3M ScotchPrint RIP.

- The only user observation on these modules was that the Quit sequence for the RIP and Print Queue appeared to be switched, with Quit confirmation buttons as Yes/No and No/Yes, respectively.

\section{ScotchPrint 9612 electrostatic plotter (M9612)}

- The purpose of the Input Queue on the electrostatic plotter (M9612) was unclear. At one point, an image was sent and ended up in the input queue. If the use of this queue does not have value, then it should be removed and the storage space should be given to the Output Queue that is commonly used.

- The smearing of black ink on the electrostatic plotter is a major problem. The chemistry of the black ink needs to be changed to a more water-stable formula.

- The electrostatic plotter exhibited a yellow banding on the first four or five plots during an initial startup run. This caused an excessive amount of waste output, since these plots had to be destroyed to obtain a clean copy during plotter startup.

- The CRADA team was not impressed with the quality of the 1:100,000 scale BLM maps. The opinion was that the 400 dpi resolution was not sufficient to produce a plotted map of acceptable quality. A plotter that has a resolution of at least $600 \mathrm{dpi}$ would be a better choice and produce a vastly superior product. Preliminary plots off the HP2500 support this assumption. The electrostatic plotter may have a higher printing speed but the high cost of such a device removes it from consideration in most applications. 
- The sequence of cutting multiple jobs on the M9612 occasionally misregistered. The first few sheets appeared to cut at the edge of the image, then drifted to overcut and undercut subsequent images. This undercutting into the image area could drift as much as 2 inches after 10 copies (34"x34") were produced. 3M explained that this was due to a problem with the Sun Sparc board used within the plotter unit. The solution was resolved by turning off the power to the unit and rebooting the system. Simply warm rebooting (maintaining power) of the print system does not resolve this problem.

- It was suggested that operators would like the M9612 electrostatic printer to keep the last job status set to print until a new job is received (it changes the status automatically to idle).

\section{Printing system stability}

- The M9612 produced very few mechanical and output problems in both limited and extended print runs. The system was considered both reliable and consistent in operation.

- The primary mechanical problem was in regard to the roll paper cutter. On three occasions, the cutter incrementally decreased the document cutting distance into the output image. This condition was not noticeable during the first four to five copies of the printing run and cut into the image of subsequent copies. See this reference under "Product Generation: Output from scanned documents." For this reason, printing runs were limited to no more than 50 copies in an effort to monitor the quality of document cutting more closely.

- The primary output problem involved the black ink. Until the document was given time to dry, the black ink remained very unstable to the touch. After drying, the black ink could be easily smeared by reintroducing moisture, such as licking a finger and dragging it across the document.

- The USGS increased the voltage to the black fountain to compensate for reduced density of the black toner on output prints. This operation is to be expected because the ionization of the toners changes over time.

\section{Hewlett-Packard DesignJet 750C}

The Hewlett Packard DesignJet 750C (HP750C) generally performed without errors or problems. The cyan ink cartridge had a tendency to dry out more quickly than the other toners. The solution often involved removing the cyan cartridge and moistening the cartridge jets with water or saliva, then replacing the cartridge and recalibrating the plotter. The recalibration step generally took 5 minutes. In some cases, both the cyan and magenta cartridge would dry out, and the moistening and recalibration steps had to be repeated several times before uniform cyan coverage was restored. 
The 3M V6060 paper used on the HP750 consistently developed greater image quality than the HP-Special paper generally used on this plotter. Loading of this paper stock was more difficult (than HP-Special) because the media was thicker and often caught on the feeding mechanism of the HP750 (the toothed wheels). 


\section{Product Generation: Output from Postscript graphics}

According to the work plan, the CRADA team's intent was to coordinate with the NMD Graphics Program to capture digital files generated through the NMD production cycle. Under phase 3, only one such title was produced and tested. An electrostatic and an inkjet copy were produced for Prince George, Va., from a composite Postscript file created at Mid-Continent Mapping Center in Rolla, Mo. Under the current NMD digital production scenario, a colorseparate Postscript file is created for each of the five printing colors, and overprinting of the process and spot colors occurs across each file. This procedure is configured into the digital revision graphics system in NMD.

Under this prototype file of Prince George, and as a composite Postscript file, no color overprinting exists. As Postscript is inherently an overlay priority graphic format, only the last feature printed at any pixel position is replicated, and all underlying information is erased in the final graphic.

\section{Environmental Conditions}

Printer Exhaust: The external exhaust fan of the M9612 printer was specified as moving air at a rate of 200 cubic feet per minute (cfm) from the base of the printer. As the printer ink toner and chemistry involves several hazardous components, the rapid venting of this material became an initial concern in choosing a site location. After considering several locations for the phase 3 equipment within the existing floor plan of Building 810, the phase 3 participants decided to put the equipment in a trailer on the loading dock; this required a laboratory analysis of the M9612 printer exhaust. All Materials Safety Data Sheets were provided to the Government Services Administration (GSA) and the Building 810 Materials and Safety Officer. The USGS coordinated all activities associated with hazardous materials and the environment..

Room environment balancing: After the printer and fan/exhaust were installed, a humidistat was installed in the M9612 work room. The trailer manufacturer supplied a single 10-gallon humidifier to maintain the room humidity at 50 percent relative humidity (R.H.). After all equipment had been running for 3 days, the room humidity stabilized at 40 percent R.H., and a second 10-gallon humidifier was installed (on loan from the RMMC GIS Lab). The room stabilized at 50 percent R.H. after a few hours. No adjustments to room temperature were required.

Utilities: Power was supplied by the GSA. Plumbing, in the form of a 1/4-inch water-supply line, was also installed by the GSA. After several equipment problems were observed, GSA electricians rewired part of the electric supply within the trailer to isolate ground for the sensitive computer equipment. 


\section{Training}

Scanner, CD-R training: 3M shipped and delivered the ANAtech scanner, CD-R system, and Sun UltraSparc II workstations to the RMMC GIS facility. 3M conducted training on this equipment during the week of January 6, 1997. Follow up training was conducted on March 4-5, 1997, and 3M returned to supplement color calibration training on April 8, 1997.

3M Electrostatic Printer training: Training for the M9612 was conducted at the RMMC trailer facility March 4-5, 1997. This coincided with the installation of the M9612 in the RMMC trailer facility on March 4, 1997.

\section{Phase 3 Operational Lab Notes}

\section{The following are informal comments recorded during the course of phase 3:}

April 4, 1997

ANAtech has provided us with 400-dpi rescans of the 1:24,000-scale Evergreen, Colo., quadrangle developed on the Eagle 4080C scanner. This scanner has virtually twice the resolution of the Eagle 3640C (three CCD 50-array cameras over the 36-inch scanning area versus the 4080C's seven CCD array over the 50-inch scanning area). The 4080C also has 800-dpi scanning capability; but, because our Sun workstation is configured with two 1.8-gigabyte imaging partitions, the USGS quadrangles already occupy about $250 \mathrm{Mb}$ on a scan, and the CD-R allowed us to archive only $650 \mathrm{Mb}$ at a swipe. Scanning and writing to disk an 800-dpi RGB image (estimated 1 gigabyte in image size) would preclude archiving the file to CD-R and would fill most of the available hard drive space.

April 11, 1997

The field kit has been installed on the Eagle 3640C. The first attempt to scan after the modification resulted in what we term a "split image" at the stitch seam of the middle and right cameras, giving the appearance that someone had cut the image and then tried to tape it back together again.

We have consistently experienced four image problems with this scanner:

Horizontal gray shifting, where the first half of the document appears to have a dark gray value to the paper stock, and the second half of the document scanned appears to have the normal amounts of background noise.

Vertical gray shifting, where each of the three cameras on the $3640 \mathrm{C}$ appears to introduce different levels of gray into the background paper stock.

Image splitting (as described above), where there appears to be a warped and distorted splicing of the image between the middle and right cameras.

Color blobs, where, as a result of the slight offset of the RGB color detection in the pixel 
(documented as 0.003-inches), there is a color shifting to the blue of flat tinted areas of the original.

Also, we have been having one consistent mechanical problem with the scanner:

SCSI lockup, where the scanner appears to lose communication with the workstation (running ANAtech's ASCAN-C software). The software locks up and the scan does not complete while the scanner continues to pass the document through the imaging area.

This scanner was diagnosed with various SCSI communication problems, each of which involved some degree of miscommunication between the scanner and the workstation. ANAtech believes that the miscalibrations of the camera for the image splitting and vertical gray shifting are both related to the loss of camera calibration files before or at the beginning of the scan.

The $3 \mathrm{M}$ representative has mentioned several times that the intermediate $\mathrm{CD}-\mathrm{R}$ device, sitting between the scanner and the workstation on the SCSI cabling, may be the source of the SCSI problems. Our first attempt to bypass the CD-R showed that the Sun Solaria boot sequence expects this device to be on the SCSI buses, and the boot sequence failed.

We have had some success on dispelling the fourth problem (the blobs) by disabling the black mask applied by ScotchPrint to the image within the Print Module. This print module enhancement is intended to separate areas of various equal levels of gray to entirely black ink at printing. Therefore, areas that would be printed with equal amounts of CMYK ink are segregated to black only.

As explained by $3 \mathrm{M}$, the minimum threshold for determining these gray-to-black areas is an 8 percent difference in the RGB values of the scan. We expect that, as these areas also constitute the RGB pixel shift inherent in the scanner mechanics, this filter is confused as to which area to print in black and which area to print in four-color CMYK black. This variation appears to accentuate the color shifts in the image at the pixel level.

Write errors while in Photoshop The Sun UltraSparc 2 continues to record disk write errors when loading and editing the scanned image in Abode Photoshop. We have no suggestions for a resolution. The Photoshop session appears to lock up when the write error occurs. The Sun appears to resolve the problem, sounding as if it then tests the surface of the entire file system (whirring away). Then, after another pause, the Photoshop session resumes. This sequence takes about 5-7 minutes. If two consecutive write errors occur, the time involved is 10-15 minutes. See some of the notes on the Color Page

April 22, 1997

3M explained the difference between the 3M Stochastic and Map Stochastic. The Map Stochastic emphasizes the edges in a scan, which in our case will emphasize the edges in the halftone screens. The $3 \mathrm{M}$ Stochastic option is a truer stochastic screen because the result is smoother and no areas are emphasized. 3M suggested that we use the 3M Stochastic, although we had been using the Map Stochastic with good results.

3M suggested we try ENVI [GIS package] for clipping. It seemed to work faster than Photoshop but took about the same amount of time when changing the resolution. 


\section{Product Generation: Lab Notes from Color Discussion}

March 26, 1997

The system consists of a scanner (ANAtech Eagle 3640C), a workstation (Sun Ultra2 with a 2-Gb hard drive), a CD writer, and two plotters (an HP750C inkjet, and the M9612 electrostatic). 3M is lending us the ANAtech, Sun, and M9612; the Information Services Branch here at Rocky Mountain Mapping Center owns the HP750C. The process is as follows:

- $\quad$ scan the hardcopy as a 24-bit RGB TIFF at 400 dpi (file size approximately $240 \mathrm{Mb}$ )

- bring the file into Photoshop where the excess is cropped and the file size reduced to 300 dpi (file size becomes about $135 \mathrm{Mb}$ )

- identify black and white areas in the scan using the ScotchPrint software (usually the type near the scale bar is used)

- $\quad$ RIP the file and send it to a plotter. The color lookup tables that are created are geared for a specific paper/scanner/plotter combination. The ScotchPrint software uses the lookup tables to create the values to convert from the RGB of the scan to CMYK for printing. Since we have two plotters, we have two lookup tables to choose from, depending on the output device. Once the lookup tables are identified, other modifications, such as adjusting the level of a particular color or enhancing the edges, can be done on the basis of output. This sounds simple, but as you can probably guess, adjusting one of the colors usually throws the others off.

The hardware seems to be the cause of the stops and starts. The ANAtech scanner doesn't do a bad job (that is, it scans an image), but we continue to have some problems. Sometimes the scanner stops in the middle of a scan, and you have to pull the material out and start again, maybe two times, maybe five times. This is not a consistent problem, just an annoyance. We also don't appear to get consistent results; sometimes streaks appear that cannot be fixed no matter how much the colors are manipulated. The Boulder test quadrangle was scanned with the Tangent scanner by $3 \mathrm{M}$, so the results look pretty good. We have noticed different colored pixels surrounding black areas, whether they are type, scale bar, or gray urban-tint areas, and we cannot eliminate these so that a crisp black outline is obtained. Perhaps we have not tried enough combinations yet. The Sun Ultra2 workstation is having daily write errors to the hard disk. The system will try to correct itself and continue on, which just increases the time to complete the task. We have noticed that the errors are usually related to Photoshop.

We have two tasks during phase 3 of the CRADA:

- One is to evaluate the ScotchPrint software as 3M generally has used it (scan, edit, and plot) and determine what it can do to color-correct an incoming scan.

- The second task involves printing, using incoming digital data, and instructing users of software packages like Photoshop how to get the best results from the plotter. 
We have several different types of maps in addition to the 7.5-minute 24,000-scale topographic series:

- a BLM Grand Junction, Colo., 1:100,000 scale map

- a geologic map of the Front Range, Colo. (this copy was obtained from the author; it is out of print)

- the Rocky Mountain National Park map

- a DMA (NIMA) 1:50,000 scale quadrangle in Bosnia

- two 1:24,000-scale quadrangles covering Rocky Mountain National Park

- $\quad$ and, we are also going to scan some historic quadrangles dating from the late 1890's to help out the Abandoned Mine Lands Initiative.

April 11, 1996

On March 31 and April 1, we received additional training from 3M dealing with the updates to the ScotchPrint software. Four new color tables (RGB to CMYK) were developed and have reduced the number of test plots that must be generated to about three or four for a topographic sheet. The $3 \mathrm{M}$ trainers were able to see the problems we have been experiencing regarding the scanner and the workstation. During training, the workstation locked up and we recorded several write errors to the hard disk. The write errors (about 10 per week) seem to happen during a Photoshop session. The disk is not even near to being full ( 60 percent $)$ when the errors occur. ANAtech evaluated the scanner and determined that a patch kit would eliminate interrupted scans. The kit was installed on April 4, and so far there have been no aborted scans. This kit, however, did not solve problems with scan quality. The first scan after the patch was installed showed an offset in the image. The second scan showed a smaller offset; close, but not quite perfect. The same thing happened on the third scan. We will try a fourth scan next week. Scanned images still show haloing around colors, which is especially noticeable around black text. There are red pixels on the leading edge and blue pixels on the trailing edge relative to the scan direction, which cannot be eliminated. Adjustments to colors using the ScotchPrint software do not eliminate the red/blue halo because adjusting to remove halos also removes red/blue pixels that are necessary (that is, red roads and blue water).

\section{General comments regarding example packet mailed July 3 to CRADA members}

- On all of these copies, the registration is fairly good, and the color matches are usually acceptable; the areas of greatest concern are the reproduction of fine linework/type/symbols and of closely spaced contours. The linework, especially the contours, is very good quality on the original lithographs in this test; we wonder what will happen when we try to copy some of the less-than-perfect lithographs, such as those being produced by the Forest Service under the single-edition agreement. 
- As we expected, the inkjet copies are generally better than the electrostatics, but not always. We received both electrostatic and inkjet copies for Boise North and Bozeman, but only electrostatic for Livingston and only inkjet for Evergreen.

\section{BOISE NORTH}

The green depiciting the woods on the electrostatic is breaking down in small polygons (see the parcel in T.4N, R.2E, S.22, near the well). Overall, the green is not a good color match to the original. The electrostatic's contours are weak, especially the dotted supplementals (see extreme lower left corner, paralleling two intermittent drains and a boundary). The electrostatic's streams are so broken down that in some places they look more like intermittent drains than perennials (see Crane Creek across T.4N, R.2E, S.24).

\section{BOZEMAN}

On both copies, it is a challenge to read some of the fine, hand-drawn P-map lettering, although the inkjet is a little clearer than the electrostatic (see "4642AT" in T.1S, R.5E, S.25; the "T" is barely there). The problem is worse where lettering falls on built-up tint (see "BM4808" on east side of the Bozeman tint in T.2S, R.6E, S.7). On the inkjet copy, many of the east-west cased roads appear almost as a single, thick, screened black line (see US191 from west of Bozeman to the neatline); it is not as bad on the electrostatic.

\section{LIVINGSTON}

The purple built-up tint is very grainy; it doesn't look much different than the pattern in the pond near "Fairground" in T.2S,R.10E, S.18. The strange, tiny purple feature in the southeast corner of T.2S, R.10E, S.19 is a windmill, but without the lithograph for comparison, we would never have known what it was. In T.1S, R.9E, S.33, and S.28, the tight contours running northward from elevation 5921 appear bluish to the naked eye; this is due to a flood of large cyan dots. The same problem appears on other areas of dense contours. The purple dashed roads in T.2S, R.10E, S.5 are very weak.

\section{EVERGREEN}

Once again, even on this inkjet copy, fine linework in text and symbols breaks down: see "Genesee Camp" in T.4S, R.71W, S.12 and "Girl Scout Camp" in T.4S, R.71W, S.13. The picnic-table symbols in T.4S, R.70W, S.31 are barely recognizable as such. The black built-up tint is grainy.

\section{Product Generation: Lab Notes from the Accuracy Discussion}

Obviously we cannot control the accuracy of nonstable source materials. Our main concerns are to know if we are adding any noticeable errors and to make certain the system is continuing to 
maintain its initial accuracy. In addition to monitoring positional accuracy, we will be checking how accurately the system replicates symbology.

We received a copy of an evaluation of sheet-feed scanners by 3M from NIMA. We will summarize the information relevant to accuracy. The ANAtech Eagle 4080C scanner that we are using was tested, along with a Tangent SF44/100 and an Altek ALS436-C. A Microcopy Resolution test chart (black and white) was scanned at 400 dpi. Each scanner produced similar results. The line pairs lost clarity between 4.5 and 5.0 lines per millimeter, numbers that correspond to 229 to $254 \mathrm{dpi}$. In the dimensional accuracy test, the ANAtech scanner was within 1 to 2 pixels (at $200 \mathrm{dpi}$ ) of the theoretical values of the grid corners ( 24 by 36 inches). This error was determined to be within measurement error, which was $0.09 \%$.

After we submit the results of accuracy testing, we would like comments from other team members about how any applications you envision may be affected. We may also wish to begin a discussion about the need for and wording of an accuracy disclaimer and about the use of the note, "This Map Complies with National Map Accuracy Standards," note found on potential source materials.

\section{April 7, 1997}

Here is a helpful formula to use when evaluating accuracy issues:

1 --- $=$ size of pixel ( in inches)

dpi

Examples: $400 \mathrm{dpi}=0.0025 \mathrm{inch}, 350 \mathrm{dpi}=0.003$ inch

One-half of a 350-dpi pixel would thus be about 0.0015 inch or about one-half the width of an intermediate contour line. This is the width of the red and blue halos around black images. This is the error that is caused by the separate positions of the RGB scans relative to the camera lens. This error affects legibility more than accuracy because it is numerically small.

The maximum optical error of 0.008 inch is related to the geometry of the camera lens and is proportional to the angle from the lens center to the image. We assume the maximum error is equidistant from two cameras and at the edges of the scan window: 0, 12, 24, and 36 inches on the $\mathrm{x}$-axis. This error is a maximum for each camera, so it is not multiplied or added. ANAtech may be using software to minimize the optical error. This is possible because the three cameras are in fixed positions so the positions, of greatest error are also fixed. We will look through the manual to see if we can find any information on this subject.

May 1, 1997

The ANAtech 3640C color scanner will be replaced with the model 4080C-color scanner during the week of May 5. We anticipate minor integration problems associated with the color lookup tables. 3M has agreed to reset the phase 3 "clock" back to 3 months, extending phase 3 into August. 
June 3, 1997

The ANAtech Eagle 4080C has been working with only a few minor occurrences involving loss of stitch file, caused by loss of communication between the scanner and workstation. In each case, the solution is to reset the scanner and rescan. There have been two such occurrences over the last 3 weeks.

The workstation has continued to generate errors and recovery sequences, particularly in Photoshop (used to crop and resample the image). A test that 3M suggested in late June, disconnecting the SCSI cable to the CD-R and scanner, appeared to resolve this problem. Under this configuration and after a scan is completed, the operator disconnects the SCSI, does the Photoshop work, and then plots. We have found that reconnecting the SCSI (without rebooting) will then allow us to use the CD-R device.

The 4080C scanner allows us to scan at a higher-than-400 dpi resolution. We have noticed that for USGS map series previous to 1940, the amount of detail and line specifications have required us to scan at 600 to $800 \mathrm{dpi}$ in order to generate the best quality image. In this case, our TIFF images approach 1-Gb each.

Yesterday, after scanning two 17" x 22" map sheets at 600 dpi, disconnecting the SCSI, and entering Photoshop to crop, we got a "scratch disk full" message from Photoshop. Each image was 612 megabytes. We elected not to crop, archived the images, and plotted with the full-resolution images from the raster module. Although (when sent to St. Paul) the system configuration has merged the two 1-Gb disks into a single 2-Gb partition, it appears that the combination of using the 4080C for higher resolution images (thereby still larger files) and the existing disk space have placed a workflow size/space restriction on the sequence of scan-to-archive processing.

The up side is that the map reproductions, even the recent era documents, are of better quality, both in terms of image and output, because they were produced by using the $4080 \mathrm{C}$ and 600 -dpi scanning. Without resampling to the output resolution, ScotchPrint will generate a 300-dpi version of the image on the HP inkjet, although it does take a bit more time to process.

June 19, 1997

We recently reevaluated the system accuracy. We scanned a 36-inch square grid on 0.007 -inch clear Mylar on the ANAtech 4080C Scanner at 400 dpi. We printed the image using the HP750C inkjet printer and 3M's V6060 heavyweight waterproof paper. We taped the print to a light table and taped the original Mylar on top, aligning it to the center of the image, which we defined as 0,0 . We then aligned the $\mathrm{X}$ and $\mathrm{Y}$ axes, selected the four corners and five arbitrary test points, and measured the difference on both the $\mathrm{X}$ and $\mathrm{Y}$ axes. The results are as follows (errors in mils):

\begin{tabular}{|c|c|c|}
\hline TEST POINT & X ERROR & Y ERROR \\
\hline 16,14 & 7 & -8 \\
\hline 16,13 & 4 & -1 \\
\hline 13,7 & 5 & -1 \\
\hline $12,-9$ & -2 & 1 \\
\hline
\end{tabular}




\begin{tabular}{|c|c|c|}
\hline 4,14 & 0 & 0 \\
\hline $5,-4$ & 5 & 0 \\
\hline 8,7 & 8 & 0 \\
\hline 16,14 & 23 & -5 \\
\hline 16,13 & 12 & -3 \\
\hline AVERAGE & 7.3 & 2.1 \\
\hline
\end{tabular}

All but one value is within the 20-mil (0.02-inch) maximum error that ANAtech specifies. All but two values are equal to or less than 8 mils (0.008-inch), which is the maximum optical error. We did not do a separate evaluation for the inkjet printer, so it is possible the maximum scanner error may be equal to the optical error, which is related to lens geometry and is not correctable. The two values greater than 8 mils may have included an additional error from the printer. We also measured the image size against the Mylar original. We compared each of the four sides and the greatest difference was 6 mils. This confirms that the inkjet printer is adding additional error. We will repeat the test using the 3M M9612 electrostatic printer. We also noticed our axes are reversed from ANAtech's. Our X is perpendicular to the roller and our Y is parallel to it.

July 25, 1997 SYSTEM ACCURACY—REPEAT TEST

We have completed a repeat system accuracy test. All the hardware and parameters are the same as in the first test. Since we did not save our previous image file, we also rescanned the grid:

\begin{tabular}{|c|c|c|c|c|}
\hline TEST POINT & X ERROR (1) & Y ERROR (1) & X ERROR (2) & Y ERROR (2) \\
\hline 16,14 & 7 & -8 & -2 & 4 \\
\hline $16,-13$ & 4 & -1 & 14 & 14 \\
\hline 13,7 & 5 & -1 & 5 & -3 \\
\hline $12,-9$ & -2 & 1 & 12 & 7 \\
\hline 4,14 & 0 & 0 & 4 & 0 \\
\hline $5,-4$ & 5 & 0 & 0 & 3 \\
\hline 8,7 & 8 & 0 & 3 & 4 \\
\hline 16,14 & 23 & -5 & 12 & 14 \\
\hline $16,-13$ & 12 & -3 & 14 & 0 \\
\hline AVERAGE & 7.3 & 2.1 & 7.3 & 5.4 \\
\hline
\end{tabular}


We conclude from these results that the error for any point is random within an accuracy limit of about 20 mils. In general, the error increases as the distance from the center increases. We think that the randomness is at least partly a result of trying to align the paper plot with the Mylar grid. We suspect that the difference between the two average errors for the Y-axis (3.3 mils) is a function of the variability of both the system and the testing.

October 20, 1997

Here are the results of our accuracy test using the 3M M9612 electrostatic printer. We used the same TIFF file of the Mylar grid that we used in our last test of the inkjet printer (July 24). We tested a single copy and then we tested the last copy, of a batch of 20, to test for any variability of accuracy. We were surprised that the last copy had an average error in both $\mathrm{X}$ and $\mathrm{Y}$ that was more than three times greater than the first test. We then ran a batch of 40 copies to see if the error increased. The last copy had an average error similar to the first copy we checked. After checking every copy in the batch of 20 and randomly checking copies in the batch of 40 and a subsequent batch of 20 copies, we could find no other copy that was significantly different from the first test copy. Unlike the pages from the inkjet printer, every copy was smaller than the Mylar original, in both dimensions. We conclude, with the single exception, that the electrostatic printer is very consistent and the error for each test point is generally proportional to the distance from the center, unlike the random inkjet printer errors.

\begin{tabular}{|c|c|c|c|c|}
\hline TEST POINT & $\begin{array}{c}\text { ELECTROSTATIC } \\
\text { X ERROR }\end{array}$ & $\begin{array}{c}\text { ELECTROSTATIC } \\
\text { Y ERROR }\end{array}$ & $\begin{array}{c}\text { INKJET } \\
\text { X ERROR }\end{array}$ & $\begin{array}{c}\text { INKJET } \\
\text { Y ERROR }\end{array}$ \\
\hline$*-15,14$ & -20 & -11 & -2 & 4 \\
\hline$*-15,-13$ & -18 & -6 & 14 & 14 \\
\hline 13,7 & -14 & -6 & 5 & -3 \\
\hline $12,-9$ & -9 & -3 & 12 & 7 \\
\hline 4,14 & -5 & -5 & 4 & 0 \\
\hline $5,-4$ & -8 & -2 & 0 & 3 \\
\hline 8,7 & -9 & -4 & 3 & 4 \\
\hline 16,14 & -9 & -1 & 12 & 14 \\
\hline $16,-13$ & -12 & -5 & 14 & 0 \\
\hline AVERAGE & 11.6 & 4.8 & 7.3 & 5.4 \\
\hline
\end{tabular}

*These points were -16 inches for the inkjet printer test. The electrostatic printer allows a maximum image width of 34.5 inches. The maximum for the inkjet printer is 35.5 inches.

May 1, 1997

PRINT-ON-DEMAND SYSTEM ACCURACY

We recently evaluated the system accuracy of the ANAtech $3640 \mathrm{C}$ scanner. We scanned a 36-inch square grid on 0.007-inch clear Mylar at $200 \mathrm{dpi}$. We cropped the margins of the image 
using Adobe Photoshop. We printed the image using the HP750C inkjet printer and 3M's V6060 heavyweight waterproof paper. The print was taped to a light table and the original Mylar was taped on top, aligning it to the center of the image, which we defined as 0,0 . We then aligned the $\mathrm{X}$ and $\mathrm{Y}$ axes, selected the four corners and five arbitrary test points and measured the difference on both the $\mathrm{X}$ and $\mathrm{Y}$ axes. The results are as follows (errors in mils):

\begin{tabular}{|c|c|c|}
\hline TEST POINT & X ERROR & Y ERROR \\
\hline 16,14 & -5 & +12 \\
\hline $16,-13$ & -5 & +3 \\
\hline 13,7 & 0 & +11 \\
\hline $12,-9$ & -5 & +10 \\
\hline 4,14 & +4 & +12 \\
\hline $5,-4$ & +3 & 0 \\
\hline 8,7 & -3 & -2 \\
\hline 16,14 & -6 & 0 \\
\hline $16,-13$ & +3 & -3 \\
\hline AVERAGE & -1.6 & +4.8 \\
\hline
\end{tabular}

All values are within the 20-mil (0.02-inch) maximum error that ANAtech specifies. All but four values are less than 8 mils (0.008-inch), which is the maximum optical error. We did not do a separate evaluation for the inkjet printer, so the maximum scanner error may be equal to the optical error, which is related to lens geometry and is not correctable. The four values greater than 8 mils may have included an additional error from the printer.

We were mistaken about the cause of color shifting. It could have been caused by misalignment of the red, green, and blue images because each is scanned at a different position. If this were true, the blue and red haloes would occur on the X-axis (parallel to the roller). The haloes are actually perpendicular to the roller. The haloes were not noticeable on a sample scan produced by a 4080C Scanner, which has seven cameras instead of three. Therefore the color shifting is probably related to lens geometry or optical quality.

\section{Time line of phase 3 activity}

Feb 141997 Trailer delivered to RMMC.

Feb 28 $3 \mathrm{M}$ equipment installed in trailer.

Mar 14

Several recurring equipment problems point to electric.

Mar 27

Trailer rewired for isolated ground on electrical circuits.

Apr 11 Continued problems with ANAtech Eagle 3640C scanner and Sun UltraSparc 2 disk write error. Field kit installed. 
Apr 18

May 6

May 15

May 23

June 16

July 3

July 9

July 15-16

July 16

Aug 1-29

Aug 20

Sept 5

Sept 10

Sept 23

Sept 23

Sept 30

Oct 9

Nov 3

Nov 18-19

Dec 9
3M delivers UPS power conditioner for workstation.

ANAtech Eagle 3640C replaced by Eagle 4080C.

Sun UltraSparc 2 workstation crashed; shipped to St. Paul.

Workstation returns, disk write errors continue.

Eagle 4080C scanner integration completed.

Examples packet sent to all USGS participants.

ScotchPrint M9612 electrostatic printer cleaned.

CRADA technical meeting held at RMMC.

A second SCSI was added to Sun UltraSparc 2 workstation and workstation disk write errors abated.

Scanning of historical USGS quadrangles.

BLM 1:100,000-scale Phoenix North printed on HP750. M9612 printing fails; communication problems between the workstation and the M9612 investigated.

ScotchPrint M9612 communications reactivated.

Two Postscript-based publications from GD printed.

International Map Trade Association Conference meets in Washington, D.C.

Topographic Map Users Meeting takes place at RMMC.

I-857-F Geology of Colorado Springs (M9612) printed.

1:24,000 Evergreen, Colorado (M9612) printed.

1:25,000 (1906) Cripple Creek (M9612) printed.

1:62,500 (1904) Telluride (HP750C) printed.

Distributed I-856-H Geology of Denver (M9612).

CRADA display set up at GD Central Region Publications.

Distributed I-856-H Geology of Denver (M9612).

Four out-of-print GD publications duplicated.

CRADA technical meeting held in St. Paul.

Four out-of-print GD publications reprinted and sent to 3M. 


\section{Products under Phase 3}

Titles printed under phase 3

GQ-291 Geology of Ironton, CO

I-346 Geology of Franklin/Hamburg, NJ

I-1632 Geology of Craters of the Moon, ID

I- 731 Generalized Surficial Geology-Denver Area

I-855 Fort Collins Geology

Oregon-Multnomah Co. Soils Map 1919

Oregon City (3quadrangles - 1914, 1939, 1961)

Oregon State Index (2 maps - 1951, 1980)

I-857 Castle Rock Geology

I-856-H Geology of Denver

Hampton, $\mathrm{NH}$

mo_se.eps, pr_sheet1.eps (worked)

mo_se2.eps, mo_se_geo.eps, pr_geo.eps

Baltimore East \& Baltimore West

Digital Shaded Relief of United States

glacial.eps

gf_12k.eps

gf_6k.eps

contam.eps

Livingston, MT

Livingston, MT (DRG)

Bozeman, MT

Boise North, ID

Titles archived under phase 3

Bldg 810 Directory (stuff)

Directory.new.tif

I-857, 400dpi-no crop

tempfil.agfa.eps - eps file of Agfa grid

I-855F \& plotfiles

I-857F original $400 \mathrm{dpi}$, cleaned

I-856H original $400 \mathrm{dpi}$, cleaned, $-0.41 \%$ Y error

I-856H \& plotfiles

I-856 400 dpi, $-0.41 \%$ Y error

I-856G \& plotfiles

I-856G original $400 \mathrm{dpi},-0.41 \%$ Y error

Priest Lake, ID, 1911, $-0.41 \%$ Y error

Hampton, NH 300 \& 400 dpi scans, $-0.41 \%$

I-855 400 dpi
Date (1997)

October 31

October 24

October 28

October

March 4

October 22

October 22

October 23

May 27

April 17

September 11

September 11

July 7

July 23

July 8

July 9

July 9

July 9

April 18

April 18

April 18

April 18

Date (1997)

October

October

September

April

September

September

June

September

June

July

July

July

June

April 27 
butte15k_400.tif \& marysville_600.tif MT (AML)

August

Butte South, MT 800 dpi

August

Evergreen, Morrison, Ft. Logan, CO 3640 scanner

March

Montana GIS Conference (BoiseN, ID, Livingston \& Bozeman, MT)

April 16

New Evergreen (Evergreen, CO)

April 24

RMNP3 (Estes Park, McHenry's Peak, Trail Ridge, Longs Peak, CO)

March 18

RMNP1 (Longs Peak \& Trail Ridge, CO 400 dpi, 3640 scanner)

March 13

RMNP2 (Estes Park \& McHenry's Peak, CO 400 dpi, 3640 scanner)

March 13

Open House pictures

Open House pictures (MAC byte order)

March 14

Cripple Creek \& Highlands Ranch, CO

March 10

Phoenix North, AZ BLM 100k

Ouray Minig District, CO 1927/28

Prince William, VA RevPG-produced Postscript

September 10

September

August 27

Chattanooga Mining Area, CO

February

sagebrushw_drg.tif \& world file, sagebrushw_300.tif

August 25

sagebrushw_600.tif

Needle Mountains \& Ouray, CO

Baltimore West, MD

August 7

August 7

August 4

Baltimore East, MD

July 2

July 2

Avon \& Basin, MT

July 7

Clear Mylar Grid 4080 scan

ANAtech color correction tables

July 18

April

Helena and vicinity \& Helena shaded relief, MT

July 9

Elk Park \& East Helena, MT

July 8

Jefferson City \& Elliston, MT

July 7

Boulder \& Deer Lodge, MT

July 7

Telluride \& Ignacio, CO

August 4

La Plata \& Silverton, CO

July 25

Rico \& Lake City, CO

July 24

Engineer Mountain, CO

July 22

Helena \& Marysville, MT

Oregon - Multonomah, Co. 1919 Soils Map

Oregon City, OR 1961 \& Oregon State Indexes $(1954,1980)$

July 10

October 30

October 24

Oregon City, OR $(1914,1939)$

October 23

GQ-291 Ironton, CO

October 31

Central City \& Nederland, CO

October 22

Louisville \& Lafayette, CO

October 23

Albuquerque, NM 1934 62.5K

October 31

Bernalillo, NM 1888 125K

October 31

Derby \& Englewood, CO 1937 62.5K

October 31

Arvada \& Golden, CO 193762.5 K

November 7

Fort Logan \& Morrison, CO

November 12 


\title{
CUSTOMER SURVEY REPORTS
}

\author{
IMTA CONFERENCE
}

TOPOGRAPHIC MAP BUYERS

FOCUS GROUPS 


\section{Map-on-Demand Customer Survey Report IMTA96 Conference}

\section{A. BACKGROUND \& PURPOSE}

The USGS is working with $3 \mathrm{M}$ under a Cooperative Research and Development Agreement (CRADA) to develop map-on-demand systems for printing USGS products. As part of this effort, the External Awareness Working Group (EAWG) is conducting a series of questionnaire surveys to assess both the interest in map-on-demand products with customers who are map buyers (general public); and, the impacts of map-on-demand technology with customers who are map dealers or in map-related businesses (private industry). The purpose of these surveys is to obtain customer information for the CRADA team and help focus technical developments to address identified concerns.

The first of these surveys was conducted in conjunction with the International Map Trade Association (IMTA) Conference held in Denver on September 17 - 21, 1996. Visitors to the joint 3M/USGS booth and the Rocky Mountain Mapping Center tours were asked to compare a standard 1:24,000-scale topographic map with an experimental map of the same area produced by inkjet technology on 3M's waterproof paper. After doing their evaluations, respondents were asked to complete a short questionnaire. A total of 93 questionnaires were collected.

\section{B. DATA ANALYSIS}

Who responded:

Of the 93 respondents, 82 associated themselves with one or more of four different business categories. The largest groups of respondents were retailers and wholesalers of map products. (See table 1. Survey Respondents by Business Category.) The remaining respondents characterized their business as other map-related business, as publishers, and as the imaging industry. Of the 93 total respondents, 11 declined to identify themselves with any of the four business categories.

\begin{tabular}{||c|c|c|c||}
\hline $\begin{array}{c}\text { Retailer / } \\
\text { Wholesaler }\end{array}$ & $\begin{array}{c}\text { Other } \\
\text { Map-Related } \\
\text { Business }\end{array}$ & Publisher & $\begin{array}{c}\text { Imaging } \\
\text { Industry }\end{array}$ \\
\hline $49 \%$ & $31 \%$ & $28 \%$ & $9 \%$ \\
\hline 40 & 25 & 23 & 7 \\
\hline
\end{tabular}

Table 1. Survey Respondents by Business Category

Of the 93 respondents, 34 identified themselves as current USGS map dealer. 
What did they say:

\section{ALL Respondents}

- Approximately half were satisfied with the colors, text legibility, and contour / elevation clarity of the experimental map.

- 60 percent were very satisfied with the waterproof paper used on the experimental map.

- 98 percent thought the experimental map was a good quality product.

- 94 percent viewed the experimental edition as an acceptable substitute if the "standard" USGS topographic map were not immediately available

- 58 percent were willing to pay the same price for the experimental edition.

- Approximately half purchased more than 50 USGS maps in a year.

- 37 percent were currently USGS map dealers.

\section{USGS Dealers}

- All were either very satisfied or satisfied with the colors of the experimental map.

- Almost half were satisfied with the text legibility, and contour/elevation clarity of the experimental map; 16 percent were dissatisfied with the text legibility and 6 percent were also dissatisfied with the contour/elevation clarity.

- 61 percent were very satisfied with the waterproof paper used on the experimental map.

- All thought the experimental map was a good quality product.

- All viewed the experimental edition as an acceptable substitute if the "standard" USGS topographic map were not immediately available

- 56 percent were willing to pay the same price for the experimental edition.

\section{CONCLUSIONS}

1. A large proportion of the attendees of the IMTA conference is satisfied with the quality of all aspects of the experimental edition.

2. There is significantly greater satisfaction with the paper quality than with the text legibility or contour/elevation clarity.

3. Dealers have significantly higher satisfaction with the colors than do nondealers.

4. Nondealers have significantly higher satisfaction with the text legibility than do dealers.

5. Retailers/wholesalers have significantly lower satisfaction with text legibility than do respondents from the imaging industry, other map-related business, and non-map-related business.

6. Retailers/wholesalers have significantly lower satisfaction with contour/elevation clarity than do respondents from the imaging industry and non-map-related business.

7. Purchasers of 5 or fewer maps have significantly higher satisfaction with text legibility than purchasers of more than 50 maps. 
8. There is significantly stronger satisfaction with the paper quality than with any of the other categories.

9. There is significantly weaker satisfaction with the text legibility than with the colors.

10. Dealers have significantly stronger satisfaction with the colors than do nondealers.

11. Respondents from non-map-related business have significantly weaker satisfaction with text legibility than do the imaging industry and other map-related business.

12. Purchasers of 5 or fewer maps have significantly stronger satisfaction with the text legibility than do purchasers of more than 50 maps.

13. A large proportion of the attendees ( 97.1 percent) thinks that the experimental edition is a good-quality product.

14. A large proportion of the attendees ( 92.0 percent) thinks that the experimental edition would be an acceptable substitute if the standard USGS topographic map were not immediately available.

15. Dealers are significantly more likely to find the experimental edition an acceptable substitute than are non-dealers.

16. A large proportion of the attendees would be willing to pay the same or more for the experimental edition as for the standard USGS topographic map. (between 79.8 percent and 92.2 percent would be willing to pay the same or more.)

17. Of those willing to pay the same or more for the experimental edition, most are willing only to pay the same. Only from 19.8 percent to 37.0 percent are willing to pay more.

18. Respondents who are retailers/wholesalers and other map-related business are significantly less likely to be willing to pay the same or more than respondents from the imaging industry.

19. Respondents from non-map-related business are significantly less likely to be willing to pay more than are respondents from the other classes. 


\section{WE NEED YOUR HELP PLEASE!}

As a participant in the $16^{\text {th }}$ Annual Conference of the IMTA, we would like to have your evaluation of the displayed map produced by experimental technology as compared to the "standard" USGS topographic map.

1. Please rate your level of satisfaction with the following characteristics of the experimental edition. MARK YOUR CHOICE WITH A CHECK $(\checkmark)$.

\begin{tabular}{|l|l|l|l|l|}
\cline { 2 - 5 } \multicolumn{1}{c|}{} & Very satisfied & Satisfied & Dissatisfied & Very dissatisfied \\
\hline Colors & & & & \\
\hline Text legibility & & & & \\
\hline Contour / elevation clarity & & & & \\
\hline Paper & & & & \\
\hline
\end{tabular}

2. Overall, do you think the experimental edition is a good quality product?

$\square$ Yes $\square$ No

3. If the "standard" USGS topographic map were not immediately available, would the experimental edition be an acceptable substitute?

$\square$ Yes $\square$ No

4. If the "standard" USGS topographic map were not immediately available, what would you be willing to pay for the experimental edition?

$\square$ More $\square$ Less $\square$ The same

5. How many USGS maps do you purchase in a year?

$\square 5$ or fewer $\square 6$ to $50 \quad \square$ More than 50

6. Please check the phrase that best characterizes your business.

$\square$ Retailer/Wholesaler $\square$ Publisher $\square$ Imaging industry $\square$ Other map-related business

7. Are you currently a USGS map dealer?

$\square$ Yes $\square$ No

Comments: 


\section{Methodology}

\section{QUESTIONNAIRE DESIGN}

Representatives from EAWG and the CRADA Team brainstormed basic questions for the Mapon-Demand surveys.

Initial draft of questionnaire reviewed by $3 \mathrm{M}$ and others in NMD.

Draft questionnaire pretested in the Reston ESIC. Completion time was approximately 5 minutes.

General public questionnaire finalized with custom changes for IMTA conference.

\section{DATA COLLECTION}

Interview team formed to work onsite in booth and warehouse to solicit responses.

Business cards collected and notes taken during these interviews.

Respondents reminded to answer questions through the eyes of their customers.

Copies of the 3M/USGS Prototype Map used as incentives for prospective respondents.

\section{DATA ENTRY}

Numbered questionnaires and entered raw data using SNAP software.

Completed initial data entry, including questions and case data (4 hours).

\section{DATA VERIFICATION}

Compared random sample of raw data with corresponding questionnaires. No data entry errors found.

Reviewed NO REPLY data for additional information. Some changes made to raw case data.

Checked for internal inconsistencies in the data.

Reviewed questionnaires for additional information and interpretation. Some changes being made to raw case data.

Prepared quality assurance report.

\section{DATA ANALYSIS}

Performed a statistical analysis of the data for each question and developed some initial conclusions.

Tabulated frequency and percentage reports for all respondents.

Tabulated frequency and percentage reports for USGS dealers. 
Reviewed and analyzed comments for additional information.

Obtained feedback from CRADA team, NMD Business Partners manager, External Awareness Working Group (EAWG), and others. 


\section{One-on-One Interview Summaries}

Short interviews were conducted with potential respondents to explain the joint USGS/3M mapon-demand development efforts and the questionnaire survey. The interviews were useful in ensuring a high response rate and in providing additional customer information beyond the questionnaire survey. Four USGS interviewers compiled the following summaries:

\section{$H$.}

The interviews incorporated the questions of the written survey. Many of the interviews were conducted with USGS Business Partners. A prevailing question from everyone interviewed was about the price of the experimental map. The area of price was one for which we had no concrete information to answer those posing the question. Of course, this is a very important issue to any businessperson. Those surveyed said they would be willing to pay the same or more just to get the product. For those stating they would pay more, there are sure to be definite parameters, but they were not discussed. The quality of the product was affirmed, and when respondents were asked if it would be an acceptable substitute, the answer was "yes." The paper on which the experimental product was printed was most acceptable to everyone interviewed. There were several technical questions about the equipment used, and those questions were referred to the $3 \mathrm{M}$ representatives at the booth.

\section{C.}

The interviewees included representatives from large wholesalers who sell maps to retail stores, retailers who sell maps to recreational users, small specialty businesses, and USGS map dealers. Most of the comments fell into several groups: quality of USGS maps, new ideas, implications of the new map-on-demand technology, and the new dealer discount rates. Commenting on the quality of USGS maps, one said that the USGS has a product with no peer. Another stipulated that most consumers would not notice differences, but dealers do not want to see any sliding back in quality. Some interviewees shared new ideas about the cookie cutter capability of future systems and map customization. Commenting on the implications of this new technology, one indicated that waterproof paper would eliminate their laminating operation. Other comments concerned how the technology would help make maps more available and make it more economically feasible to store maps. Many of the interviews were dominated by the new discount schedule for dealers. Some thought it was generous at the five count but did not work for orders of one to two maps. Others noted that the new rates allowed a lot of firms to get back into the map business.

\section{D.}

Comments during interviews with visitors to the USGS 3M CRADA booth at the International Map Trade Association meeting fell mostly into the areas of map inventory, paper, database, delivery, price, and quality. Visitors generally reacted positively to the prospect of reduced map inventory requirements, were generally complimentary of the paper used on the test maps, 
grasped the concept of printing from digital files, and wanted to know where and how those files would be available. They anticipated quicker delivery of maps with map-on-demand and were willing to pay higher prices for maps-on-demand. Some expressed concerns about the quality of the map product, particularly the text. Comments made on the different areas of concern are shown below.

\section{Inventory}

Reduce inventory.

Likes the idea that MOD would allow him to reduce inventory.

MOD will reduce inventory.

"Some day dealers will realize that maps-on-demand requires no inventory"

"The question is how far will map-on-demand filter down - to the home?" "Create a map on your computer and send it off to the map dealer to be printed ..."

Concern is that "the USGS would become complacent on reprinting out-of-stocks since they would have maps-on-demand to fall back on."

\section{Paper}

Paper is terrific.

"Waterproof paper would be an improvement."

Customers purchase maps, mark them up as they wish, and then bring them back to the store to have them laminated. The paper on the maps-on-demand sample would eliminate the laminating business.

Concern: repeat sales if paper is indestructible.

\section{Database}

"Where will we get the data?"

"Why should I cooperate and provide data since they will go into the public domain?"

"Where will the scanned data be available?"

\section{Delivery/Price/Quality}

Timely delivery.

MOD will work if the customer wants the maps quickly and the quality is good.

Less worried about price increase [than quality].

Willing to pay more for the maps.

"Print a little hard to read."

\section{E.}

Many of the IMTA attendees were confused about the digital data that will be used to produce map-on-demand products. An explanation was given about USGS DRG's and the problems associated with the DRG's for hard-copy output. The individuals were also told that the USGS 
has not populated a data base optimized for map-on-demand printing systems and that the USGS/3M CRADA will help define the requirements for creating optimal map-on-demand digital files.

Many respondents were impressed with the quality of the map-on-demand version. One individual could not see the difference between the map-on-demand version and the original lithograph and therefore was confused about what we were trying to accomplish.

Overwhelmingly, the respondents liked the quality of the map-on-demand waterproof paper, some even suggesting it was better than the lithographic paper.

The map dealers that were interviewed were initially concerned about 3M's role in the map-ondemand CRADA. Some suggested that $3 \mathrm{M}$ would squeeze out the small map dealers and put them out of business. Other map dealers suggested that the map-printing systems and data would be too expensive for their operations.

Copyright issues were mentioned by some of the IMTA attendees. The attendees were confused about paying royalties for data used to make customized map products. However, most attendees were excited about the possibility of making customized maps suited to individual data requirements.

Generally, the IMTA attendees were positive about the USGS/3M CRADA and the work that has been done thus far. The attendees suggested that regular updates on the CRADA progress be posted to the World Wide Web. 


\section{Map-on-Demand Customer Survey Report Topographic Map Buyers}

\section{A. BACKGROUND and PURPOSE}

The USGS is working with 3M under a Cooperative Research and Development Agreement (CRADA) to develop map-on-demand systems for printing USGS products. As part of this effort, the External Awareness Working Group (EAWG) is conducting a series of questionnaire surveys to assess both the interest in map-on-demand products by customers who are topographic map buyers (general public) and the impacts of map-on-demand technology on customers who are map dealers (business partners). The purpose of these surveys is to obtain customer information for the CRADA team and help focus technical developments on identified concerns.

The topographic map buyers survey was conducted through the Information Services Branch at the Rocky Mountain Mapping Center during December 1996. This involved mailing survey packages containing map samples and questionnaires to 1,000 successive customers ordering topographic maps through the Denver Distribution Center. The intent of this survey was to assess the reactions of the topographic map buyers to the mass-production, electrostatic version of the on-demand map. The mail-out included a 1:24,000-scale USGS topographic map and an experimental map of the same area produced using an electrostatic printer on waterproof paper. The respondents were asked to compare the standard and experimental maps and to complete a short questionnaire. A total of 282 completed questionnaires were received.

\section{B. DATA ANALYSIS}

Who responded:

The respondents were asked to identify their purpose(s) for using USGS topographic maps by selecting one or more of 5 different user-type categories. Since it was allowable to choose more than one category, the percentages depicted in the table total more than 100 percent. The largest groups of respondents were recreational, business, and resale users of map products. The remaining respondents characterized their topographic map use as educational and display/decoration. All of the respondents identified themselves with at least one of the five usertype categories. 
Table 1. Survey Respondents by Map Use Category

\begin{tabular}{|c|c|c|}
\hline Map Use & Number of Respondents & Percent of Respondents \\
\hline Recreation & 150 & $53 \%$ \\
\hline Business & 107 & $38 \%$ \\
\hline Education & 74 & $26 \%$ \\
\hline Display/Decoration & 38 & $14 \%$ \\
\hline Resale & 85 & $30 \%$ \\
\hline
\end{tabular}

What they said:

For the purpose of analysis, many of the tables presented combine satisfied and very satisfied into the single category satisfied; dissatisfied and very dissatisfied were also combined into the single category dissatisfied)

- From 75 percent to 80 percent were satisfied or very satisfied with the colors and paper of the experimental map. (See table 2, Satisfaction with Characteristics of Experimental Map.)

- From 64 percent to 69 percent were satisfied or very satisfied with the text legibility and contour/elevation clarity of the experimental map. (See table 2)

Table 2. Satisfaction with Characteristics of Experimental Map

\begin{tabular}{|c|c|c|c|}
\hline Category & $\begin{array}{c}\text { Number of } \\
\text { Respondents }\end{array}$ & $\%$ Satisfied & $\%$ Dissatisfied \\
\hline Colors & 281 & 74.7 & 25.3 \\
\hline Text & 281 & 63.7 & 36.3 \\
\hline Contour & 280 & 68.6 & 31.4 \\
\hline Paper & 279 & 80.3 & 19.7 \\
\hline
\end{tabular}

- 71 percent thought the experimental map was a good quality product. (See table 3, Satisfaction with Overall Quality of Experimental Edition.)

Table 3. Satisfaction with Overall Quality of Experimental Edition

\begin{tabular}{|c|c|c|}
\hline $\begin{array}{c}\text { Number of } \\
\text { Respondents }\end{array}$ & $\%$ Yes & $\%$ No \\
\hline 276 & 70.7 & 29.3 \\
\hline
\end{tabular}

- 84 percent viewed the experimental edition as an acceptable substitute if the "standard" USGS topographic map were not immediately available. (See table 4, View Experimental Edition as 
an Acceptable Substitute.)

Table 4. View Experimental Edition as an Acceptable Substitute

\begin{tabular}{|c|c|c|}
\hline $\begin{array}{c}\text { Number of } \\
\text { Respondents }\end{array}$ & $\%$ Yes & $\%$ No \\
\hline 275 & 84.4 & 15.6 \\
\hline
\end{tabular}

- About 44 percent were willing to pay the same or more for the experimental edition. (See table 5, Amount Willing to Pay for Experimental Edition.)

- About 56 percent were willing to pay less for the experimental edition. (See table 5)

Table 5. Amount Willing to Pay for Experimental Edition

\begin{tabular}{|c|c|c|}
\hline $\begin{array}{c}\text { Number of } \\
\text { Respondents }\end{array}$ & $\begin{array}{c}\% \text { Same } \\
\text { or More }\end{array}$ & $\%$ Less \\
\hline 278 & 43.9 & 56.1 \\
\hline
\end{tabular}

- 36 percent purchase five or fewer USGS maps in a year.

- 37 percent purchase more than 50 USGS maps in a year.

- All but one resale user (dealer) buy more than 50 maps per year.

- There is no significant difference in overall satisfaction between dealers and nondealers.

- A dealer is defined as any respondent who both purchases more than 50 USGS maps in a year (question 5) and uses the maps for resale (question 6).

- Display/decoration is hardly ever the sole purpose for buying a topographic map.

\section{Analysis of Comments}

More than half of the respondents included comments on their questionnaires (163 of 282).

Comments were analyzed and grouped by question or category as appropriate. Some comments were allocated to multiple questions or categories. Percent was calculated by dividing by the total number of respondents - 282. (See table 6, Comment Analysis.)

Table 6. - Comment Analysis

\begin{tabular}{|l|c|c|}
\hline Type of Comment & Number & Percent \\
\hline Satisfaction with map characteristics - (Question \#1) & 1 & 0.4 \\
\hline Good quality product - (Question \#2) & 6 & 2.1 \\
\hline
\end{tabular}




\begin{tabular}{|l|c|c|}
\hline Type of Comment & Number & Percent \\
\hline Acceptable substitute - (Question \#3) & 17 & 6.0 \\
\hline Willing to pay - (Question \#4) & 8 & 2.8 \\
\hline Maps purchased annually - (Question \#5) & 10 & 3.5 \\
\hline Purpose(s) maps used - (Question \#6) & 13 & 4.6 \\
\hline Reason for Dissatisfaction with Experimental Edition & 84 & 29.8 \\
\hline Reason for Satisfaction with Experimental Edition & 15 & 5.3 \\
\hline General Statement of Preference & 48 & 17.0 \\
\hline Marketing Appeal of Experimental Edition & 13 & 4.6 \\
\hline Question About the Experimental Edition or USGS Maps in General & 26 & 9.2 \\
\hline
\end{tabular}

A closer examination of the three most prevalent comment types reveals some additional detail. These three categories account for more than two-thirds of the comments provided by the respondents and represent a generalization of the raw comments analyzed.

Reason for dissatisfaction with experimental edition - (29.8 percent)

Colors are too dark and intense, especially for the urban and vegetated areas; text legibility is too grainy and blurry; contours lack clarity and are difficult to follow; paper tears easily and is not durable; print can be easily erased, especially when wet; colors run when wet; product is not suited for field work or outdoor use; resolution and clarity of product in general are poor.

General statement of preference - (17 percent)

Standard USGS topographic maps are an outstanding product; experimental electrostatic map requires improvement; experimental map would be considered as a temporary substitute at a lower price, and if it were more "instantly" available; experimental map would be beneficial if center point plotting were possible, as well as the ability to print customized layers.

Question about the experimental edition or USGS maps in general - (9.2 percent)

- Information on cost, availability, and distribution of experimental maps desired

- access to digital plotting files by Internet or CD-ROM requested

- site license requirements and equipment needs requested

- information on how to acquire digital files to support print-on-demand desired

- complete coverage availability requested

- concerns regarding how well experimental map would hold up under sunlight and humidity noted. 


\section{CONCLUSIONS}

Overall Satisfaction

1. The majority of topographic map buyers (70.7 percent) think that the electrostatic experimental edition is a good quality product.

2. Most topographic map buyers ( 84.4 percent) think the experimental edition would be an acceptable substitute if the standard map were not immediately available.

3. Most topographic map buyers would not be willing to pay the same or more for the experimental edition as they would for the standard USGS topographic map.

4. There is no significant difference in overall satisfaction between dealers and nondealers.

\section{Satisfaction with Map Characteristics}

1. A majority of topographic map buyers are satisfied with the quality of all aspects of the experimental edition.

2. There is greater satisfaction with the paper than with the text legibility or the contour/elevation clarity.

3. There is greater satisfaction with the colors than the text legibility or the contour/elevation clarity.

4. Nondealers have stronger satisfaction with the paper than do dealers.

\section{Satisfaction Based on Map Use}

1. Buyers who use topographic maps for display/decoration are more likely to think the experimental edition is a good quality product than those who buy for recreation, business, resale, or education.

2. Buyers who use topographic maps for business have greater satisfaction with text legibility than those who buy for recreation use.

3. Buyers who use topographic maps for education have stronger satisfaction with the paper than do those who buy for resale.

\section{Satisfaction Based on Number of Maps Purchased}

1. Those who buy from 6 to 50 topographic maps per year are more satisfied with the paper 
than those who buy more than 50 .

2. Buyers of five or fewer topographic maps per year have stronger satisfaction with contour/elevation clarity than do buyers of more than 50 maps.

3. Buyers of five or fewer topographic maps per year have stronger satisfaction with the paper. 


\section{OMB No. 1028-0054 APPENDIX I}

Expires 2/28/2000

\section{WE NEED YOUR HELP PLEASE!}

We thank you for your order and appreciate your assistance.

We have enclosed with your order a pair of maps for your evaluation. One map is a standard USGS topographic map, and the other is a map produced by experimental technology. Your answers to these questions will help the USGS evaluate this experimental edition.

Please compare both maps and answer the questions below. After you have completed the questions, just fold the page in half, seal it, and drop it in the mail. It is prestamped and preaddressed for a speedy return. The samples are yours to keep.

1. Please rate your level of satisfaction with the following characteristics of the experimental edition. MARK YOUR CHOICE WITH A CHECK $(\boldsymbol{})$.

\begin{tabular}{|l|l|l|l|l|}
\cline { 2 - 5 } \multicolumn{1}{c|}{} & Very satisfied & Satisfied & Dissatisfied & Very dissatisfied \\
\hline Colors & & & & \\
\hline Text legibility & & & & \\
\hline Contour/elevation clarity & & & & \\
\hline Paper & & & & \\
\hline
\end{tabular}

2. Overall, do you think the experimental edition is a good quality product?
$\square$ Yes
$\square$ No

3. If the standard USGS topographic map were not immediately available, would the experimental edition be an acceptable substitute?
$\square$ Yes
$\square$ No

4. If the standard USGS topographic map were not immediately available, what would you be willing to pay for the experimental edition?

$\square$ More $\square$ Less $\square$ The same

\section{How many USGS maps do you purchase in a year?}

$\square 5$ or fewer $\square 6$ to $50 \quad \square$ More than 50 
6. For what purpose(s) do you use USGS topographic maps?

$\square$ Recreation $\square$ Business $\square$ Education $\square$ Display/decoration $\square$ Resale 


\section{M/USGS Print-On-Demand Maps}

\section{Exploratory Focus Groups}

\section{Final Report}

MMM \#802

Prepared for:

3M Corporate Marketing

June, 1997 


\title{
Background and Objectives
}

$3 \mathrm{M}$ and the U.S. Geological Survey have entered into a cooperative research and development agreement to investigate maps-on-demand technology. This cooperative agreement will potentially help the USGS to develop print-on-demand alternatives to the current lithographic maps, and help 3M develop commercial instant print-on-demand map printing systems.

As part of this development process, input from USGS Business Partners as well as non-USGS Business Partners was requested. A series of four focus groups was scheduled, two each in Denver and San Francisco.

These focus groups were conducted with the following specific objectives:

- $\quad$ Obtain reaction from USGS Business Partners and non-Business Partners to a new method of providing maps to their customers

- Determine potential benefits from this new system, as well as the potential issues to overcome with print-on-demand prototype maps

- $\quad$ Obtain reaction to print-on-demand prototype maps

\author{
Methodology \\ Location and Dates $\quad$ Accudata Market Research \\ Denver, CO. \\ June 4, 1997 \\ Ecker and Associates \\ San Francisco, CA \\ June 5, 1997 \\ Research Design: Interview Design Focus Groups \\ Number of Groups: $\quad$ Partners-2 \\ Non-Partners-2 \\ Respondents per group: $\quad 5-8$ \\ Length of group: $\quad 1 \frac{1 / 2}{2}$ hours \\ Interview Flow: Introduction \\ Brief Discussion of Current Situation \\ Discussion of Interest in New System \\ Discussion of Current Operating System \\ Reaction to Prototypes \\ Reaction to Proposed Payment Structure \\ Conclusion/Wrap-up
}

\section{Conclusions/Implications}

There are several conclusions/implications to discuss on the basis of the findings from this research: 
1. During the initial discussion held during these focus groups, the respondents identified several issues or concerns they have with ordering and maintaining USGS maps in their outlet. Among the issues mentioned were the following:

- $\quad$ Order turnaround time; while turnaround time for regular orders has improved, the respondents felt that they were not able to get maps to their customers as quickly as they would like to; faster turnaround time provided by a print-on-demand system may potentially solve this issue

- $\quad$ Minimum orders; minimum order quantities have forced some outlets to reduce the number of map titles they carry in stock; with the print-on-demand system, it may be possible to carry and offer a wider variety of titles

- $\quad$ Special orders; customers are not currently able to preview any map not in stock; with a print-on-demand system, they may have the ability to do so

2. The respondents identified several benefits and potential issues with this print-on-demand system. The major benefit was identified as the ability to customize a map to fit the consumer's needs. Other benefits included the following:

- Printing only the actual maps that were needed; carry less inventory

- Less time would be spent ordering and dealing with inventory

- This would offer an additional customer service/ business-building opportunity to these outlets

- Customers would most likely have the ability to preview the map they wanted prior to actually printing the map

The major issue with this print-on-demand system was based on the cost factors associated with this product idea. The respondents were concerned about the investment they would have to make in equipment for their computer system as well as the cost per map from this new print-on-demand system versus the current acquisition and distribution system.

Also of concern was who would provide the training that was needed, as well as what level of expertise was needed to operate the system. This issue could affect the turnaround time of printing the maps in the store.

There was a great deal of uncertainty among the respondents when discussing the various options available to them to procure this product. It is imperative that a clear estimate of the potential costs involved in this system be developed and reviewed with consumers.

3. There was little use of the Internet now for reviewing or printing maps. There were options mentioned that are becoming available, such as Wildflowers Productions. These options are being well received by consumers and offer a quality product. There were some respondents who did mention a concern that the Internet may become more of a 
competitor to them. The potential to find maps on the Internet and print them at home was a potential some respondents could envision. This points out the need to consider other competitors and what they are and can offer in terms of products to compete with the USGS maps.

4. Reaction to prototype maps was generally positive, with the prototype seen as being acceptable for recreational users. There were some who felt that the quality was not acceptable for use by professionals who rely on a clear, precise image. For these and other respondents, there were concerns over the clarity, as some lines and information were described as "fuzzy" and "less-crisp" and, therefore, less readable.

The other major issue with the prototype was that it was simply the same map as a printed map currently available. The lack of customization created some doubt over whether this system could be used to customize maps. Respondents need to be shown what customization was possible to better understand the capability of this system. Since this is the major benefit the respondents were looking for, future research to review the potential of this customization should be strongly considered.

5. Most respondents appeared interested in this print-on-demand system for producing USGS maps. However, without specific information about the potential cost per print and a better understanding of their ability to customize maps, their reactions are somewhat questionable. All of this needs to be better defined and reviewed with similar respondents to determine their actual level of interest. Without this, their actual interest and the depth of that interest is unclear. Followup qualitative research is recommended to help obtain further feedback on this print-on-demand system for USGS maps.

\section{Discussion of Current Situation}

At the beginning of each group, the respondents were asked to briefly describe the different types of maps they sold. A number of different map producer/providers were mentioned, including the USGS, Wildflowers Productions, Thomas Express Maps, and Travel Illustrated. When asked if there were some maps they sold more of than others, the respondents mentioned selling local area maps for hiking and (or) biking. These maps were often USGS maps and used to mark the trails to be hiked or the trails to ride.

When asked about the ordering process and the problems/issues they faced, the respondents consistently mentioned the following issues:

1. Order Turnaround Time

- Historically turnaround time was described as 6-8 weeks for orders from the USGS; however, in many cases that had been reduced to 2-3 weeks

- Some Business Partners in both Denver and San Francisco mentioned traveling to the 
local USGS office to pick up special order maps

- The ability to stock only those maps needed at a lower level would be a benefit to both the retailer and the end users

- Often more remote outlets were unable to make this trip and, as a result, felt this turnaround time was still an issue; as a result, special orders for them were difficult to fulfill from the USGS

- This turnaround time, while an improvement, often did not equal that of the other non-USGS suppliers; in fact, some respondents mentioned they could get overnight delivery of orders from Wildflowers Productions.

- The ability to reduce this time would be beneficial to both the retailer and the end user

2. Minimum Order Quantities

- The need to order a minimum of five maps per title was an issue for some respondents; although they were eligible for a discount, the discount was less than previously available

- As a result of this change in the minimum order quantities, several of the respondents mentioned they did not stock as many "titles" as they had before; this policy limits the number of maps they carry - resulting in the potential need for more special orders

\section{Inability to Preview Maps}

- The respondents mentioned that some consumers become frustrated because they cannot preview the maps they are ordering prior to getting the actual maps

- Many consumers like to look at maps; some are interested in looking at maps before ordering them; currently, there is no way this can be accomplished for most USGS maps

- The ability to preview a map would be a benefit to consumers would like to see and the map providers would like to offer

\section{Discussion of the Potential Benefits of a Print-on-Demand System}

1. After discussing the problems/issues they deal with in terms of ordering/stocking USGS maps, the respondents were asked about what potential benefit they could envision in a printon-demand map system. The benefits mentioned were heard on a fairly consistent basis across the groups. There were several respondents in the Denver non-Business Partner group that was fairly advanced map producers. These respondents typically had fairly sophisticated printing systems that were more specialized and more advanced than most of the other respondents recruited across this project.

2. Among the benefits these remaining respondents could envision were:

- The respondents hoped and assumed that this new system would provide the ability to customize maps to make them more user friendly; this was something Wildflowers 
Productions and Thomas Express Maps were currently offering

- The respondents also hoped that this system would allow their customers to preview the maps they wanted, prior to printing the actual map; they wanted the ability to "pull-up" the specific area the customer wanted in this map

- Another benefit this system would offer was the ability and flexibility to print only those maps that are needed; this would result in lower inventory costs as well as less effort involved in maintaining that inventory

- Printing only those maps that are needed meant less "wear and tear" on their inventory; the maps would only be printed when needed

- A computer/CD-Rom-based system may provide the opportunity to stock maps of other areas, offering a broader geographic area to their customers

- There were several respondents, both partners and non-partners, who hoped that this computer-based information would be more up-to-date, or possibly updated more often

- Another benefit was that there would be no order/reorder time

- Also mentioned was that with a print-on-demand system, there would be less down time spent marking/organizing maps in their store

- Another major benefit mentioned was this print-on-demand system would allow them to offer additional/special customer service; this had the potential to be a business-building opportunity

3. While the respondents did mention many different benefits, there was a feeling among many of the respondents that the ability to customize a map was the most important benefit. Otherwise, there was a sense that this print-on-demand system would be somewhat less appealing. In addition, there were several issues/concerns mentioned by these respondents about this print-on-demand system. The issues raised by these respondents were potentially major issues, and without information about these issues, the respondents were unable to fully discuss and evaluate this idea.

4. Among the issues raised were the following:

- One issue/question raised was what would the cost per map be with this system; what was their cost going to be for generating a print-on-demand map versus ordering a map from the USGS

- Another major issue was what the investment would be to get this system in operation at their facility; most respondents had a computer (mainly IBM) for their business; however, they typically had a black-and-white laser printer; they questioned the investment needed to upgrade their system

- Also mentioned as a concern was how were they going to be trained to operate this system; for many respondents there was the question of who would operate the system at their store; they assumed the system would have a certain degree of difficulty in its operation

- Related to this issue was how long it would take to print a map; there was concern that printing one map would take a long time - up to ahalf hour - and how productive could they be if this were the timeframe

- There was concern about the amount of space needed to store all of the data that will be needed to operate this system; how much computer storage space was needed, or how much room was needed to store the CD's for this system 
5. Several of the respondents in the non-Business Partners group in Denver were well beyond the need for this system. They were more advanced in terms of computer capabilities, and this system, as described, was seen as "elementary" and very basic.

6. The respondents were also asked about an alternative to the print-on-demand system. This alternative would be based on having a central location in a city where the needed maps would be printed. Reaction to this alternative was mixed at best. Their reactions to this alternative included the following:

- Having a central location to print the maps would mean less investment was needed in the hardware needed to print the maps

- Turnaround time would likely be improved; a map could be delivered by overnight delivery; this would likely be acceptable for a custom map

- There was concern that this would increase the cost of each map; they did not believe this would be a cost-effective option

- Another concern was the loss of immediacy; the ability to print-on-demand was a major benefit in this system

- Also of concern was the loss of ability to preview the desired map on the computer prior to printing

- Some also expressed concern whether this printing outlet would not end up being a competitor to the current partners and nonpartners

7. When asked about what turnaround time would be acceptable, there were some respondents who thought a print-on-demand system implied that the turnaround time should be immediate. Others felt that the ability to receive a customized map would be a big enough benefit that users would be willing to wait for a day or so to get it. There were a few respondents that described it as potentially being like a photo-processing system where some pictures were developed in an hour and some were done overnight. The faster the turnaround time, the more the customer would have to pay.

8. Other alternatives and options to this print-on-demand system were discussed. One of these was the use of the Internet to access/print maps. While some of these respondents did have access to the Internet, they did not use this access to look for maps to be used for their customers. Once again, the lack of the correct printer was an issue for a few respondents; however, the respondents did not have a strong interest in using the Internet now to print the maps needed. There were some respondents that did mention they were concerned about the Internet and what impact it would have on their map business in the future. Some envisioned their customers simply going to the Internet in the future to get the maps they needed.

9. Another alternative mentioned by several respondents was Wildflowers Productions. Their CD-ROM-based system was well received by those that had seen and used the system. Although currently available for limited areas, the interactive nature of the system and the ability to customize maps were very appealing to consumers who had used it, according to these respondents. While not all respondents were aware of this system, those who were very positive in their reactions and comments.

\section{Reactions to Prototype Maps}

1. The respondents were given a printed USGS map and a computer-generated print of the same map to review. After reviewing these maps for several minutes, many of the 
respondents found the overall quality of the map to be acceptable. Although not considering it equal in quality to the printed map, the respondents believed the computer-generated map to be acceptable for most recreational uses. Comments such as the following were heard:

"... generally, pretty good."

"... good for the recreational user."

“... it's generally pretty good quality ... the customer would find this acceptable."

"... the overall quality is good ... most won't know or see the difference."

"... the quality is acceptable but not great."

" ... for on-demand (printing), it's good quality."

2. Among the positive comments heard about the prototype maps were the following:

- $\quad$ For most respondents, the paper quality was seen as appealing; the paper was seen as heavier and likely more durable; several respondents also commented that the paper seemed waterproof and this, along with the perceived durability, would be better for using the map

- Again, for some respondents, the colors on this print-on-demand prototype were better, the colors were darker, making some of the items easier to read

- Some respondents assumed that they could customize the maps printed with this system; the ability to offer their customers options/choices made the quality of this prototype more acceptable; if the actual map could be customized to print only that the area needed, that made the map more appealing

3. This ability to customize was seen by many respondents as the main benefit of this print-ondemand system. If they could offer customized maps to their customers, it became something special, a unique customer service offering. Although customization was important, there was also the concern that this service may become available on the Internet in the future. This possibility caused them concern over the amount of their potential investment and whether that investment would be paid out.

4. The following were issues/concerns mentioned by the respondents after reviewing these maps:

- The cost of the system and of printing each map compared to what they currently did

- Most respondents found the overall map, especially the lines and elevation numbers, difficult to read; the line quality was described as "fuzzy" and "less crisp," making it difficult to read and, overall, less appealing

- Many respondents felt that they may not be able to customize the maps as they had intended; the fact that the map was simply a print-on-demand replica of an original print USGS map implied that the system was not capable of customization; as mentioned above, the need to customize is critical for this project to have a chance to succeed - Some respondents wondered about the paper quality; the heavier paper, while helpful in some situations, was seen as possibly adding weight to a backpack

5. While the overall quality of the map was acceptable, some respondents still felt that the lack of customization shown in the prototype implied that they could not customize with this system. As this development process continues, the ability to customize these print-ondemand maps needs to be illustrated to respondents and USGS map purchasers. 


\section{Discussion of Various Payment Structures}

1. At the end of each group, the respondents were asked for their reactions to three separate payment structures for this print-on-demand system. Overall, the respondents had a very difficult time discussing these options because of the lack of specific information about costs. Without these numbers and other information, these options were very difficult to evaluate.

2. The three options mentioned and the respondents' comments about each option are listed below:

\section{Free Software with Royalty Charge for Each Printed Map}

- This was described as the closest option to what they currently do; in this case, they would pay only for the actual maps they used

- This was a better starting point for this system because you paid only for what you used

- A major concern mentioned again was the investment they would have to make to print these maps; what enhancements did they need to make to their systems, as well as what investment would they have to make for the printers

- Another issue raised was how would this system operate and how would they keep track of the number of maps they sold

- Some respondents believed that they would be more likely to get free upgrades if they used this "pay as you go" system; if they turned in their old software, they felt they would most likely get new, updated information more quickly

\section{Lease Software with a Monthly Fee}

- The only benefit mentioned regarding this option was that it might be more cost effective as this business grew

- Again, the respondents felt that they would have to enhance or upgrade their systems to operate this print-on-demand system

- Given the lack of specific information available on this option, the respondents had a very difficult time discussing its merits

\section{Purchase Entire System}

- This was seen as a very risky option because of a lack of specific information and uncertainty over where and how this business would develop

- This was also seen as lacking flexibility because of being a dedicated system for printing only maps

- The respondents assumed this would be a fairly big investment; many respondents were from small retail outlets, and this option sounded very expensive to them

3. This discussion of various payment structures was difficult for the respondents because they lacked specific information about the costs. It appeared that the system would be more expensive per print and would necessitate added investment in their computer systems. These questions need to be answered before additional research begins. 


\section{Interest in Print-on-Demand System}

1. The respondents were asked to rate their interest in this new print-on-demand system and to state why they were or were not interested in the idea. In most cases, the respondents said that they were interested in the system but had several questions and concerns. The benefits they associated with this system included the following:

- It offered a new, unique way to provide additional customer service

- They hoped that this additional customer service would take the form of map customization; these respondents saw potential benefits in adding and deleting information, printing only the area needed, and offering a broader range of areas

- Turnaround time for orders would be much faster and inventory costs would be less

- The respondents also saw print on demand as a move to the future for them; it would help them be seen as more up-to-date in their product offerings

2. The respondents in all the groups raised similar issues. These issues included the following:

- What level of investment would be needed to get this system running in their stores; would it be worth the investment

- How difficult will this system be to operate; what training is available

- Although told that maps could be customized, respondents did not see any examples of such customization, as a result, capability was still an issue

- The demand for this type of map was unknown; also would maps such as this become available through the Internet, and would the map dealers lose their market

- For some respondents, this system was not that unique or advanced; with the availability of other options, such as Wildflowers Productions and Thomas Express Maps, these USGS maps may not be that unique

3. These issues need to be addressed before completing additional research. Without having more detailed financial information and seeing examples of customized maps, the respondents will be unable to provide clear reactions, and direction to help develop this new product 


\section{Technical Recommendations (USGS/BLM)}

\section{Background}

This section describes the recommendations for technical specifications for map-on-demand hardware and software in the USGS National Mapping Division (NMD) and the Geologic Division (GD). Technical specifications are also included for the Bureau of Land Management. The Water Resources Division of the USGS did not complete recommendations for technical requirements for this publication. These reports were compiled from CRADA members who have been involved with the CRADA from its inception (July 1996) and who have extensive expertise and background in these issues in relation to their current job functions.

\section{National Mapping Division Recommendations}

The main use for map-on-demand technology in the NMD will be, in descending order of importance, (1) printing maps of Open-File Reports (those never printed and those digitally produced and composed), (2) limited printing of out-of-print or historic maps, and (3) printing a very limited, but highly visible, number of maps to be used for emergencies.

A map-on-demand system that relies on a 600-dpi plotter appears to be the threshold of acceptable quality, and this resolution produces a degree of quality that is appropriate for a wide range of USGS maps. The first phase of the CRADA focused on a specific quadrangle, the Boulder quadrangle, rather than on a wider variety of NMD's topographic maps. The Boulder 1:24,000-scale quadrangle, though dating to 1960 , represented the transition to a coarser symbology on NMD's topographic products, and this trend to simplify NMD map symbology has continued. Integrating some of the geologic thematic maps showed the shortcomings of the phase 3 electrostatic printing system with regard to document size, image resolution, color resampling, and production efficiency. The development of the 600-dpi inkjet system, which was used to print the USGS 1:24,000-scale Evergreen quadrangle with no visible break in contour line symbology, was the breakthrough in acceptance.

Input data are presumed to be either Postscript or image (as TIFF) data, or to be derived from scanning paper documents as TIFF images. There are standards for such data: ESRI's ArcInfo supports some extensions to the Level 1 Postscript, but most packages (such as Adobe Illustrator) support Postscript Level 2 (which also supports most color models, including RGB, CMYK, and L*A*B---also know as "lab," an international color standard). For TIFF Revision 6, the palette-reduced color as 8-bit uncompressed or as RGB 24-bit uncompressed would be adequate for the complexities of most documents.

On the scanning workstation, the user interface and software need to be easy to use and provide functions that can do raw, 24-bit imaging, color remapping, and matching to either a standard or an adaptive, or "palette-reduced," 8-bit palette. 
$3 \mathrm{M}$ has always advocated standardizing color reclassification in $\mathrm{L}^{*} \mathrm{~A} * \mathrm{~B}$ space rather than relying on a specific vendor's RGB-to-CMYK translation table. The 3M CRADA did not complete any investigations of this under phase 3 , but we believe that this is an area worth pursuing.

On the printer workstation, the map picture (as a Photoshop or TIFF image) requires: elements of image cropping; image rotation (not just cardinals, but fine tuning); cleaning image dirt and scratches; some functions to allow image "repair" to remove stains and markings; the ability to queue and control plot management; and the ability to save the RIPed file for future plotting. ScotchPrint allowed us to "white point" the paper stock, regardless of a wide range of paper conditions, and to enhance the crispness of the line symbology. Photoshop has some of these functions, but they are applied one at a time and are highly interactive. Plotting options should include rotation and control over the number of copies; however, we're not sure about scale-tofit and paneling: the first would lose control of scale and the second would presume that we are processing documents over 36 inches in the short dimension.

We are not convinced that a customized map product is something that the NMD should pursue. We would advocate printing static, precomposed graphics, rather than generating and printing varying versions that are based on user or point-of-sale changes. A step in this direction would also make it very difficult to track what products are being supported, as each variation represents a different map or map composition.

Printing precomposed digital maps or reproducing maps from scans of the original does not require georectification of the image. This process may differ from any digital archive requirements of the NMD, but avoiding rectifcation would yield tremendous overhead savings. Our argument against the general rule of georeferencing this type of graphic data includes the following points: (1) the images of published graphics vary in projection and datum references, and standardizing these on a particular projection (UTM) and datum (NAD27) alters the graphic accuracy of the original document, (2) reprojecting and rubber sheeting takes a tremendous amount of time and creates high production overhead costs, and (3) many users would prefer some other type of coordinate system (such as their State plane), and would elect to reproject (thus, rubber sheet again) the image anyway. If map compilation information is in the margin of the image or graphic and some reference graticules are along the edge or within the image, the users should be able to do as they please.

At the EROS Data Center (EDC), the main graphic products are image-based maps, almost always done as one-of-a-kind products to accompany and promote digital data that are distributed on CD-ROM or the Web.

For image maps, high graphic quality is required because making an attractive graphic is the whole point of printing them. The latest map-on-demand system, with a 600-dpi plotter, produces a quality level sufficient for image maps and would work for printing limited numbers of maps. Input would be from Postscript data, not from scanning paper plots.

Right now, limited-run image maps are produced on inkjet plotters similar to the map-on-demand HP inkjet, using Adobe Photoshop and Illustrator, and the HP software drivers for the Macintosh. What must the $3 \mathrm{M}$ system do to create an improvement over current methods? Since the map-on-demand hardware uses the same plotter that everyone has now, the $3 \mathrm{M}$ software must add value to the system. The following software features would add value to the 
current image-mapping workflow:

- Color separation, gamut mapping, and color matching. The conversion of RGB-to-CMYK is the biggest problem in plotting image data. Even some very basic tools for improving image rendition would be a big step forward.

- Job control functions, including queuing and plot queue management

- Plot time options, such as paneling, scale-to-fit, rotation, and number of copies

The discussion above refers to the production of image maps in our standard work flow, where we have data compiled for predefined areas and are planning to design and produce one map. To look beyond that, a real map-on-demand system would enable user-defined areas and selection of overlays, somewhat like the Web pages that we use to show satellite data set availability, where you choose a geographic area and see an image of that area with roads and boundaries.

A map-on-demand system would let a customer choose an area of interest and the image and overlays to be shown, then the system would do the rest. The USGS is doing something similar with the National Atlas, using imagery only as a backdrop for vector data sets, but a real imagebased map-on-demand system would have imagery with many different dates so that a person could compare, for instance, an image from 10 years ago with one from today. Would such products appeal to the public? Is the USGS prepared to supply data for such products?

Map-on-demand has been a dream for some time. With the high-quality Postscript-based plotters available, the onus is on the USGS to create and maintain the up-to-date data sets that are required to produce maps. Even if we only created up-to-date paper maps, a scanner could capture something useful for map-on-demand, even if further cropping and paneling were required to produce a user-defined map. This is the point in development reached at the end of the CRADA. Getting its maps up to date is the basic problem that the USGS has to solve to make map-on-demand a possibility.

\section{Geologic Division Recommendations}

\section{Introduction and Background}

The key to success for the map-on-demand system would lie in the certainty that the map the author proofed and approved is the same map that the end user receives from the distributing map-on-demand system. For example, if the author designed four distinct shades of green on the map and the end user received a map with only three discernible shades of green, a failure has occurred - map information was lost.

To establish consistency of output from various sites, the author must be able to mirror the capabilities of the distributing map-on-demand system. Therefore, the system needs to be reasonably priced to allow for many systems at various sites. Also, standardization of variables needs to be established to ensure consistency. These variables include toner, paper, environmental conditions, electronic file format, RIP software, RIP dithering pattern, color management, and the output device and its settings.

The author must be assured that the electronic file that is sent will ultimately be used to produce 
a map that is a true representation of the map that was given final approval.

\section{Requirements for the MOD system}

\section{(1) A reasonably priced system}

The most highly variable cost in the system may be the software RIP package. Certainly, a $\$ 30,000$ UNIX-based package would be too costly, while a $\$ 3,000$ to $\$ 5,000$ PC-based package would increase the affordability of the system to multiple authors at various sites. We need this affordability to be able to mirror capabilities at the distributing site. This is critical to digital authors since the "proof is in the plotting"! Other hardware components should be value priced, which should be easily accomplished with the intense pricing competition in this area.

\section{(2) A robust, versatile RIP software with certain features}

The software must be robust enough to successfully interpret all our Postscript files (even the large ones, $80+\mathrm{Mb}$ ) created in various software packages, such as Arc/Info, ArcView, Adobe Illustrator, and Quark Express. Furthermore, these files will be coming from various platforms, such as UNIX, PC, and MAC, and they may very well consist of both vector and raster data. If there is a failure in reading a file, one would expect a meaningful error message.

The software must be versatile enough to function well not only in the single-user, tightly controlled mode at the distribution map-on-demand site but also in the multiuser, remote access mode at the author sites. For the remote access user, sending a file to the map-on-demand system should consist of nothing more than sending the file across the network (File Transfer Protocol), which can easily be accomplished with a script file at the end of the author's program for creating the map. This is very convenient and allows for large, time-consuming plots to be sent in the evening. The software daemon should be able to start processing the file with no further instruction from the user. Please note that a fancy menu interface for sending a file can be more of a bother than it is worth, and it more likely hinders the user by requiring user interaction. It is also important that the author be able to remotely monitor the queue and that the queue show the following information for each file: file name, file size, owner of file, and status of processing. Also, for paper-saving reasons, the software should allow for easy nesting and rotating of jobs.

\section{3) High-resolution, large-format output}

The output device must have a resolution of 600 dpi or higher, and the capability of producing a map that is 60 inches by 6 feet. The system may consist of multiple plotters, some of which would be smaller format and produce the majority of smaller size maps. The final product must be UV-fade resistant and waterproof, available in matte, semi gloss, and high-gloss finishes. The plotter must be cable of being operated in "stand-alone mode" (cutting each map off the roll after completion) and "take-up mode" (rolling all completed maps onto an empty paper core).

\section{4) Color management}

The color management system must provide a means for creating color consistency of different plots from the same electronic file. If it were needed, our authors could be instructed to include 
a color bar of RGB and CMYK within their files to allow for color calibration of the output.

5) Standardization of variables

Establishment and adherence to standardization of variables needs to be done to ensure consistent, high-quality output. These variables include toner, paper, environmental conditions, electronic file format, RIP software, RIP dithering pattern, color management, and the output device and its settings.

\section{IMPORTANT}

Please note that the needs of the digital author differ in two main ways from the needs of those providing restoration of paper maps. First of all is affordability for multiple systems, and second is the ability to accurately interpret our Postscript files, both old and new formats.

\section{Bureau of Land Management Projected BLM requirements and specifications for map -on-demand}

[Note: This is a long-range, visionary view. At this time, the database and technology do not fully support this scenario.]

\section{$\underline{100 \mathrm{~K} \text { Map Series Product }}$}

This product will attempt to meet the needs of the public for acquiring information regarding an area of interest from a map that includes reference and current BLM Land Status information. Print-on-demand products for 1:100,000-scale map series will be based on USGS 1:100,000scale digital line graph (DLG) data available in Spatial Data Transfer Standard Review (SDTS) format on the Internet. The data from each 1:100,000-scale map-sheet will be used to create seamless layers of each theme. All data layers, including BLM Land Status, will be projected to Geographic, GRS1980, NAD83. These data layers will be imported to ESRI's (arc coverage/shape file) format for use by a customized, user-friendly, kiosk, graphical user interface environment, that is based on either ARCVIEW 3.0 or ARC Explorer. The proposed interaction would loosely reflect the following scenario:

The user would be given an option to define the 1:100,000-scale map sheet of interest by name or by graphic query (much like the Geo-Data home page interface for DLG data). The user would arrive at a screen that indicated the outline of the map, and then be told what background or base themes were available to choose from for that sheet. The user would be told to indicate or turn-on the themes of interest. The themes would then be displayed (using standard symbology) on the screen, showing the user what the print will look like. The user would then be told that the map can be printed, with a fee; the user would print the map, pay for it, and take it. 


\section{$\underline{\text { Automated Land and Mineral Record System (ALMRS) Data Product }}$}

This product will allow the public to acquire information from the Automated Land and Mineral Record System (ALMRS) regarding an area of interest, in the form of a map that includes reference and current BLM ALMRS information. Map-on-demand products will include one of the following base data themes and an overlay of ALMRS information. The options for base data includes USGS 1:24,000-scale DLG, USGS 1:24,000-scale digital raster graphics (DRG), digital orthophoto quadrangle images, accurate to 1:24,000-scale National Map Accuracy Standards (NMAS). (These base data themes may need to be prioritized by desirability for acquisition.) All base data layers will be projected to Geographic, GRS1980, NAD83 to build seamless data layers of each. The vector data will be stored as ESRI (arc coverages/shape files) and the raster data will be stored as ERDAS L.IMG/TIFF/GEOTIFF files. These data layers will be accessed by the user through a customized, user-friendly, kiosk, GUI environment that is based on either ARCVIEW 3.0 or ARC Explorer. The proposed interaction would loosely reflect the following scenario:

The user would be given an option to define the area of interest as a Township or a Section. The user would subsequently be given the option of identifying the area of interest by name (that is, legal description) or by graphic query. The user would arrive at a screen that indicated the outline of the map and then be told what background or base themes were available to choose from for that sheet. The user would be told to indicate or turn on the themes of interest. The themes would then be displayed (using standard symbology) on the screen, showing the user what the print will look like. The user would be told that the map could be printed, with a fee; then the user would print the map, pay for it, and take it.

\section{System Requirements and Specifications}

- $\quad$ Tangent Scanner 500 dpi and associated host system, connected to a network, connecting it to a central data store/processing center National Applied Resource Science Center (NARSC).

- Central processing center includes GIS and image-processing software to create the seamless data layers, matching colors, contrast, and seamless edges. Listed below are Unix or NT workstations (for example, SUN SparcStations or UltraSparcs), sample specifications:

100-Mips Unix

200-MHZ Pentium II NT, Windows NT

128-Mb RAM

10-Gb disk space

24-bit display capability

Image processing software (ERDAS IMAGINE)

GIS software (for example, ARC/INFO)

- $\mathrm{CD}$ writer if the data themes are to be distributed by means of CD media 
- Public Room:

Windows NT

200-MHz Pentium II

64-or 128-Mb RAM

Disk space adequate for data storage

$\mathrm{CD}$ drives to accommodate $\mathrm{CD}$ data access

Enhanced video with minimum 4-Mb video RAM

ARCVIEW 3.0 or ARC Explorer

Printer drivers for hardcopy devices

- Public Room printers:

HP2500 for larger format prints

HPXXX (DeskJet series that is comparable to the HP2500) for 8.5"x 11" prints

\section{Issues for BLM:}

1. How well do ARCVIEW 3.0 and ARC Explorer print the raster products that are mentioned?

2. Find out if any HP DeskJet produces similar results to those of the HP2500.

3 . Test configurations to ensure capacity and horsepower.

4. Customize ARCVIEW or ARC Explorer for user interface.

5. Determine data distribution method: network, CD-ROM, local server.

6. Devise a way to match quality of printed product in resolution and color.

7. Must be comparable in cost to printed map.

8. Do research on storage capabilities.

9. Investigate length of time needed to plot versus user requirements.

10. Incorporate use of additional data, such as State, county, and wilderness boundaries. 


\section{Bureau of Land Management Final Report}

\section{Participation in the USGS-3M \\ Cooperative Research and Development Agreement (CRADA) for Print-On-Demand Mapping Capabilities}

Index

Introduction

Background

Results

Recommendations

Conclusion

Bureau of Land Management Report

Participation in the USGS-3M

Cooperative Research and Development Agreement (CRADA) for Print-On-Demand Mapping Capabilities 


\section{Introduction}

New print-on-demand technologies make possible the immediate availability of hardcopy paper maps for distribution. The National Imagery and Mapping Agency (NIMA, formerly the Defense Mapping Agency) has established print-on-demand facilities, called "Remote Replication Systems" (RRS), to provide paper maps and charts from hardcopy and digital sources.

In July 1996, 3M and the U.S. Geological Survey (USGS) entered into a Cooperative Research and Development Agreement (CRADA) to investigate maps-on-demand technology. This cooperative agreement potentially helps the USGS to develop print-on-demand alternatives to the current lithographic maps and helps $3 \mathrm{M}$ develop a series of commercial instant print-on-demand map printing systems. Both a high-productivity map production system, as well as a low-cost, field deployable point-of-sale map printing system for retail sales and other commercial applications, were to be addressed. This agreement was directed toward helping the USGS meet its goal of moving from a map distributor to map information provider and allowing $3 \mathrm{M}$, in cooperation with the USGS, to develop a series of commercial map printing systems. No funding is allowed to be exchanged in a CRADA; information and resources are for research purposes only.

The USGS, considered to be a Federal laboratory, has the authority through the Solicitor's Office to participate in a CRADA; the Bureau of Land Management (BLM) does not have this authority. The BLM requested participation through the USGS and committed participation from the National Applied Resource Science Center (NARSC) and the National Information Resource Management Center (NIRMC) in October 1996. BLM's participation in the 3M/USGS CRADA helps with investigations and recommendations concerning specifications for providing the best map-on-demand digital files, archiving digital files to databases, and configuring the appropriate hardware and software. Evaluation of and transition to these technologies and subsequent adoption and implementation of these technologies are critical to BLM's automation activities and are cited in the Automated Land and Mineral Record System (ALMRS) contract.

\section{Background}

The CRADA addressed the following topics:

- $\quad$ digital storage and archive systems, software, and media development

- $\quad$ user software interface development

- $\quad$ scanning resolution

- map accuracy, geometric correction

- $\quad$ color mapping and calibration

- data access, sources, and databases

Two teams were formed to work on color and accuracy/stability. These teams investigated color enhancement, scale stability, geometric accuracy, and reproduction of map symbols, tints, and 
patterns. The BLM participated in both investigations. The USGS also formed teams to study printing system stability to evaluate press run consistency and customer assessment of inkjet and electrostatic output. Although the BLM did not participate in these teams, the USGS results have been included in this report. Testing of data storage and media, including the file sizes and compression techniques, was also conducted by $3 \mathrm{M}$.

3M Print-on-Demand System:

Sun UltraSPARC2 workstation with $2 \mathrm{~Gb}$ hard drive ANAtech Eagle 3640C sheet feed scanner (36 inch, 400 dpi) [Replaced with Eagle 4080C] HP755C Design Jet inkjet plotter

3M Scotchprint 9612 electrostatic plotter

Young Minds CD writer

3M Scotchprint software for electrostatic and inkjet systems

3M personnel provided training for USGS and BLM participants on the operation of the ANAtech scanner, Sun UltraSparc workstation, CD-R system, 3M 9512 electrostatic printer, and 3M's proprietary Scotchprint map printing software.

\section{Process Summary:}

Scan the 7.5-minute quadranglerangle hardcopy map as a 24-bit red, green, and blue (RGB) TIFF at 400-dpi (file size approximately $240 \mathrm{Mb}$ ); bring the file into Photoshop, where the excess is cropped and the file size reduced to $300 \mathrm{dpi}$ (file size becomes about $135 \mathrm{Mb}$ ): identify black-andwhite areas in the scan using the Scotchprint software (usually the type near the scale bar is used); Raster Image Process (RIP) the file and send to a plotter. The color look-up tables that were created are geared for specific paper/scanner/plotter combinations. The Scotchprint software uses the look-up tables to create the values to convert from the red, green, blue (RGB) of the scan to cyan, magenta, yellow, and black (CMYK) for printing. Look-up tables are needed and developed for each output device. Once the look-up tables are identified, other modifications, such as adjusting the level of a particular color or enhancing the edges, can be done on the basis of output.

\section{Results}

The initial setup and training went well. From the training and initial results, it was clear that in a production environment there would have to be some operator interaction to get the best product from scanned maps. A test limiting the color palette to 256 colors in Photoshop was performed with acceptable results. This will give a 3-to-1 size reduction on scanned maps; that is, $240 \mathrm{Mb}$ to $80 \mathrm{Mb}$. The USGS also tested the scanned bar code used on their maps, and they were able to read the bar code on the map-on-demand product with a bar code scanner.

The BLM's initial impressions were that the software was a beta version, in that it was not a finished product, not as automated as was hoped, and had only fair performance. Software from $3 \mathrm{M}$ is unique in that it closes the loop to an on-the-fly system by quickly matching colors, which 
are tied to look-up tables. The quality of the printed colors is close to the original colors. The main problem $3 \mathrm{M}$ is trying to solve is consistent color matching. The BLM confirmed the need for technical operator involvement.

After the initial set-up and training were completed, several problems occurred that caused minor delays in testing the system. Examples of system problems include the following:

1. ANAtech scanner had a color misalignment in the cross-feed axis.

2. ANAtech scanner white point varies considerably across the scanned map.

3. An Algorithm problem created a blur when using higher levels of edge enhancement.

4. ANAtech scanner screws caught the paper being scanned and caused a cross-scan density change at the beginning of the scan.

5. Crop and resize of scanned data need to be faster, which relates to the software application.

6. A Rotation problem occurred with a scanned BLM map.

7. The ANAtech scanner had a scan accuracy of 0.326 percent in the feed direction using a film target.

Most system problems revolved around the ANAtech scanner, which exhibited technical, mechanical, and image quality problems that severely affected the system testing. The initial quality exhibited at the $3 \mathrm{M}$ facility in St. Paul could not be reproduced with this scanner.

Scanner problems consist of the following:

1. Horizontal gray shifting, where the paper stock in the first half of the document appeared to have a dark gray value and the second half of the document scanned appears to have the normal amounts of background noise.

2. Vertical gray shifting, where each of the three cameras on the $3640 \mathrm{C}$ appear to introduce different levels of gray into the background paper stock.

3. Image splitting, where there appears to be a warped and distorted splicing of the image between the middle and right camera.

4. Color blobs, as a result of the slight offset of the RGB color detection in the pixel (documented as 0.003 in). There is a color shifting to the blue on flat tinted areas of the original.

5. A lockup where the scanner appears to lose communication with the workstation (running ANAtech's ASCAN-C software). The software locks up and does not complete the scan, but the scanner continues to pass the document through the imaging area.

In order to solve these recurring problems, 3M worked with the scanner as well as with the ANAtech company to resolve scanner performance issues. The USGS and 3M explored viable options in other scanner vendors, such as Tangent and Contex/IDEAL. The scanner was eventually replaced with an ANAtech 4080C scanner. The CRADA was extended because of the difficulty and frustration in using the original scanner and the additional time needed to set up the look-up table color charts to work with the replacement scanner. The ANAtech 4080C provided 
better image quality, up to $800 \mathrm{dpi}$, which required developing a resample procedure to keep the file sizes down so that they would work with the remaining system components.

\section{Accuracy Test Results:}

Several methods and tests were evaluated to find the best method for determining the accuracy of the system components. Since paper is a nonstable material, it was necessary to control the input with a known, accurate, stable base grid. The BLM provided a test grid digital file that was generated using Microstation, with a mathematical positional accuracy of one-ten-thousanths of

an inch. This digital file was then plotted on the AGFA Imagesetter at 2,000 dpi on clear 0.007-in film. It should be noted that use of an additional step, plotting the original data file using the AGFA Imagesetter, caused a slight degradation in the accuracy on the actual grid. This grid was then used for testing the entire system.

Evaluation of the accuracy test results led to several broad conclusions. The limited testing revealed that the absolute accuracy (the error from the known grid) was higher for the inkjet. The electrostatic plotter was very consistent with the error for each test point proportional to the distance from the center. The inkjet was not as consistent from plot to plot as the electrostatic, and the error was generally random from plot to plot. The ANAtech scanner lists a maximum error of no more than 0.02 in. Results from testing indicate the total system error is generally less than this value.

\section{Color Observations:}

The 3M software for print-on-demand had several features that vastly improved color matching compared to raw scanned and uncorrected data. The system self-adjusts by comparing the color that the scanner records and correcting that value by using a color look-up table specific to the scanner and the plotter. By correcting in this manner, the plotter and the scanner are using the same reference table to correct the final plot. This closed-loop color system will, therefore, compensate for a plotter or scanner that is not adjusted exactly for a specific color.

Generally, color was observed for readability rather than being precisely matched to the original printed map through spectral analysis. The use of screens in the printed map makes it almost impossible to have an exact color replication because of the depiction of dot patterns. Overall, the color correction was very good, except for the brown colors on the map. This is understandable because the brown colors are offset printed as spot colors from a separate plate over other colors. On the electrostatic plotter, Scotchprint 9612, black consistently smeared. Samples from the inkjet were tested for fading by displaying half of a plotted map in a southfacing window for a month. The other half of the map was used as a control to judge the amount of fading. The inkjet seemed to be fade resistant, as the colors had no noticeable difference from the original plot. A sample of the inkjet waterproof paper was also tested. Twenty-four hours after the plot was finished, the sample was soaked in water for 2 days, and no bleeding or smearing of inks occurred. 


\section{Environmental and Maintenance Observations:}

In general, the system does not require special environmental considerations. Workstation, scanner, and CD writer all operate in an office environment. The HP line of Design Jet plotters operates in the typical office environment, because the chemistry of the ink requires no additional ventilation. However, the 3M 9612 electrostatic plotter requires a controlled environment of temperature and humidity. For the CRADA, this required the use of a humidifier to reach environmental specifications. The fumes of the electrostatic plotter are toxic and thus require that exhaust be vented outdoors. For the CRADA, a special fan and duct system was installed to vent the exhaust. Maintenance for the Design Jet series of plotters is very minimal. The only maintenance required during the CRADA was the replacement of ink cartridges. The 9612 is designed as a high-output device and is not intended to produce a few plots on an irregular basis. If the plotter is used and will not be used again for several days, it is necessary to clean the heads on the machine. Even if the plotter is used regularly, cleaning is still necessary at regular intervals. The cleaning solution and other chemicals used by the electrostatic plotter require special strorage in a fire-safe cabinet.

\section{USGS Survey:}

The USGS conducted a general survey on the map-on-demand system products. The survey was conducted at the International Map Trades Association (IMTA) Conference held in Denver in September 1996. The purpose of the survey was to discover both the interest in map-on-demand products of customers who are map buyers (general public) and the impacts of map-on-demand technology on customers who are map dealers or in map-related businesses (private industry). Participants at the IMTA Conference were asked to compare a standard 1:24,000-scale topographic map with an experimental map of the same area produced by inkjet technology and then complete a short questionnaire. The resulting report, Map on Demand Customer Survey Report, provides statistical information (see the Customer Service section of this report). The following data are noteworthy:

Inkjet:

- 98 percent thought that the experimental map was a good quality product.

- 94 percent viewed the experimental edition as an acceptable substitute if the standard USGS map were not immediately available.

Electrostatic:

- 69 percent thought that the experimental map was a good quality product.

- 82 percent thought that the experimental map would be an acceptable substitute if the standard USGS map were not immediately available.

The USGS and 3M conducted secondary market research through focus groups. The focus groups were conducted with the following objectives: (1) to obtain reaction to print-on-demand prototype maps, (2) to obtain reaction from USGS Business Partners and Non-Partners to a new method of providing maps to their customers, and, (3) to determine potential benefits from this 
new system, as well as the potential issues that must be overcome with print-on-demand prototype maps. Results of this research can be found in the 3M/USGS Print-On-Demand Maps Exploratory Focus Groups - Final Report (see the Customer Service section of this report).

The USGS and 3M also prepared a paper for presentation at the International Cartographic Association (ICA) Conference in Sweden, June 1997, titled Maps-On-Demand.

The 3M company equipped a booth at the IMTA Conference in Washington, D.C., September 1997, which included software improvements resulting from the CRADA and an HP 750C Design Jet inkjet plotter. The software interface contained an index map of the United States with hot links to available coverage by State.

\section{BLM Specific Testing:}

Testing of the 3M print-on-demand software and hardware primarily involved 7.5-minute USGS topographic maps, and the results were informative for BLM. In an effort to evaluate the system specifically for BLM, it was necessary to test the system on a BLM mapping product. For this testing, the Phoenix North, Arizona, 1:100,000-scale map was selected. A flat copy of the map was scanned at 400 dpi using 24-bit color. This file was clipped in Photoshop and resampled to 300 dpi for the inkjet. The first attempt used standard settings for statistic and color curves. These settings were plotted and the results evaluated for color, clearness, and so on. The color curve was adjusted to push the black, which was already at high intensities. A second test plot was created and results were optimal. Past testing has shown that further color curve adjustment may improve one or more colors, but usually degrades another. Twenty copies were produced on the inkjet and electrostatic using existing device-specific color tables. Quality of the test plots was primarily limited by the 300-dpi resolution on the inkjet and the 400-dpi resolution on the electrostatic. Most of the image quality degradation was due to the low resolution of the output devices. Additional testing of this scan produced very little overall improvement in image quality. Color curve adjustments improved some colors and text and reduced the quality of others.

Toward the end of the CRADA, a 600-dpi HP DesignJet 2500CP plotter became available at 3M for demonstration purposes. To use the higher dpi of the HP2500, several USGS 7.5-minute topographic maps were scanned at 600 dpi and plotted using the HP2500 plotter. The quality improvement was exceptional. It should be highlighted that a 1:100,000-scale map scanned at 600 dpi using 24-bit color resulted in an image file of over 1.2 Gb. Standard UNIX compression resulted in an $800+\mathrm{Mb}$ file. The plotting time at 600 dpi on the HP2500 is substantially higher because of the higher resolution; it took approximately 30-40 minutes to plot the BLM Phoenix North quadrangle.

\section{Technology Update:}

The Scotchprint 9612 electrostatic printer, which was evaluated under the CRADA, is no longer 3M's high-volume printing solution, but rather an intermediate solution. The 3M company has developed the SP 2000 single-pass electrostatic printer for commercial use, and the output rate is approximately six to eight times the rate of the M 9612, or 350-400 maps per hour versus 60 maps per hour on the M 9612. 
The $3 \mathrm{M}$ company is also marketing a 52-inch inkjet plotter, which would refine the capability to produce some larger format products but would not increase capability over the HP750C rate of six to eight maps per hour.

The HP DesignJet 2500CP Plotter is a color thermal inkjet, much like the existing HP750C plotters. The main difference between these two plotters is the maximum resolution. The HP2500 has a maximum resolution of 600 dpi compared to the maximum 300 dpi for the HP750C. The HP2500 will accept HP-RTL, HP-GL/2, and Adobe Postscript level 3 languages.

As new components are added, they are compatible with the older proposed system components.

\section{Cost:}

Although no money is allowed to be exchanged in a CRADA, to get an idea of what the materials would cost for map production, the following approximate costs were derived:

1. For a USGS 1:24,000-scale topographic quadrangle, inkjet output on 3M's waterproof paper (V6060) approximate cost referenced is \$5; for output on 3M's Scotchprint 9612 electrostatic printer and water-resistant electrostatic paper approximate cost is $\$ 4$. The 7.5-minute USGS quadrangle is approximately half the size of a BLM 1:100,000-scale map.

2. For regular paper (non-water-resistant stock), to reproduce a quadrangle on an inkjet using standard HP special paper stock, approximate cost is \$2.50; for electrostatic output on standard electrostatic paper, approximate cost is $\$ 1$.

This system is not a replacement for high-volume maps and offset press, which cost between $\$ 0.25$ to $\$ 0.45$ per sheet, depending on the size of the press run. The system was evaluated for an immediate demand for out-of-stock maps filled in hours rather than weeks for standard reprints. Value to BLM was also seen in low-traffic maps where the map content is relatively static. The eastern half of Colorado is a good example.

Current retail price for the HP2500CP is $\$ 11,995$. A second model, HP2000CP, which does not include RIP software is available for $\$ 9,995$.

\section{Recommendations:}

Possible use of one system to service all of BLM would most likely be located at the National Applied Resource Science Center. Since 3M's role is primarily system integrator, BLM should incorporate existing components and buy what is lacking. Use of this system would target less dynamic maps and low-demand maps.

Continue to monitor the technology for use and access of databases versus scanned files. Because of continual rapid advancements in technology, recommend assessments at 8-14 month intervals, or as events make it appropriate. Hardcopy images will be needed in BLM Information Access Centers in conjunction with additional releases of ALMRS.

Consider data compression algorithms to assist in providing scanned data across Internet access. 


\section{Conclusion:}

BLM's involvement with the CRADA was for experience, learning, and recommendations on possible BLM applications using this technology. BLM also provided 3M and the USGS with input during the course of system testing, the closeout meeting, and preparing the final recommendations in this report. From BLM's position, the print-on-demand system needed to produce a high-quality printed product with the capability to overlay ARC/INFO vector data. The strength 3M map-on-demand system is in using preprocessed files as a replacement to map storage. Investigation of this technology has emphasized that this system is not a digital mapping system where one has flexibility in content and corrections to make custom maps. This system duplicates the static nature of printed maps in a digital form, but value was seen in low-traffic maps where the map content is less dynamic. BLM, with its emphasis on geographic information systems and the Automated Land and Mineral Record System (ALMRS), is more interested in using databases for producing customized products identified by users. When BLM moves to a digital mapping system, such as ALMRS or the1:100,000-scale Program, the database would present a print-on-demand capability. With the growth of Internet access, geospatial data are more readily available and incorporated with other data for support information, reports, and overall business functions. Accessing a database for map production is more appropriate with the direction of the Internet and the future. Monitoring further development of plotting technology is important, as effective methods to produce a hardcopy will be needed once databases are accessible and provide a viable option to map production. 


\section{U.S. Geological Survey Technology Transfer Information Partnerships}

\section{Print-on-Demand Technology}

The U.S. Geological Survey (USGS) seeks partnerships with innovative companies who possess the technical expertise and resources to facilitate the USGS's transition to print-on-demand technologies. The USGS requires the hardware and software and the technical expertise to integrate print-on-demand capabilities in solving three problems with its current printing process:

Map Reprinting of Out-Of-Stock Maps. In the current lithographic process, the time required to replenish out-of-stock maps ranges from 90 to 180 days. Many USGS maps sell only a few copies per year. Large-format (approximately 22.5" x 27") print-on-demand technologies are needed to provide high-quality maps on demand. Image durability, cost per map, format size, and speed are important considerations.

Printing Books, Pamphlets, Open-File Reports, and Other Agency Publications. The USGS produces numerous documents that have a relatively limited but mandated audience. Currently, the USGS has a large stock of books and reports in storage. A process is needed to print on demand small-format documents that typically combine text, images, and charts, in color and in black and white.

Archiving, Cataloguing, and Tracking All Survey Products. The USGS currently does not possess a centralized data base of its inventory of both paper and digital products. A production information system is needed to archive, catalogue, and track information about agency products and to make this information easily accessible to both USGS personnel and its customers. The product information system should be able to incorporate information from existing databases and allow access from remote logins through the Internet.

The USGS would like to enter into a relationship with any business that can contribute in any or all of the above three areas. Partnerships with the USGS will follow the guidelines set forth under the Technology Transfer Act of 1986 for establishing cooperative research and development agreements (CRADA). All proposals and communications can be directed to the points of contact noted below. The USGS looks forward to hearing from you!

John Evans

U.S. Geological Survey

Data and Information Delivery

521 National Center

Reston, Virginia 20192

Phone: 703-648-6285

E-mail: jevans1@usgs.gov 
Wayne Vickers

Data and Information Delivery

519 National Center

Reston, Virginia 20192

Phone: 703-648-4671

E-mail: wvickers@usgs.gov

U.S. Geological Survey

Technology Transfer Office

104 National Center

Reston, Virginia 20192

Phone: 703-648-4450

fax: 703-648-5470

E-mail: tto@www.usgs.gov

For more information about other cooperative opportunities with the USGS in this or other areas of technology, please contact the USGS Technology Transfer Office, listed above.

URL: http://www.usgs.gov/tech-transfer/factsheets/5.html

Comments and feedback: tto@www.usgs.gov

Last modification: Friday, 23-May-97 11:29:57 EDT 


\section{PRINT-ON-DEMAND PRESS RELEASE}

Department of the Interior

U.S. Geological Survey

119 National Center

Reston, VA 20192

Public Affairs Office

703-648-4460

\section{For Release: UPON RECEIPT (Mailed Wed., Aug. 14, 1996)}

\section{PRINT-ON-DEMAND MAPS COMING FROM 3M AND USGS}

Print-on-demand maps are coming soon, thanks to a cooperative agreement between the U.S. Geological Survey and 3M of St. Paul, Minn.

The two organizations have signed a cooperative agreement for the USGS to develop on-demand alternatives to hardcopy maps and for $3 \mathrm{M}$ to develop a series of commercial instant map-printing systems.

The new print-on-demand capability will provide an alternative to the traditional USGS printed map products. For example, a customer will be able to print a specific topographic map in a matter of minutes.

A long-term benefit for the USGS is to maintain a map inventory designed to meet the demand for specific products while improving customer service.

"3M engineers have a long history of creating innovative graphic products,"

said Richard Witmer, acting Chief of the USGS National Mapping Division.

"We're pleased that they will be working with USGS cartographers on the technology needed to develop on-demand electronic printing systems." "We think that this partnership will improve our responsiveness to our customers by creating systems that will give immediate access to all USGS map products. "And we encourage proposals from other private sector 
organizations for cooperative work in support of the USGS mission."

The partnership will develop a high-volume map printing system for the USGS to use in its production facilities and a low-cost, point-of-sale map printing system for retail sales and other commercial applications. Cooperative agreements - called Cooperative Research and Development Agreements - or CRADA's - are being used increasingly by the USGS and private organizations.

As the nation's largest civilian mapping agency, the USGS has more than 74,000 map titles in stock and distributes more than 6 million maps annually to people around the world.

\section{$*$ * USGS ***}




\title{
FACT SHEET
}

\section{Technology Transfer Opportunities: On-Demand Printing in Support of National Geospatial Data}

\author{
Introduction \\ The U.S. Geological Survey (USGS) and the 3M company of St. Paul, Minn., have entered into a \\ cooperative research and development agreement (CRADA) to investigate maps-on-demand \\ technology to support the production of USGS mapping products. The CRADA will potentially \\ help the USGS develop on-demand alternatives to lithographic maps and help $3 \mathrm{M}$ develop a series \\ of commercial instant map printing systems.
}

\section{Joint Research and Development Program}

The CRADA was begun in July 1996, and a joint effort of 16 months is anticipated for the map-on-demand segment. The USGS and 3M may consider future cooperative activities that could extend the CRADA time line. The CRADA statement of work describes a six-phase program that will investigate both ink jet and electrostatic printing technologies. The map-on-demand CRADA deals with the following topics:

- digital storage and archive systems, software, and media development

- evaluation of user requirements

- customer and user software interface development

- scanning resolution

- map accuracy, geometric correction

- color mapping and calibration

- data access, sources, and data bases

- investigation of geographic information systems (GIS) software

The USGS will provide expertise in map products, color replication, and the use and application of digital data and GIS's.

3M will provide most of the hardware and software used for investigation, both proprietary and commercial off-the-shelf products, and expertise in map product and printing software.

Optimization of ink jet and electrostatic printing systems for replicating USGS map products will be the primary goal of the CRADA, with optimal replication of the 1:24,000-scale topographic map as the primary focus. Thematic map products from the USGS, as well as map products from other cooperating agencies, will also be investigated. Customer assessment activities will be used to gather responses to the prototype map-on-demand product. The USGS and 3M also plan to participate in map trade shows and technical mapping conferences to showcase their progress and solicit responses during the CRADA. 
Investigation of electrostatic printing systems will allow the USGS to explore the feasibility of high-productivity map-printing systems, and investigations of ink jet systems will focus on lowvolume requirements for use in retail environments.

\section{Benefits of CRADA}

A long-term potential benefit for the USGS is to maintain a map inventory designed to meet the demand for specific products while improving customer service. The partnership could ultimately improve USGS responsiveness to our customers by creating systems that will give immediate access to all USGS map products.

3M hopes to commercialize the map-printing systems developed under this CRADA and provide the inks, paper, and other consumables that these systems will use. Of great interest to $3 \mathrm{M}$ is the low-cost desktop point-of-sale system that is to be developed under phase 4 of the CRADA. The company believes there is a worldwide market for this kind of technology.

\section{Future Cooperative Activities}

The following topics may be jointly investigated by the USGS and $3 \mathrm{M}$ after the 16-month CRADA is completed:

- advanced imaging systems development

- print-on-demand for textual data and products

- development of advanced map-on-demand capabilities using Internet interfaces and remote and (or) distributed data bases

- direct digital to plate technology

Additionally, there may be opportunities for other companies to establish partnerships with 3M and (or) with the USGS to explore custom products and services. Integration of GIS capabilities and customization according to user-defined requirements would be the basis for joint investigation.

\section{Information}

For more information on this CRADA with $3 \mathrm{M}$, please contact:

John R. Evans

U.S. Geological Survey

508 National Center

Reston, Virginia 20192

Phone: 703-648-6285

Fax: 703-648-5939

E-mail: jevans1@usgs.gov

or, 
R. Kent Stewart

$3 \mathrm{M}$

1101 Fifteenth St., NW.

Washington, DC 20005

Phone: 202-331-6981

Fax: 202-331-2805

E-mail: rkstewart@mmm.com

For further information on CRADA opportunities with the USGS National Mapping Division, please contact:

Ernie Brunson

U.S. Geological Survey

519 National Center

Reston, Virginia 20192

Phone: 703-648-4643

Fax: 703-648-5542

E-mail: ebrunson@usgs.gov

For information on other USGS products and services call 1-800-USA-MAPS, e-mail esicmail@usgs.gov, or fax 703-648-5548.

Receive information from the EARTHFAX fax-on-demand system, which is available 24 hours a day at 703-648-4888.

The address for the USGS home page is <URL: http://www.usgs.gov/>

July 1,1996 
Statement of Work for

On-Demand Map Printing in Support of the National Geospatial Data 


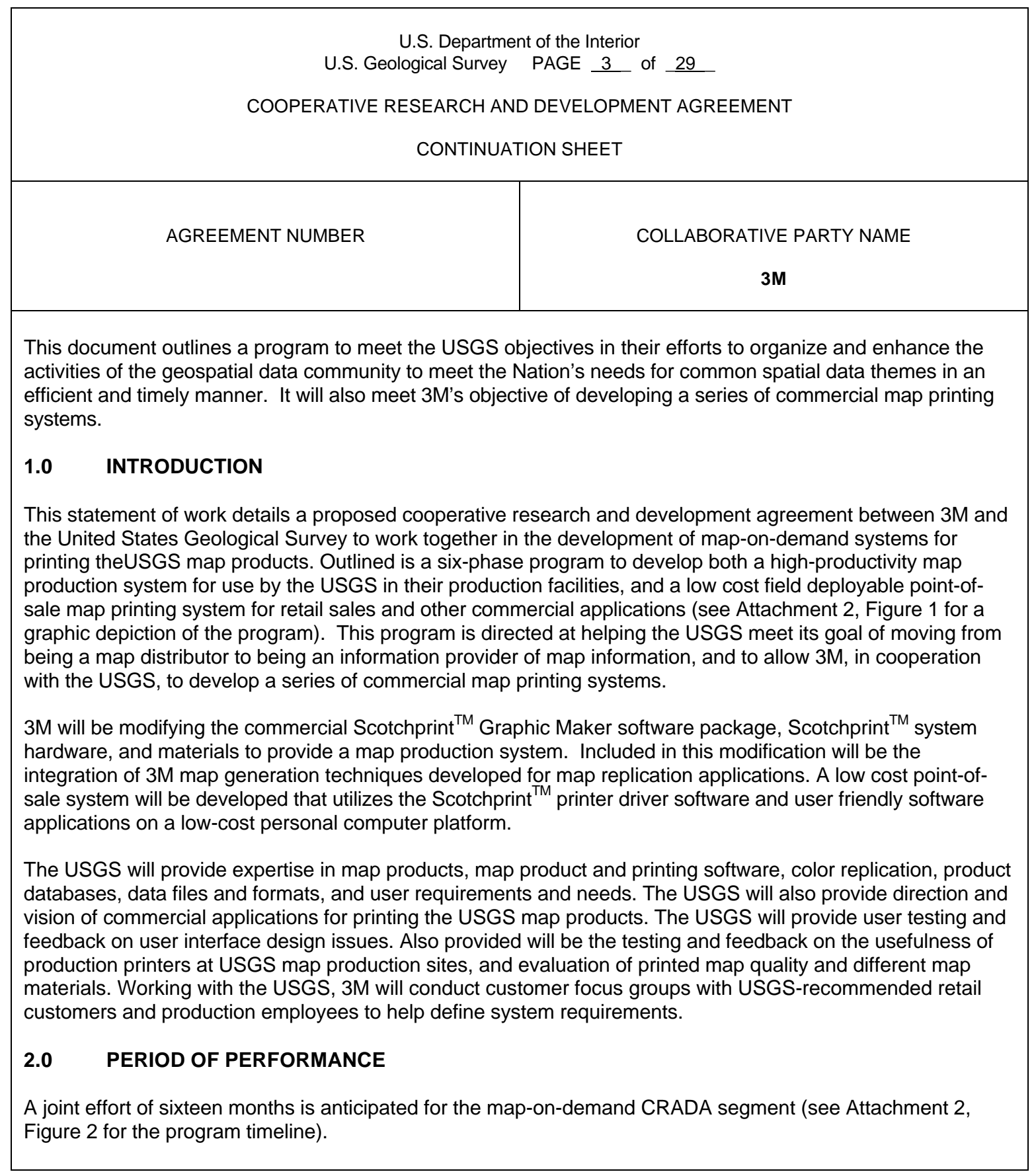




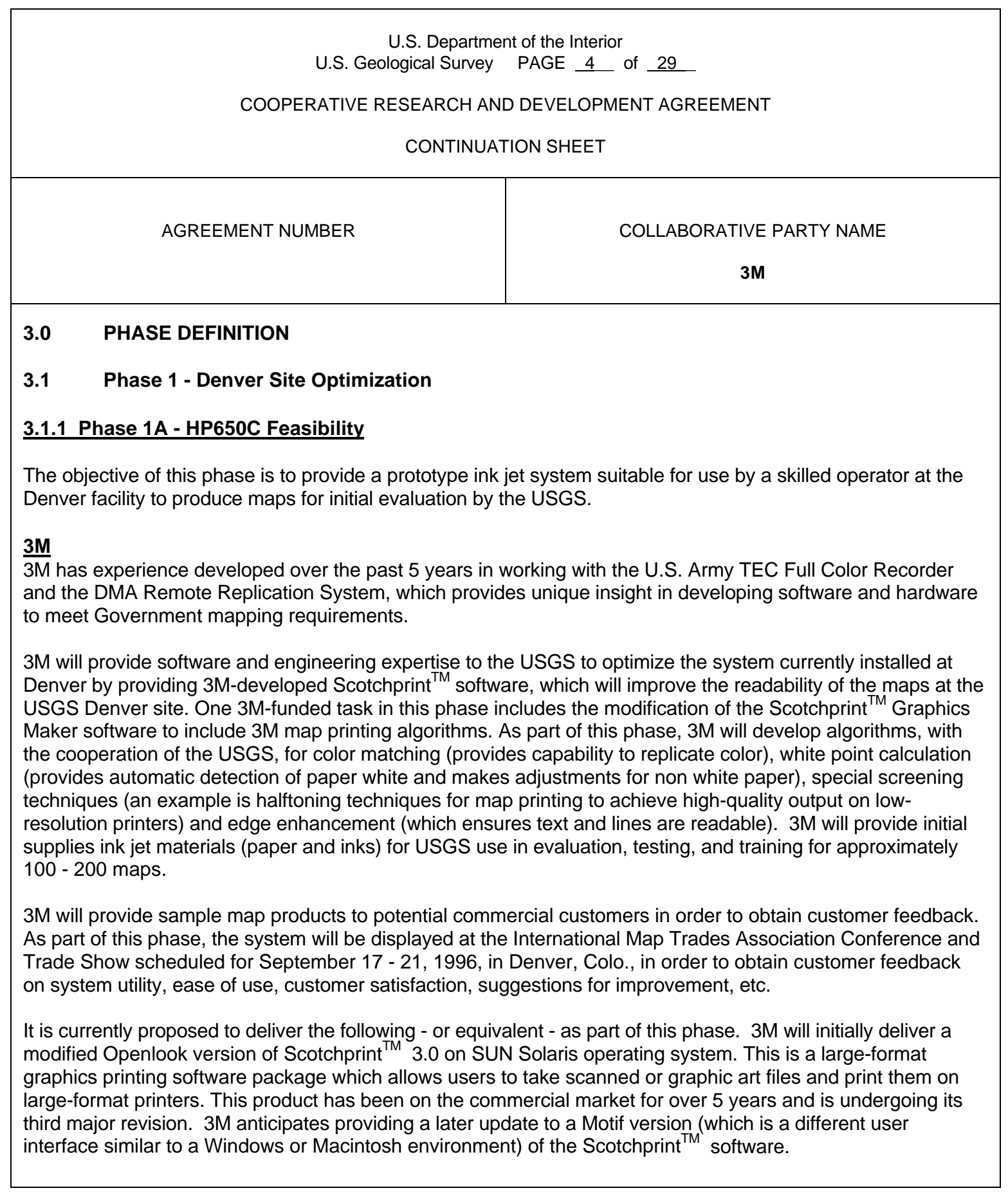




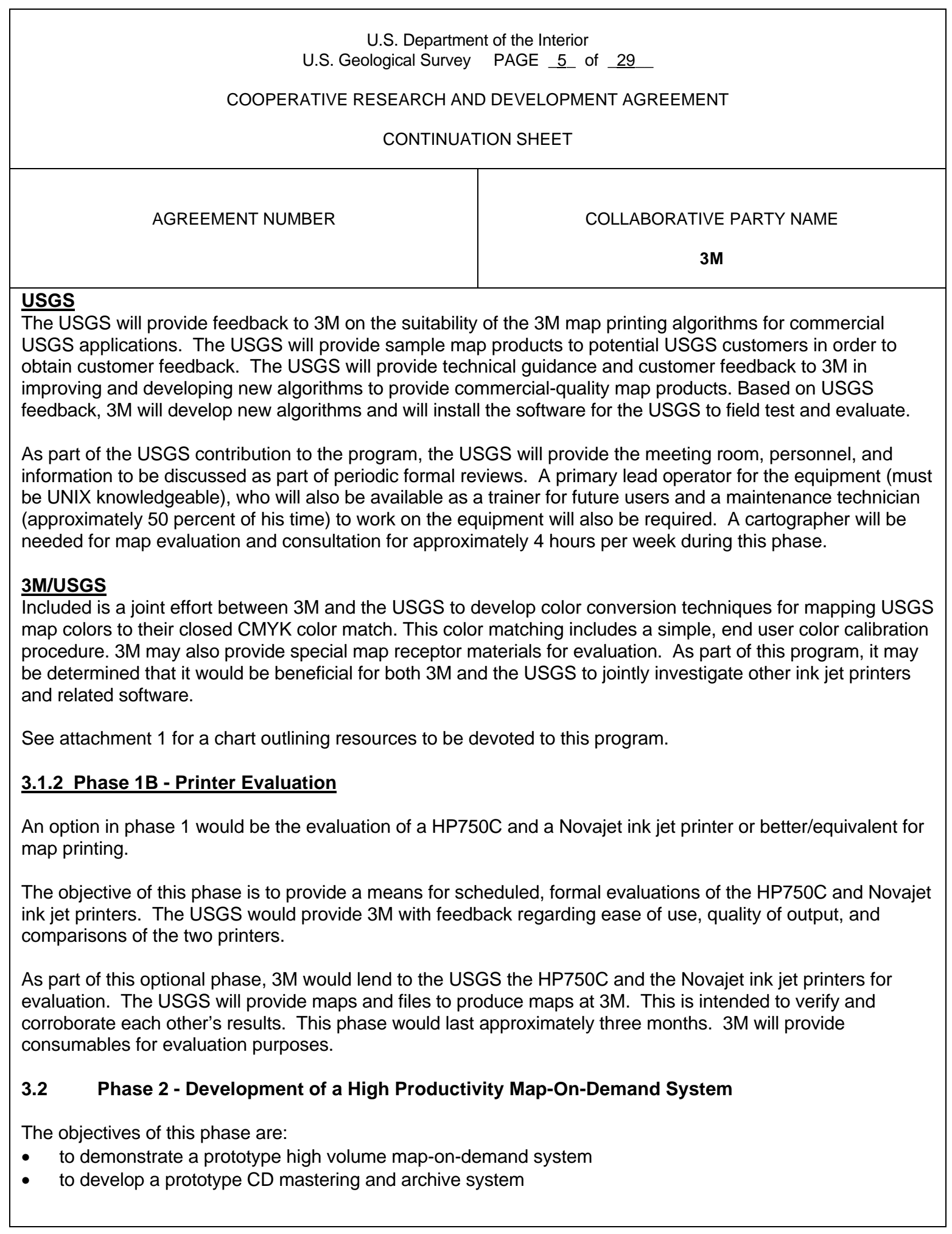




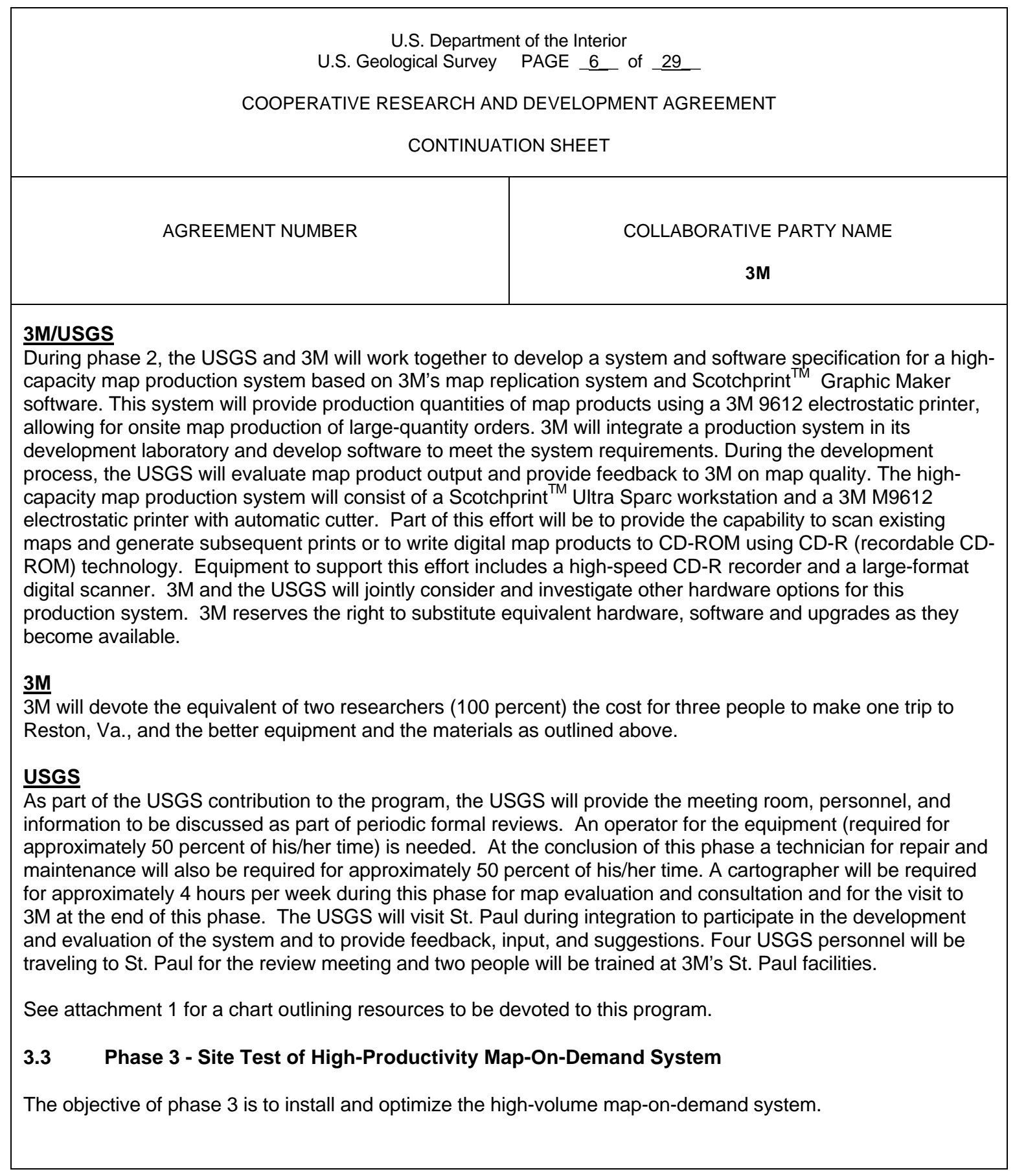




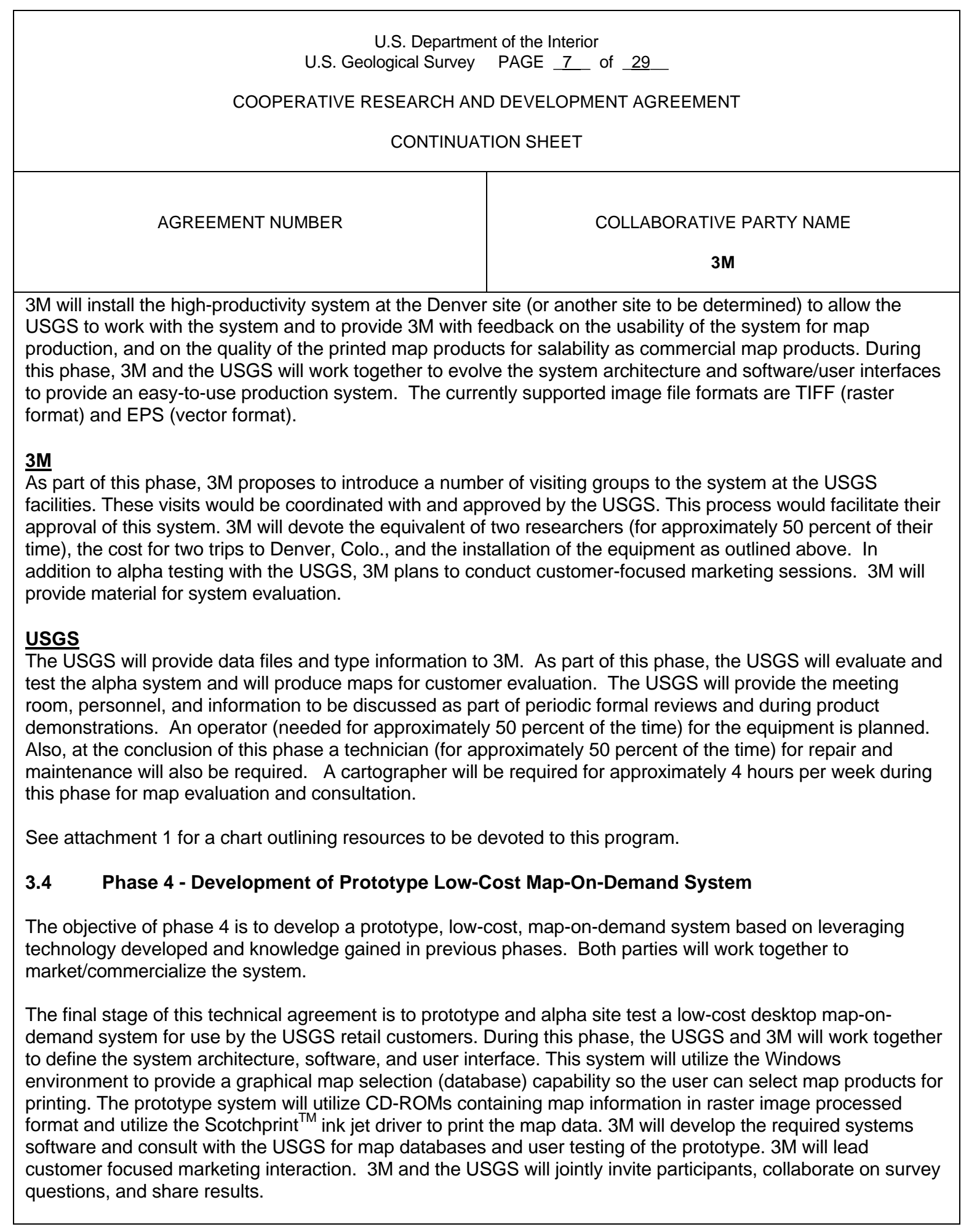




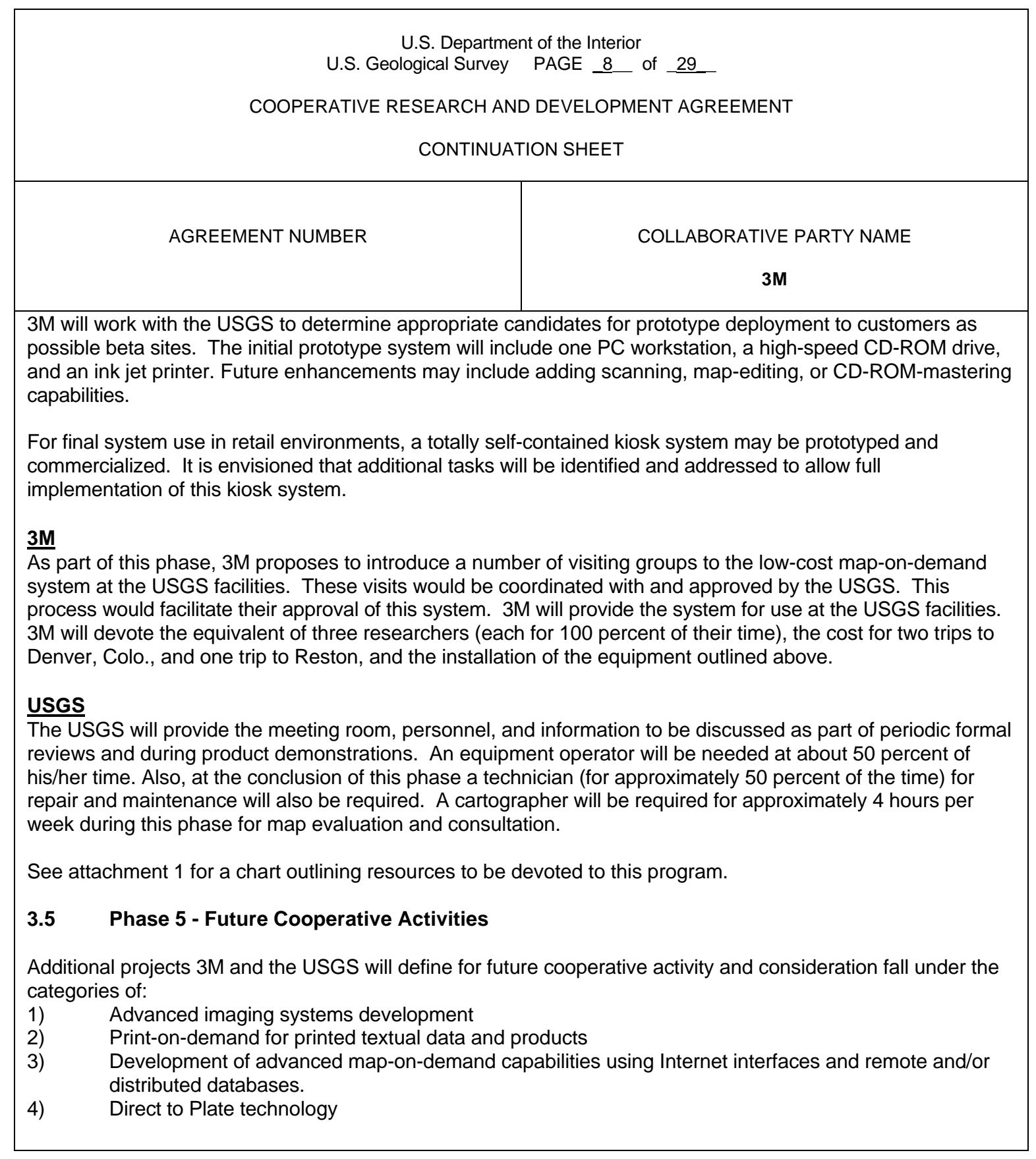




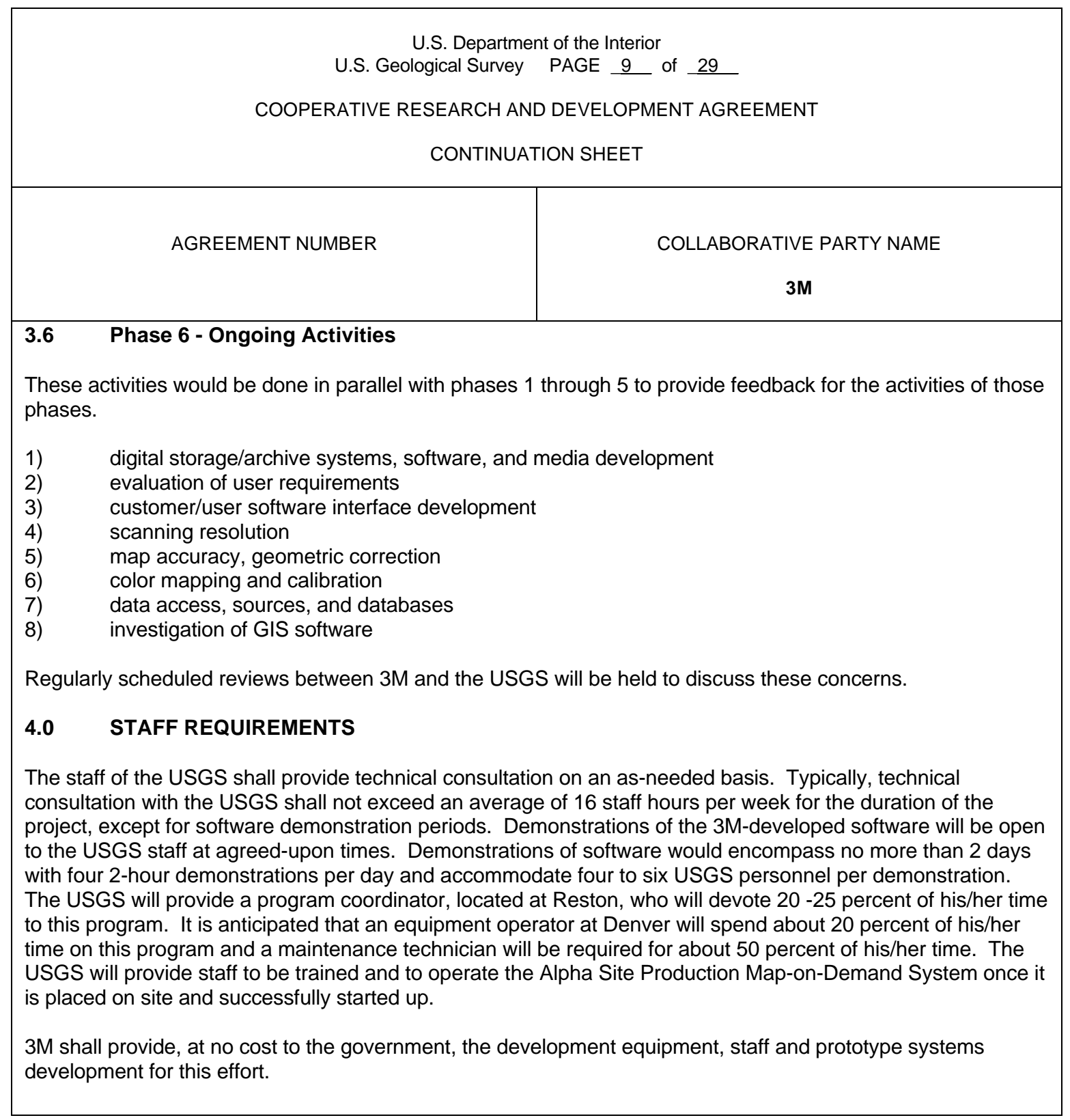


NOTE: PAGES 10 THROUGH 29 OF THE CRADA DOCUMENTS ARE THE GENERAL PROVISIONS, WHICH ARE NOT INCLUDED IN THIS REPORT. 


\section{Frequently Asked Questions}

1. Why did the USGS enter into a Cooperative Research and Development Agreement with $3 \mathrm{M}$ ?

The USGS wanted to investigate maps-on-demand technology to support the production of USGS mapping products. The results of the CRADA will potentially help the USGS to develop on-demand alternatives to lithographic maps.

2. What do you mean by maps-on-demand?

Currently, the USGS uses conventional lithographic printing techniques to produce a paper copy of the vast majority of its inventory of mapping products. With the advent of newer technologies, high-speed, large-format printers have been coupled with innovative computer technologies to allow access to digital map data and output to hardcopy. It is now possible to store and retrieve data from vast geospatial data bases, customize those data to user-defined requirements, and print out a map on an as-needed basis---thereby eliminating the need to store paper maps in warehouses.

3. What types of printing devices were investigated under the CRADA?

Both inkjet and electrostatic printing devices were evaluated. For high-volume printing, electrostatic printers are preferred. An example of a high-capacity electrostatic printer is 3M's ScotchPrint 9512/9612, which prints all four colors simultaneously at 400 dpi and with a throughput rate of up to 60 maps per hour. For applications that require less throughput, a thermal inkjet printer can be used, printing at 300 or 600 dpi.

4. What does a map-on-demand product cost?

3M estimates that an inkjet system printing on normal imaging paper costs approximately $\$ 0.61$ per square foot for inks and materials. If wet strength paper is used, the cost is approximately $\$ 1.30$ per square foot for inks and materials.

For electrostatic printing systems, the cost for materials is approximately $\$ 0.27$ per square foot. Again, if wet strength paper is used, the cost for materials increases to approximately $\$ 0.94$ per square foot.

5. Where does the data come from for map-on-demand products?

Having access to suitable data is a key enabler for maps-on-demand. There are two sources of digital map data; scanned paper maps and vector data. If vector data are provided, the process is fairly straightforward. If original paper maps are the source material, they need to be scanned to create the digital files from which prints can be made.

Once the map data are made available, the files must be converted to a printer native 
format. 3M software can be used to convert either a TIFF (Tagged Image File Format) or EPS (Encapsulated PostScript) file format to print format.

6. Is the quality of the map-on-demand product as good as the lithographic version?

Map-on-demand technologies are constantly improving and advancing; however, at the current time the lithographic process provides superior output quality. The USGS and 3M have conducted customer service surveys and found that the majority of respondents thought that the map-on-demand version was an acceptable substitute for the original.

7. Where can I get a map-on-demand product?

This is an emerging technology and is slowly evolving into the mainstream for government and commercial applications. The USGS and other Federal, State, and local agencies are investigating map-on-demand alternatives to lithographic versions. A key issue is still the availability of map data.

8. What are the benefits of a map-on-demand system?

If digital data are readily available, map-on-demand systems allow just-in-time delivery of customized geospatial information. A large paper inventory of map products is no longer necessary. Rapid response to emergency situations with up-to-date map data is a reality. Revisions can be made on-the-fly using geographic information systems in conjunction with the map-on-demand technologies. Retail stores can customize their products to suit the ever-changing needs of their customers. Overhead costs are reduced, since shelf space is no longer necessary to store large paper maps. Increased costs associated with the equipment and materials can be weighed against having access to a customizable inventory suited to each business needs. 


\section{M Product Literature}

(Source: http://www.mmm.com/imagegraphics/f_n.html) 


\section{Product Information}

\section{Innovative technology helps you build your business and meet customer needs.}

Six years ago $3 \mathrm{M}$ revolutionized the world of large-format digital graphics with its introduction of the $3 \mathrm{M}^{\mathrm{TM}}$ Scotchprint ${ }^{\mathrm{TM}}$ Electronic Graphics System. The system -- a 3M designed electrostatic printer, special software, laminator and materials, including graphics marketing films, overlaminates and toners--produces durable, warranted, outdoor weatherable graphics.

Today, this digital electrostatic printing system is flourishing with 3M Scotchprint Graphics Authorized Manufacturers producing graphics in more than 35 different countries around the world.

$3 \mathrm{M}$ continues to revolutionize the world of large-format digital printing by constantly improving upon its original Scotchprint electrostatic system, as well as developing new materials to meet other emerging digital printing technologies (including large format thermal ink jet printing).

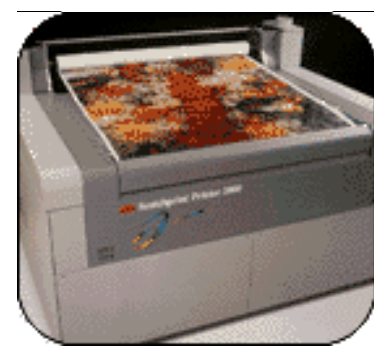

In 1995, 3M introduced the Scotchprint ${ }^{\mathrm{TM}}$ Printer 2000 -- a revolutionary break through in large format four color printing system. Today graphics manufacturers around the world are enjoying

increased productivity and outstanding image quality with the Scotchprint 2000 . The printer is capable of producing four color graphics at the rate of 2,600 square feet (241.5 square meters per hour). It has a 52 inch $(132 \mathrm{~cm})$ image area and will print four colors, in a single-pass with resolution levels ranging from 25 to 400 dots per inch (DPI). 
This remarkable printer can accept digital files, print from disk to media without creating screens, print a single graphic or thousands of copies and take in art and produce graphics the same day.

Enhancing the capabilities of this revolutionary new high-speed electrostatic printer are a number of new $3 \mathrm{M}^{\mathrm{TM}}$ Scotchcal ${ }^{\mathrm{TM}}$ Direct Print Electrostatic Marking Films, including 3654-10 and 3684-10. These new adhesive-coated marking films represent a breakthrough in electrostatic printing. You can print graphics directly on to these pressure sensitive films, eliminating the use of a transfer media and saving time, production labor and costs.

$3 \mathrm{M}$ is also revolutionizing the world of large format thermal ink jet printing with pigmented thermal ink jet inks and imaging media that produce outdoor weatherable graphics.

The 3M Scotchprint Electronic Graphic System, the Scotchprint 2000, 3M Scotchcal Direct Print Electrostatic Marking Films and 3M Thermal Ink Jet Materials. Truly the technology of the 21 st century.

If you would like to learn more about the Scotchprint Electronic Graphic System, call 1800-374-6772 and ask for the 3M Scotchprint Electronic Graphic System brochure. (75-51000442-9) If you would like to learn more about 3M Thermal Ink Jet Materials, ask for the Make a Big Impression brochure (75-51000779-9).

For more information inside the U.S., call 1-800-374-6772.

The $3 M^{\mathrm{TM}}$ Scotchprint ${ }^{\mathrm{TM}}$ Electronic Graphics System. 
The Scotchprint Electronic Graphic System is a unique package of hardware, software and materials from $3 \mathrm{M}$. Different versions of the Scotchprint system exist: each has a high resolution color scanner, a powerful host computer and a four-color electrostatic printer. A typical user configuration includes a Power PC Maclntosh ${ }^{\mathrm{TM}}$ or a Pentium ${ }^{\mathrm{TM}}$ PC with a desktop color scanner such as the Howtek ${ }^{\text {TM }}$ D4500 for input. All of these systems use the patented $3 \mathrm{M}^{\mathrm{TM}}$ Scotchprint Graphic maker software which breathes new life into the system.

Creating a large-format, full-color graphic begins by scanning and digitizing hard copy input on the Scotchprint system's color scanner. This can include color artwork, line illustrations, color or black and white photographs, digitized files or transparencies. Once the color scanner or desktop publishing software scans the original artwork and converts the data into digital information, it can be easily repositioned, cropped, and resized.

The data is sent to an electrostatic imaging printer which, in one pass, produces a fourcolor image in a matter of minutes. The graphics can be produced on a variety of films for any application. Newly introduced directprint vinyl films are intended for promotional and short-term applications. With Scotchprint image and transfer media, the image is transferred onto one of a number of different $3 \mathrm{M}^{\mathrm{TM}}$ Scotchcal ${ }^{\mathrm{TM}}$ Electrostatic Vinyl Marking Films using a heat and pressure lamination process to create a warranted $3 \mathrm{M}^{\mathrm{TM}}$ Scotchprint ${ }^{\mathrm{TM}}$ Graphic.

Hardware, software and graphic materials each play a vital role in the creative, production and application processes that have made Scotchprint full-color graphics one of the most exciting new business opportunities that has emerged in the sign and graphic arts industry. 
If you would like to learn more about the Scotchprint Electronic Graphic System, call 1-800-374-6772 and ask for the $3 \mathrm{M}$ Scotchprint Electronic Graphic System brochure (75-5100-0442-9).

3M Scotchprint ${ }^{\mathrm{TM}}$ Electronic Graphics System--The Process

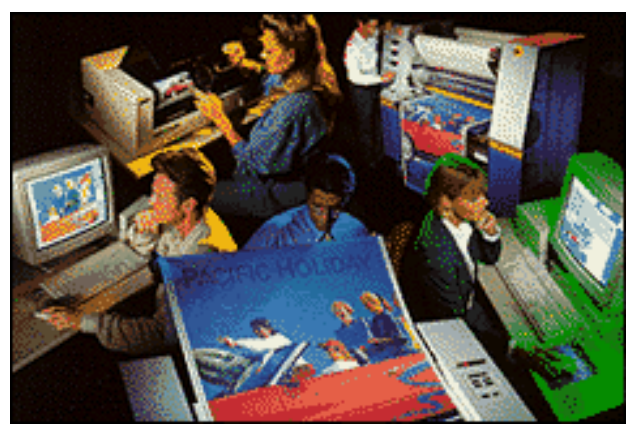

\section{Artwork and Origination.}

The Scotchprint system may include a height resolution scanner for converting color artwork, line illustrations, color or black and white photographic prints, color transparencies--even images taken directly from brochures or magazines. In addition, the system will accept files from other external scanning, desktop publishing (DTP) or computer-aided design (CAD) systems. Files can be supplied on most popular formats including 3.5 inch computer diskette, optical disk, ZIP disk, Syquest ${ }^{\mathrm{TM}}$ cartridge and photo CD.

\section{Image Composition and Manipulation} Using a design station you can digitally position, crop and size the image. Color also can be corrected or modified at this stage. Additional images may be imported, edited, retouched and combined with the original image, while full merging of text and logos is also provided for total creative flexibility.

\section{Processing}

The system's powerful workstation utilizes $3 \mathrm{M}^{\mathrm{TM}}$ Scotchprint ${ }^{\mathrm{TM}}$ Graphic Maker software 
which is optimized for fast Raster Image Processing (RIP) to process files to directly drive the printer. This eliminates the need for costly, time-consuming film separations. The operator can choose from unique $3 \mathrm{M}$ halftones or stochastic screening processes at the resolution which is best suited for the intended graphic application. The workstation's many facilities include automatic paneling of large graphics (including overlapping, if required), and final graphic sizing. At this stage, the operator also selects the required number of copies to be printed.

\section{Printing}

The 3M Scotchprint System offers a range of digital printers to suit the user's specific needs. Using sophisticated electrostatic imaging technology, the printer can build images at up to $400 \mathrm{dpi}$ resolution at up to 420 square feet $(40 \mathrm{~m} 2)$ /hour by depositing toners (cyan, magenta, yellow and black) onto $3 \mathrm{M}^{\mathrm{TM}}$ electrostatic imaging paper (for direct use for promotional paper poster and shortterm/temporary graphic applications), or onto $3 \mathrm{M}$ image and transfer media (for transfer onto $3 \mathrm{M}^{\mathrm{TM}}$ Scotchcal ${ }^{\mathrm{TM}}$ or $3 \mathrm{M}^{\mathrm{TM}}$ Controltac Plus Electrostatic Marking Films).

\section{Image Transfer}

Using the thermal transfer laminator, the Scotchprint graphic is transferred under heat and pressure from the transfer media to Scotchcal ES vinyl marking film. (The laminator also can be used to transfer images directly to certain substrates such as foamcore panels). As with the printers, 3M offers a choice of laminator formats and sizes designed to meet the customer's individual requirements.

\section{Overlaminating the Graphic}

To provide maximum protection against weathering, fading, scratching, graffiti and vandalism, and to provide an easily-washable graphic, a choice of clear protective overlaminates (matte, gloss, high gloss, antigraffiti) can be applied using the laminator. 


\section{Graphic Marking Materials}

$3 \mathrm{M}$ is unique because it manufactures a total system of compatible graphic marking materials to create warranted $3 \mathrm{M}^{\mathrm{TM}}$

Scotchprint ${ }^{\mathrm{TM}}$ Graphics or short-term graphics which are not warranted. Every item--from toners, concentrates and transfer media, to receptor marking films and overlaminates-has been developed by $3 \mathrm{M}$. The range of imaging papers, receptor marking films and overlaminates used to create warranted Scotchprint ${ }^{\mathrm{TM}}$ Graphics and short-term electrostatic graphics enables the user to fulfill virtually any application including removable and permanent self adhesive opaque graphics, retro-reflective and back-lit graphics.

\section{M ${ }^{\mathrm{TM}}$ Scotchprint ${ }^{\mathrm{TM}}$ Graphic Maker Software}

Scotchprint Graphic Maker Software handles all your large format graphic production needs from posters and floor graphics to banners, bus sides and even larger surfaces. This software packages produces images of exceptional quality with fast RIP speeds. It also has special features, such as auto layout and step and repeat, that maximize productivity. This software package allows you to optimize your materials. It is the first to incorporate an Adobe ${ }^{\mathrm{TM}}$ Configurable Postscript Interpreter (CPSI) Level II into large format printing and it allows for the production of images ranging from 25 to 400 pixels per inch. Other features include 29 halftone patterns to eliminate moire patters and a closed loop color calibration that calibrates colors directly from an RGB scanner to the printer, allowing you to create your own color look-up tables and to adjust the CMYK color curve. 
Ink Jet Imaging Materials are clear, opaque and translucent polyester and vinyl imaging media and overlaminates specially designed for use with large-format thermal ink jet printers. These materials are designed for the production of large-format promotional signs, posters and banners used in stores, museums, zoos, entertainment centers and sports facilities. The films are for both indoor and outdoor use where UV and abrasion resistance are issues.

If you would like to learn more about $3 \mathrm{M}$ Ink Jet Materials, call 1-800-374-6772 and ask for the Make a Big Impression brochure (75-5100-0779-9).

\section{Make a big impression with $3 \mathrm{M}^{\mathrm{m}}$ Thermal Ink Jet Materials.}

Imagine creating large-format promotional signs, posters and banners with rich, vibrant colors. Or producing customized, full-color graphic images on demand from a digital file. Or, using thermal ink jet technology and $3 \mathrm{M}$ media to deliver high quality images for pointof-sale viewing. With new thermal ink jet media and pigmented thermal ink jet inks from $3 \mathrm{M}$, the world's leader in large-format graphics, meeting customer requirements is easier than ever.

\section{Vibrant}

The entire color palette is yours with $3 \mathrm{M}^{\mathrm{TM}}$ Thermal Ink Jet Materials. The 3M patented, pigmented inks and specially formulated thermal ink jet materials deliver truer, more accurate, more vibrant colors and better quality images overall. Thermal ink jet imaging is an excellent choice for short runs and customized applications wherever largeformat promotional graphics are needed--from retail settings, museums and zoos, to entertainment centers and sports facilities.

\section{Fast}

With on-demand digital imaging and $3 \mathrm{M}^{\mathrm{TM}}$ Thermal Ink Jet Materials, we've put time back on your side. Now, when a dazzling full-color 
banner needs to be printed by 9:00 the next morning, you can meet the deadline whether you're creating two, ten or twenty prints.

\section{Affordable}

High quality, large-format graphic images produced with $3 \mathrm{M}^{\mathrm{TM}}$ Thermal Ink Jet Materials are timely and affordable. Thermal ink jet printers using $3 \mathrm{M}^{\mathrm{TM}}$ Thermal Ink Jet Materials can deliver large-format graphics at a lower cost per square foot than other alternatives, particularly when printing quantities under 25 . Using 3M materials reduces labor and time needed to output images, laminate them to the appropriate materials and add protective laminating film.

\section{Compatible}

$3 \mathrm{M}^{\mathrm{TM}}$ Thermal Ink Jet Materials are available for use with large-format thermal ink jet printers.

If you would like to learn more about $3 \mathrm{M}^{\mathrm{TM}}$ Thermal Ink Jet Materials, call 1-800-3746772 and ask for the Make a Big Impression brochure (75-5100-0779-9).

For more information inside the U.S., call 1-800-374-6772.

\section{The 3M"m Scotchprint ${ }^{\mathrm{m}}$ Printer 2000. The future of digital printing.}

The 3M ${ }^{\mathrm{TM}}$ Scotchprint ${ }^{\mathrm{TM}}$ Printer 2000, with its significant advances in printing speed, quality and the ability to print on heavier media, is truly the future of large-format graphic printing. This state-of-the-art printing system yields high-quality digital graphics that are produced faster and easier with lower start-up costs. With the ability to print at resolutions from 25-400 pixels per inch in a single pass, it will produce four-color images at speeds up to 2,600 square feet per hour. This revolutionary machine is perfect for anyone who needs to produce hundreds of graphics in a hurry or a full-sized, jumbo prototype in minutes. You 
can even keep the same graphic while customizing the copy. For example, a retail poster's graphics could remain the same, while the words could easily be changed for different product displays within the store, or for another store location.

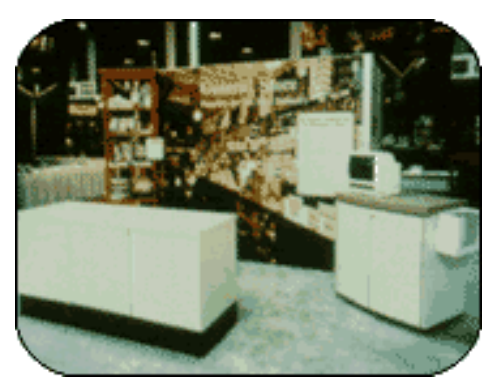

You can print 80 square feet in two minutes

The Scotchprint Printer 2000 can adjust to the media being printed, whether it's transfer media, interior or exterior imaging paper or the family of new $3 \mathrm{M}^{\mathrm{TM}}$ Scotchcal ${ }^{\mathrm{TM}}$ Direct Print Electrostatic Marking Film. Another significant advancement is its ability to accept rolls up to 54 inches wide with a 52 -inch imaging area. This makes production of seamless, backlit advertising display panels easier than ever. The printer system can also accept digital files, print directly from disk to media without producing screens, processes art and produces finished graphics in a day. The optional external wind/unwind and toner control modules make the Printer 2000 a complete production system.

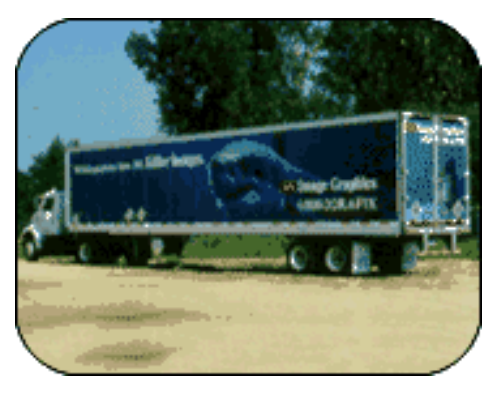

Print all three sides of this 48 foot trailor in 21 minutes

This revolutionary new printer is the latest advancement of the $3 \mathrm{M}^{\mathrm{TM}}$ Scotchprint ${ }^{\mathrm{TM}}$ 
Electronic Graphic System, which has dramatically changed the way large-format, high impact color graphics are produced. In addition to its unsurpassed image quality, the $3 M^{\text {TM }}$ Scotchprint ${ }^{\mathrm{TM}}$ Printer 2000 features high productivity digital printing for any run length and will print four colors in a single pass at 400 dots per inch (dpi).

This printer is a true volume printer's machine. It can provide printers with the capability to print $4002-x 3$-foot $(.5 \mathrm{~m} 2)$ posters in one hour, full coverage graphics for an $8 \times 48$-foot semi-trailer in 21 minutes, or an $8 \times 10$-foot $(7.43 \mathrm{~m} 2)$ display in two minutes. At the same time, it's ideal for the printer who quickly needs one or two prototype graphics.

With all of the features this new technology offers, think of all the new markets you can now go after to build your business.

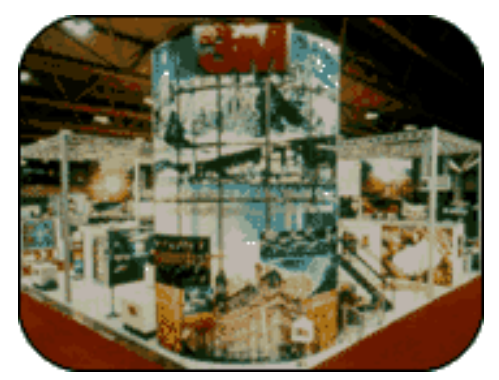

Print this $\mathbf{3 3}$ square meter graphic in nine minutes

The Scotchprint Printer 2000 is significantly more productive than existing printers. In comparison to the existing Scotchprint ${ }^{\mathrm{TM}}$ Printer 9512, which prints at the rate of seven square feet per minute, the Scotchprint 2000 is six times as fast. The Scotchprint Printer 2000 will print the image on transfer media, interior or exterior imaging paper, or $3 \mathrm{M}^{\mathrm{TM}}$ Controltac ${ }^{\mathrm{TM}}$ Plus Direct Print Electrostatic Marking Film. The printer automatically adjusts to the media being printed -- whether that's transfer media, imaging paper or the new 3M direct print marking films. 


\section{The Bare Facts}

Printing Productivity: 2,600 sq. ft. (241.5M) per hr.

Print Resolution: 400 dpi

Registration Accuracy: $+/-5$ mils. $(.127 \mathrm{~mm})$

Image Width: 52 inches: $(132 \mathrm{~cm})$

Adhesive-Backed Marking Film: Yes

Media Handling: Roll fed

Roll Size: 54 inches $(137 \mathrm{~cm})$ width

Toner: $3 \mathrm{M}$ Scotchprint toners

\section{With Options}

For graphics manufacturers that require optimized productivity both for short and long run lengths, 3M offers three optional add-on modules for the Scotchprint Printer 2000 including:

- Fifth Printing Station: Used for special spot colors or wear-coat applications. This option will be available in the first quarter of 1997.

- Large Unwind Stand: This module allows for much larger rolls of materials including paper rolls and transfer media of more than 4000 linear feet $(1,219 \mathrm{~m})$.

- High-Capacity Toner System: This optional toner module allows for up to eight hours of continuous printing without changing toner bottles.

\section{$3 M^{\mathrm{TM}}$ Scotchprint ${ }^{\mathrm{TM}}$ Printier 2000 Specifications}

If you would like to learn more about the Scotchprint Electronic Graphic System, call 1-800-374-6772 and ask for the 3M Scotchprint Electronic Graphic System brochure (75-5100-0442-9). 